\title{
Health deviation and daily functioning in elderly rheumatoid arthritis patients
}

Citation for published version (APA):

Bal, R. M. (1992). Health deviation and daily functioning in elderly rheumatoid arthritis patients. [Doctoral Thesis, Maastricht University]. Rijksuniversiteit Limburg. https://doi.org/10.26481/dis.19920423rb

Document status and date:

Published: 01/01/1992

DOI:

10.26481/dis.19920423rb

Document Version:

Publisher's PDF, also known as Version of record

\section{Please check the document version of this publication:}

- A submitted manuscript is the version of the article upon submission and before peer-review. There can be important differences between the submitted version and the official published version of record.

People interested in the research are advised to contact the author for the final version of the publication, or visit the DOI to the publisher's website.

- The final author version and the galley proof are versions of the publication after peer review.

- The final published version features the final layout of the paper including the volume, issue and page numbers.

Link to publication

\footnotetext{
General rights rights.

- You may freely distribute the URL identifying the publication in the public portal. please follow below link for the End User Agreement:

www.umlib.nl/taverne-license

Take down policy

If you believe that this document breaches copyright please contact us at:

repository@maastrichtuniversity.nl

providing details and we will investigate your claim.
}

Copyright and moral rights for the publications made accessible in the public portal are retained by the authors and/or other copyright owners and it is a condition of accessing publications that users recognise and abide by the legal requirements associated with these

- Users may download and print one copy of any publication from the public portal for the purpose of private study or research.

- You may not further distribute the material or use it for any profit-making activity or commercial gain

If the publication is distributed under the terms of Article $25 \mathrm{fa}$ of the Dutch Copyright Act, indicated by the "Taverne" license above, 


\section{Health deviation and daily functioning in elderly rheumatoid arthritis patients}


$28+4$

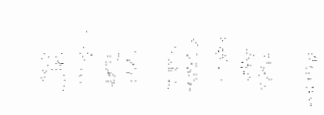




\title{
Health deviation and daily functioning in elderly rheumatoid arthritis patients
}

\author{
Proefschrift
}

ter verkrijging van de graad van doctor aan de Rijksuniversiteit Limburg te Maastricht, op gezag van de Rector Magnificus, Prof.Mr. M.J. Cohen, volgens het besluit van het College van Dekarien, in het openbaar te verdedigen op donderdag 23 april 1992 om 14.00 uur door

\section{Rosa-Maria Bal}

geboren te Eindhoven in 1958 
Promotor:

Co-promotor:

Beoordelingscommissie:
Prof.Dr. H. Phillpsen

Dr. J.P.H. Diederiks

Prof.Dr. H.F J.M. Crebolder (voorzitter)

Prof.Dr. J.M.J.P. van der Linden

Prof.Dr. H. Huijer-Abu Saad

Prof.Dr. G.A.M. Winnubst (Rijks Universiteit Utrecht)

Dr. P.J.G. Schreurs (Rijks Universiteit Utrecht)

\section{Cip-gegevens Koninklijke Bibliotheek, Den Haag}

\section{Bal, Rosa-Maria}

Health deviation and daily functioning in elderly rheumatoid arthritis patients / Rosa-Maria Bal ; [ill. by the author]. - [S.I. : s.n.]. - Ill.

Proefschrift Maastricht. - Met lit. opg. - Met samenvatting in het Nederlands. ISBN $90-9004800-6$

NUGI 750

Trefw.: reumatoide arthritis / thuiszorg ; ouderen.

\section{Productic: Datawyse Maastricht, Ruud Lalivelld}

Druk: Krips Repro Meppell

Lay out: Ingrid Lathouwer

Cover-design: Michiel Jaunssen

Financial suppont by Het Nationaal Reumafonds for the publication of this thesis is gratefully acknowleged. 


\section{Contents}

Acknowledgements

1 Introduction

1.1 Chronic illness and dependency ........................................................11

1.2 RA and continuity of care ...................................................................12

1.3 Health deviation, outcome, and control factors.....................................12

1.4 Research goals ......................................................................................13

2 RA patients and problems with daily functioning....................................

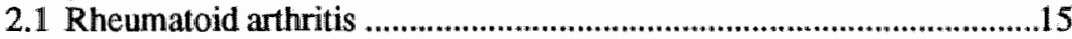

2.1.1 Some medical aspects of RA...................................................15

2.1.2 The medical treatment of RA ..................................................16

2.2. Disease related complaints and RA ..................................................17

2.2.1 Pain, fatigue, stiffness and RA ................................................17

2.3 Daily functioning and RA.................................................................19

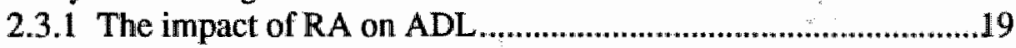

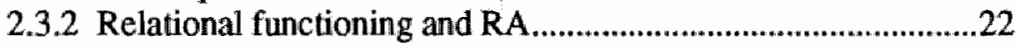

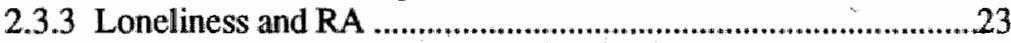

2.4 Factors influencing the problems of RA patients .................................23

2.4.1 Social position and attitudes.......................................................24

2.4.1.1 Health perception: the meaning of RA to the

RA patient...................................................................24

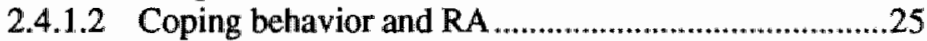

2.4.1.3 Social position and RA ...............................................26

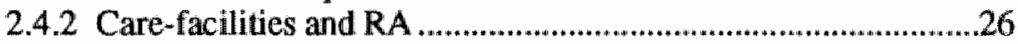

2.4.2.1 Social support and RA ..............................................26

2.4.2.2 Professional help and RA .......................................27

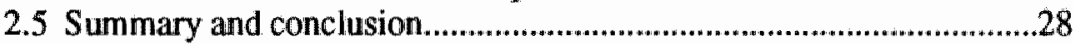

3 Research questions and research model.....................................................31

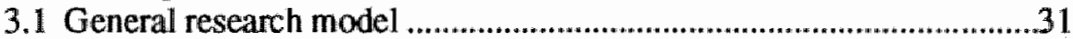

3.2 Health deviation variables ...................................................................33

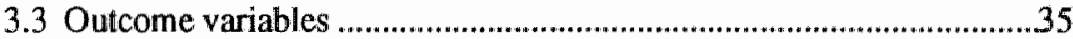

3.3.1 Difficulties performing activities .............................................35

3.3.2 Rest and activity pattern .........................................................37

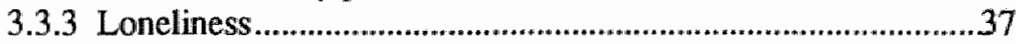

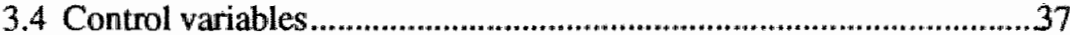

3.4.1 Health perception: the meaning of RA........................................38

3.4.2 Coping behavior ...........................................................................38

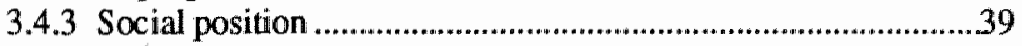




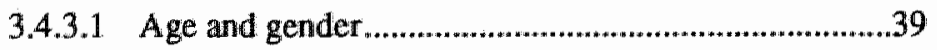

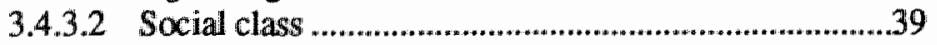

3.4.3.3 Dependent care facilities ...............................................40

3.4.4 Personal network ...........................................................................40

3.5 Relations in the research model.............................................................40

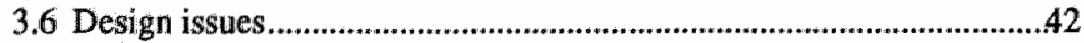

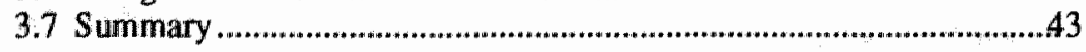

4 Population and methods..........................................................................45

4.1 Population ............................................................................................45

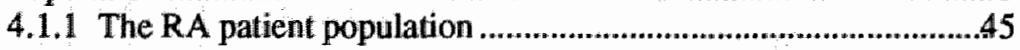

4.1.2. The reference group..................................................................46

4.1.3 Response ...................................................................................47

4.1.4 Time schedule ......................................................................48

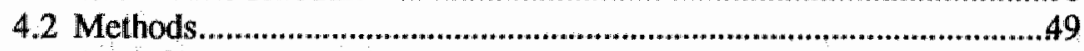

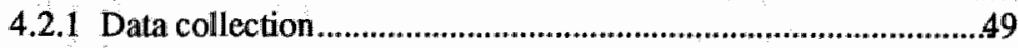

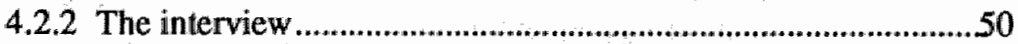

4.2.2.1 Activities of daily functioning.....................................51

4.2.2.2 Loneliness.................................................................53

4.2.2.3 Functional capacity...................................................53

4.2.2.4 Duration of RA .........................................................53

4.2.2.5 Clinical data............................................................54

4.2.2.6 The meaning of RA ...................................................54

4.2.2.7 Coping behavior ..........................................................54

4.2.2.8 Dependent care facilities .............................................55

4.2.2.9 Education level and social class .................................55

4.2.2.10 Personal network ..........................................................56

4.2.2.11 Professional help.........................................................57

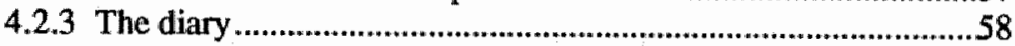

4.2.3.1 Main activity per quarter of an hour.............................58

4.2.3.2 Pain level per hour........................................................58

4.2.3.3 Level of fatigue............................................................59

4.2.3.4 Duration of morning stiffness........................................59

4.3 Non-response and non-completion analyses ......................................59

5 Descriptive results of outcome, health deviation, and control variables.

5.1 Results of MANOVA and t-test analyses for outcome, health de-

viation and control variables.............................................................61

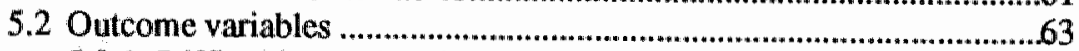

5.2.1 Difficulties performing activities of daily functioning in the RA patient group .

5.2.1.1 Difficulties performing activities of daily functioning of the RA patients and reference group. 
5.2.2 Rest and activity pattern of RA patients diary group and reference diary group........................................................................66

5.2.3 Loneliness..................................................................................69

5.2.4 Relations between the outcome variables ….................................70

5.3 Health deviation variables .....................................................................71

5.3.1 Functional capacity.................................................................71

5.3.2 Pain, fatigue, and duration of morning stiffness ...........................72

5.3.3 Duration of RA ......................................................................73

5.3.4 Relations between the health deviation variables ..........................74

5.4 Control variables.........................................................................................75

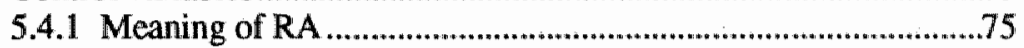

5.4.2 Coping behavior .........................................................................

5.4.3 Dependent care facilities .........................................................76

5.4.4 Professional help given to the RA patients ................................76

5.4.5 Personal network ..................................................................77

5.4.6 Relations between the control variables....................................78

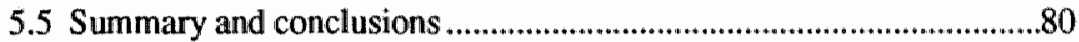

6 The impact of the health deviation variables on outcome variables .....82

6.1 Health deviation and outcome variables................................................82

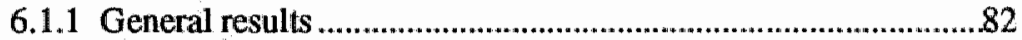

6.1.2 The impact of health deviation on ADL ..................................83

6.1.2.1 Functional capacity and ADL ..................................83

6.1.2.2 Pf-complaints, duration of morning stiffness and ADL .............................................................................84

6.1.2.3 Changes in ADL and changes in health deviation........85

6.1.3 Health deviation and relational functioning ...............................86

6.1.3.1 Functional capacity and relational functioning.............87

6.1.3.2 Pf-complaints, duration of morning stiffness and relational functioning.....................................................8.

6.1.3.3 Changes in health deviation and changes in relational functioning .............................................................8. 88

6.1.4 Health deviation and loneliness.................................................89

6.1.4.1 Functional capacity and loneliness.............................89

6.1.4.2 Pf-complaints, duration of morning stiffness and loneliness .................................................................90

6.1.4.3 Changes in loneliness and changes in health deviation

7 The impact of control variables on health deviation and outcome variables.....................................................................................................93

7.1 The impact of control variables on health deviation ..............................93

7.1.1 Social position, attitudes and health deviation.............................99

7.1.2 Care-facilities and health deviation...........................................95 
7.1.3 Changes in control variables and changes in health devia-

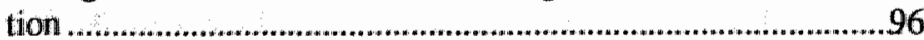

7.2 The impact of control variables on outcome variables ..........................97

7.2.1 Social position, attitudes and ADL ..........................................98

7.2.2 Care-facilities and ADL .............................................................98

7.2.3 Care-facilities and obtaining and using aids and ap-

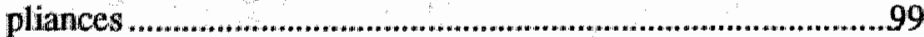

7.2.4 Social position, attitudes and relational functioning..................100

7.2.5 Social position, attitudes and rest ...............................................100

7.2.6 Social position, attitudes and loneliness......................................100

7.2.7 Care-facilities and loneliness......................................................101

7.2.8 The relation between changes in control variables and changes in outcome variables.

7.3 Multivariate relations between health deviation, control and outcome variables .....................................................................................104

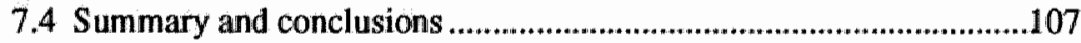

8 Summary, discussion, and conclusions..................................................111

8.1 Problem statement and research questions ...........................................111

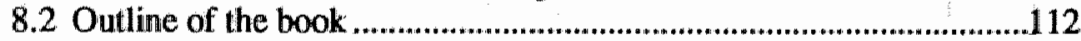

8.3 Conclusions........................................................................................113

8.3.1 Problems of elderly RA patients with daily functioning ..........113

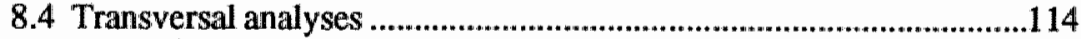

8.4.1 Transversal bivariate analyses.................................................114

8.4.2 Transversal multivariate analyses .........................................117

8.4.3 Longitudinal analyses ............................................................119

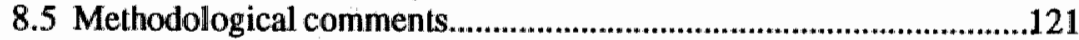

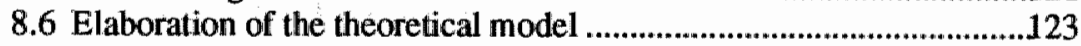

8.7 Practical considerations .......................................................................126

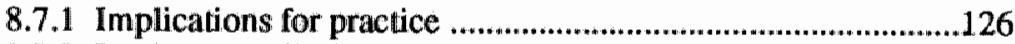

8.7.2 Implications for future research .................................................

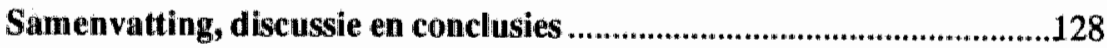

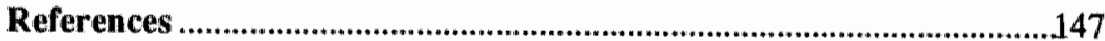

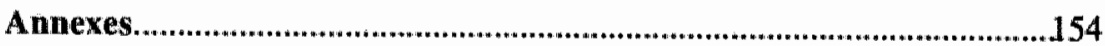

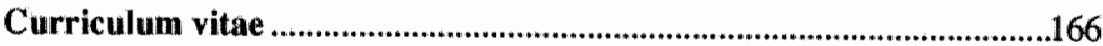




\section{Acknowledgements}

Sixty-five rheumatoid arthritis patients and fifty references were interested in participating in this study. Without them this thesis could not have been written. I would like to thank them for their time-investment during the two years of the data-collection, and for the opportunity for us to get insight in their daily life. We were always welcome in their homes, which made interviewing a pleasant and often learning experience.

Next to the participants, many other persons were involved in the completion of this study, to whom I would like to express my thanks. First of all, the Landelijke Vereniging voor Thuiszorg, whose financial support for this study is greatfully acknowledged.

Then, their have of course been my promotors, Hans Philipsen and Jos Diederiks. Discussions with both of them were al ways very stimulating. I would like to thank them for their comments and suggestions on the various concepts of this manuscript. Hans learned me a lot more about the pittfalls and opportunities of research. Talking to him was very motivating, his creative ideas were a stimulance in looking at the data from different perspectives.

Other people have meant a lot to me during the various stages of the project. The advisary committee of the Community Nursing Association of Breda (Piet Hein Jonkergouw, Nelleke Burgers, Patricia Gho) for their comments on the various research instruments and their suggestions during the data collection period. Merrit Plug, whom I would like to thank for her enthousiasm with which she did the majority of the interviews. Marian Tilly, who helped me with encoding the diaries, which was very time consuming. Vonka Schaffers, who joint me looking for patients records in a fuggy archive on a hot summerday. Lori Mees, who in a very short period of time did a great job in correcting my English. Cecile aan de Stegge who carefully read the Dutch summary. Ingrid Lathouwer, who did the lay-out, and made it look like a real book. Michel Janssen, who made the front page.

Then of course there were many others. Many friends supported me during this period. Few of them I would like to mention. First of all Hans and Peter who were usually there when needed.

I would especially want to acknowledge my second living-room 'Le TraitD'Union'. Jul and Paul, during all the ups and downs you always supported me. It meant a lot to me, thanks.

Last but not least my family. My brothers and sister and their partners who continued to show interest and support. My parents, who continiously stimulated me to explore new areas of knowledge. 



\section{INTRODUCTION}

\subsection{Chronic Illness and Dependency}

The introduction of the 'Memorandum on Chronic Illness Policy" of the Ministry of Welfare, Public Health and Cultural Affairs (WVC, 1991) states that a strenuous effort should be given to reducing the societal disadvantages of the chronically ill. In this respect, special attention should be given to the shortcomings of the health policy: non-professional and professional care for patients with chronic conditions, health education, research, and societal position of chronically ill.

Chronic illnesses are generally described as: irreversible diseases, without prospect of total recovery and a rather long duration. Demographic developments (aging population) and factors as improved diagnostic and therapeutic facilities in health care will, in the next decades, lead to an increased number of chronically ill (Van den Bos, 1989; WVC, 1989d; WVC, 1991). Chronic illnesses have a rather long duration, are generally not life threatening, and are accompanied by increasing dependency of patients on non-professional and professional help. Therefore, it is expected that the use of health care will increase (Kooiker, 1990).

Amongst several chronic illnesses, as described in the 'Memorandum on Chronic Illness Policy' (WVC, 1991) are rheumatic disorders. The 'Memorandum on Rheumatism Policy' of the Ministry of WVC (WVC, $1989 \mathrm{~d})$ reported that there are 3 million people suffering from a rheumatic disorder. One of these rheumatic disorders is rheumatoid arthritis (RA). RA is a chronic systemic disease, of which the precise cause is unknown. Approximately 0.3 to $0.5 \%$ of the Dutch society suffer from RA. RA is more frequent in femalles than in males, and has a higher prevelance and incidence in older age groups. A considerable part of the RA patients become severely handicapped, which implicates increasing dependency on non-professional and professional help in these patients. As stated in the 'Memorandum on Chronic Illness Policy' and the 'Memorandum on Rheumatism Pollicy" the acclimatisation of the need for help and the thelp offered by nonprofessionals and professionals appears to be difficult. Part of these problems have to do with the variability, sometimes on a day-lo-day basis, with the problems of the daily functioning of RA patients, and a lack of insight into these problems of daily functioning, especially by general practitioners, community nurses, and home aids.

Much research is focused on the causes of chronic illness. Relatively neglected areas are:

- the development of problems of the chronically ill during the course of their disease, the consequences of the disease and its subsequent treatment, with everyday functioning,

- the development of dependency of chronically ill patients on non-professional and professional care, that is the needs of chronically ill for care in relation to problems of everyday functioning.

In summary it can be stated that with an increasing number of elderlly in the society more people will suffer from chronic conditions, such as RA. Therefore, the demand on the health care system is likely to increase. Up until now, not 
much research has been done on the dependency of RA patients, that is the consequences of RA and its treatment for daily functioning of elderly RA patients. More insight into the development of problems of elderly RA patients with daily functioning in the course of the disease process will provide information for nonprofessionals and health care professionals and will give indications for changing demands for health care.

\subsection{RA and Continuity of Care}

This study is part of the research programme 'Continuity of care', with different studies on the continuity of care for people with a chronic or prolonged disease, living at home. Within the programme the following aspects of 'continuity of care' are (were) the subject of study:

- the care for people with a chronic or prolonged disease over a period of their patient career,

- the continuity of care over time,

- the coherence in the care given by different professionals and services,

- the mobilisation and use of self-care and informal care, and

- coping with the potential discontinuity of both the lay and professional cultures, and of hospital and primary health care.

The emphasis of this study was on the first, fourth and fifth point mentioned. Therefore, a prospective cohort study with a longitudinal research design was chosen. In case of professional help special attention was to be given to the role of community nursing in the care for elderly RA patients. However, after the first interview period it appeared that only a few patients did actually receive help from community nurses. Therefore, on this point, the attention changed to the care received by RA patients from informal caregivers and health professionals in general.

\subsection{Health Deviation, Outcome, and Control Factors}

RA, whose course is often unpredictable, and its treatment can cause different problems for the everyday functioning of patients. In addition to the physical consequences of the disease and the treatment, social and psychological factors play an important role in the variability of problems in the course of the disease process. Knowledge about these problems is particularly important to patients and to professional and non-professional care providers in order to be able to give adequate help.

In contrast to acute illmess, patients with chronic conditions are more or less permanently confronted with changes in everyday life. Armstrong (1987) points out that Parson's model of the sick role cannot be used in case of chronic diseases. "Parson's model was limited to the acutely ill who were only temporarily placed in the sick role with its attendant passivity and dependency because they 
could expect recovery; with chronic and disabling illnesses, the temporary role was inappropriate, and worse, if patients were encouraged to view themselves as passive and dependent this could be more disabling than the illness itself" (Armstrong, 1987). In relation to RA this means that the RA patient has to integrate the disease, its treatment, and its consequences into everyday life, without taking up the sick-role. This puts a strain on both the patients and the care providers, because the patient should be viewed as a "normally" functioning person, but sometimes as a person with a disease.

Within the context of this research, RA, the consequences for daily functioning, the psychological and social factors are viewed in terms of health deviation, outcomes of the health deviation process, and control factors (figure 1.1).

Figure 1.1: Health deviation, outcome and control factors in relation to RA.

HEALTH DEVIATION

(RA and its treatment)

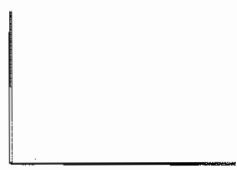

OUTCOME

(Problems with daily functioning)

(Psychological and social factors)

The concept of health deviation is a central notion in Orem's theory of Self Care (Orem, 1980). Health deviation is: being ill or injured, having specific forms of pathology including defects and disabilities, and being under medical diagnosis and treatment. Health deviation affects not only specific structures and physiological or psychological mechanisms, but also integrates human functioning. Health deviation may bring about feelings of illness, of being sick, of not being able to function normally. These feelings, which are related directly or indirectly. to the nature of health deviation, will influence what the person may choose to do.

Outcomes of the health deviation process have to be seen as the consequences of RA and its treatment for everyday functioning of the palient.

Control factors are viewed as psychological and social factors influencing health deviation and outcome factors as well as the relation between health deviation and outcome, some examples of this are social support and coping behavior. The above-mentioned concepts will be further explored in chapter 2 .

\subsection{Research Goals}

The goal of this study is to gain insight into the development of the problems facing the elderly RA patients, living in the community, with everyday functioning, in the course of their disease, and the factors (health deviation and control factors) influencing these problems. 
This thesis consists of eight chapters. Chapter 1 , the introduction, is a general introduction of this study. Chapter 2 starts with a brief outline on RA and its medical treatment and continues with a neview of the literature dealing with the problems of elderly RA patients with daily functioning, and the factors influencing these problems. In Chapter 3 , the research questions are stated as well as the research model. The research model is used as a guideline for the analyses of the results. Further, design issues will be discussed. Chapter 4 reviews the research methods and patients used in this study. Besides this sampling of the study groups will be discussed. In Chapter 5 the descriptive results are presented, transversally as well as longitudinally. Chapter 6 places its emphasis upon the impact of health deviation on the outcome of the disease process. Chapter 7 deals with the impact of the control factors on health deviation and outcomes of RA, as well as the relation between the health deviation and outcomes of RA. Finally, chapter 8 contains the conclusions, discussions, research recommendations as well as some methodological discussions on the use and problems of longitudinal designs in relation to chronic illness. 


\section{RA PATIENTS AND PROBLEMS WITH DAILY FUNCTIONING}

\subsection{Rheumatoid Arthritis}

\subsubsection{Some Medical Aspects of RA}

"RA is the most destructive of the theumatic diseases. It is the disease responsible for the image of an incapacitated person confined to a wheelchair with twisted, swollen joints and gnarled, deformed hands;,..." (Smith Pigg, Webb Driscoll, and Caniff, 1985). In many instances people still hold this image of RA patients. However, RA is a progressive disease with remissions and exarcebations. Its course is extremely variable and may be related to the type of onset, age of the patient at onset, and the presence of rheumatoid factor in high titers (Koerner \& Dickinson, 1983). A medical definition of RA is given by Van der Korst (1980). He describes classical RA as "a syndrome, starting after adolescence, which is characterized by a chronic 'sterile' symmetric polyarthritis, mainly localised in the joints of the hand and feet, except for the distal interphallangeal joints. This polyarthritis is markedly attended with an increase of anti-immunoglobulins in the serum, and with subcutanus noduli on the stretch side of the joints, specifically the elbows. Another important feature is the erosive destruction of the affected joint". A closer look at the order in which the joints are affected during the disease process will show a typical progression, starting in the hand and feet, spreading first to both the wrists and the ankles as well as the interphalangeal joints, followed by the elbows and knees and in the end the hips and cervical spine will be affected. However, some joints are seldom involved, for example the sacroilliac joints (Bird, Le Gallez, and Hill, 1985). Smith Pigg et al. (1985) point out that "although this arthritis is the most frequent and notible manifestation of the disease, there are extra-articular features, such as rheumatoid nodules, arteritis, neuropathy, scleritis, pericarditis, lymphadenopathy, and splenomagaly".

RA is seen two to three times more frequent in females than in males. Older age groups also show elevated prevalence and incidence (Van der Korst, 1980; Grennan, 1984; Duthie et al, 1964; Kirwan and Silman, 1987). The occurance of RA is hardly influenced by climate or weather (Rasker, Peters, and Boon, 1986; Sibly, 1985; Hollander, 1985), country or ethnic group (Kirwan and Silman, 1987; Van der Korst, 1980; Grennan, 1984). Genetic factors play a role in the development of RA. There is a three-fold increased prevalence in first degree relatives (Van der Korst, 1980; Grennan, 1984). Up until now it remains unclear as to what extent psycho-social factors play a role, if any, in relation to RA (Van der Korst, 1980). 
Usually the RA patient presents to her ${ }^{1}$ physician complaints of fatigue, symmetric and polyarticular joint pain, and morning stiffness that may retuin in the evening or after periods of inactivity. In addition, joint pain may force the patient to decrease her activity, causing additional muscle weakness (Koemer \& Dickinson, 1983). Acute onset of the disease occurs in 10 to $20 \%$ of patients and may be associated with systemic upset and low grade fever (Grennan, 1984). Both monoarticular and polyarticular types of onset are seen. Early progression to the typical symmetrical peripheral pattern of joint involvement is associated with an unfavourable prognosis (Ragan et al., 1962; Koemer and Dickinson, 1983; Grennan, 1984). On the basis of literature four categories can be identified conceming the classification of the onset of RA (Van der Korst, 1980; Koemer and Dickinson, 1983; Duthie et al., 1964; Kirwan and Silman, 1987):

1. A slow progressive form without important remissions;

2. Exarcerbations alternated with remissions in the disease activity;

3. A progressive course with clear systemic disturbance and without significant remissions;

4. "Palindromic rheumatism "converting" to RA". (Some of these patients come to their general practitioner with an acute polyarthritis and may completely recover, whille others with identical signs and symptoms will go on to develop RA).

\subsubsection{Medical Treatment of RA}

Main emphasis of the medical treatment of RA is to reduce inflammation and to prevent deformity as much as possible. As the disease process continues, the emphasis changes to the maintenance of muscle function and provision of aids and appliances as well as physiotherapy and occupational therapy (Grennan, 1984; Koerner and Dickinson, 1983; Bird, Le Gallez, and Hill, 1985).

Medical treatment of RA will differ according to the stage of the disease process and the presence of a remission or exarcerbation phase. However, in general the management of R.A concerns the following aspects (Van der Korst, 1980; Grennan, 1984):

1. Patient education concerning disease and therapy;

2. Drugs to relieve symptoms and control disease process;

3. Physiotherapy;

4. Occupational therapy;

5. General advise on rest and nutrition;

6. Treatment of acute exercabation by rest, splinting inflamed joints, plus local steroild injections and joint aspiration, high dosis of NSAID'S;

7. Orthopedic surgery.

1 Throughout this study we will use the female adverb, because the majority of the RA patients are female 


\subsection{Disease Related Complaints of RA}

In general practice patients often express complaints like pain, swelling, stiffness, and impairment of movement. These complaints are, or appear to be, located in components of the locomotor system, the causes of which are obscure (Knox, 1987). These disease related complaints will be more or less present throughout the disease process. When Rasker (1984) asked 200 RA patients what it meant for them to have RA, psycho-social consequences, as well as physical consequences, such as physical disability, pain and fatigue were mentioned. Several other authors describe the same disease-related complaints (Van der Korst, 1980; Smith Pigg et al., 1985; Bird et al., 1985; Kruisvereniging Twente, 1988; De Witte et al. 1989; Weekers et al., 1989).

\subsubsection{Pain, Fatigue, Stiffness and RA}

Pain is a major complaint of patients suffering from RA. McCaffery (1983) defines pain as: "Pain is whatever the experiencing person says it is and exists whenever he says it does". Pain may be classified as (Escobar, 1985):

1. Acute (up to a few days), in most instances the result of recent tissue damage;

2. Subacute (a few days to a few weeks);

3. Recurrent acute (rheumatoid, migraine);

4. Continuous (as observed in underlying malignant disease);

5. Chronic (more than six months).

Ehrlich (1980) decribes the recurrent acute pain as persistent arthritis pain, which tends to be modest but long-lasting. Although the pain is generally low-grade, when sustained over long periods, it becomes increasingly unbearable. The chronicity of the pain is the threat, not the intensity but the persistence makes arthritis pain unbearable.

Rasker (1984) found that, independent of the stage of the disease process, pain was mentioned by RA patients as one of the most important consequences of their disease. De Witte (1989) found in a study on 372 rheumatic patients that $84 \%$ reported to have (almost) constant pain, $11 \%$ did have pain occasionally, and $5 \%$ reported not to have pain (anymore). Pain in RA is mainly treated by drug therapy (Van der Korst, 1980; Grennan, 1984; Smith Pigg et al., 1985; Bird et al., 1985). Other approaches used are patient education (Lorig, 1982; Le Gallez, 1985; Mullen et al., 1987; Van der Korst, 1980, Bird et al., 1985) and several other kinds of therapies (Large, 1985; Kerns et al., 1986; Mannheimer, 1987; Bradley et al., 1987).

Smith Pigg et al. (1985) mentioned a special problem of pain in the elderly. On the one hand older people have more time to consider their physical condition and to become preoccupied with pain. While on the other hand, older people may feel that pain and discomfort are a normal phenomena of the aging process and thus may tolerate pain unnecessarily. Pain management in the elderly is difficult because the patients may have had a lifetime experience and beliefs about what works for relief and what does not work. 
A second important complaint of the disease is fatigue. Fatigue is a subjective complaint of weariness, exhaustion, or lassitude, frequently associated with irritability, ineffuciency, and a decreased capacity for work. Fatigue is a normal aftermath of prolonged mental or physical labor. Spontaneous and easily provoked fatigue early in the day may suggest either organic or psychiatric disease (American Rheumatism Association Glossary Committee, 1982). Fatigue as such is often not mentioned among the major complaints of RA (Van der Korst, 1980; Grennan, 1984), but recognised as an outcome of prolonged activity, as can be seen in the definition of fatigue. The Outcome Standards for Rheumatology Nursing Practice (1983), however, state as one of the outcome standards:" "The individual incorporates as part of daily activities those measures necessary to modify fatigue". One fifth of the RA patients in the study of Rasker (1984), experienced fatigue as an important disadvantage of the disease, it was mentioned more often by patients who were less dependent and more often by women of whom it was expected to continue their household activities. In a study done by De Witte et al. (1989), they found that 273 arthritis patients did experience fatigue on a regular basis, 87 were not often troubled by fatigue, and only seven patients reported not to be bothered by fatigue.

A third important complaint of RA is stiffness. Variations in its severity and duration are regarded as indicative in disease activity (Rhind et al., 1987). Early morning stiffness and stiffening with inactivity during the day is mentioned as one of the early symptoms of RA (Van der Korst, 1980; Grennan, 1984). Stiffness is defined by Smith Pigg et al. (1984) as: "the discomfort or restriction perceived by the patient when attempting the first part of easy movement of a joint after a period of inactivity". Joint stiffness covers two disturbances of function:

- a sense of added resistance when one attempts to move a specific joint, or,

- an inability to move a joint through some part of its normal range of motion (ROM).

The cause of the generalised early morning stiffness is not known (Van der Korst, 1980). Possibly it is not a direct effect of the inflammation of the joints because of its general character. It should be differentiated, however, from 'starting-stiffness' which is a typical feature of an arthretic joint. Smith Pigg et al. (1985) differentiate three factors which influence stiffness:

- mechanical factors: viscous and frictional factors resulting from the disease process in addition to the exaggerated effect of activity,

- activity: inactivity as well as excessive or unaccustomed activity,

- environmental factors: changes in environmental temperature, humidity, or barometer pressure may cause stiffness.

Consequences of stiffness for activities of daily functioning will be discussed later in this chapter.

Rhind et al. (1987) as well as Smith Pigg et al. (1985) point out that RA patients do not always make a clear differentiation between pain, fatigue and stiffness. Rhind et al. (1987) concluded in their study that it appeared that some of the RA patients who claimed to be stiff were just as likely to be referring to pain, limited movement or a combination of the two. Smith Pigg et al. (1985) point out that RA patients might translate their feelings of fatigue to more acceptable complaints such as pain, stiffness, or weakness. 


\subsection{Daily Functioning and RA}

The consequences of RA and its medical treatment for daily functioning for the RA patient can be extensive. Patients are often restricted in household activities as well as selfcare activities. Being restricted in movement also means that work and leisure activities have to be changed. Medical treatment includes a regimen concerning rest and activity. In most instances the RA patient will, if functional capacity decreases, become more dependent on assistive devices or people in the immediate environment.

Smith Pigg et al. (1985) describe four areas in which alterations occur for patients with rheumatic diseases:

- comfort alterations (pain, stiffness, fatigue, and sleep pattern disturbances),

- functional alterations (change in mobility, and change in daily living skills),

- physical alterations (change in nutritional status, change in body image, and changes in skin integrity), and

- adaptational alterations (change in self-esteem, limitations in insight).

Ample research has been done covering the different aspects as mentioned by Smith Pigg. Webb Driscoll, and Caniff, and will be discussed in the next sections.

\subsubsection{The Impact of RA on ADL}

Pain, fatigue, stiffness, decreased endurance, and diminished strength affect the range of motion (ROM) and function by limiting movement. Loss of skill, also, occurs because of loss of motion (LOM) (Smith Pigg et al., 1985). LOM is a common manifestation of joint diseases. The joint surface can be altered by erosions resulting from the inflammatory process or degeneration of the cartilage. The attempt of the bone to 'heal' itself by developing osteophytes or 'spurs" can also alter the contour and smooth surface of the joint. The ligaments and tendons can be weakened or even ruptured by the inflammatory process. Muscles, too, can be affected by inflammation. Finally, contractures limit the range of motion (Smith Pigg et al., 1985; Bird et al., 1985). A widely used concept to classify the physical ability of the RA patient is functional status, which is an individual's level of performance in activities of daily living (ADL) (Liang \& Jette, 1981). The American Rheumatism Association (Steinbrocker et al., 1949) developed a classification of functional capacity (table 2.1). In general, four different classes of functional capacity are distinguished. It is important to note that class $I$, in general, will not include those persons with RA who experience only mild disease symptoms and do not attend a doctor or seek medical advise (Kirwan and Silman, 1987). 
Class 1: Complete functional capacity with ability to carry on all usuall duties without handicaps.

Class II: Functional capacily adequate to conduct nomal activities despite handicap or discomfort or limited mobility of one or more joints.

Class III: Functional capacity adequate to perform only few or none of the duties of usual occupation or of self care.

Class IV: Largely or wholly incapacitated with patient bedridden or confined to wheel-chair, performing little or no self-care.

Due to the fact that RA is a progressive disease which affects the joints, RA patients show a gradual decline in their functional capacity. A study done by Sherrer and collegues (1986, p. 496), showed that at the beginning of their study, which involved $681 \mathrm{RA}$ patients, who were followed for an average of 11.9 years, $48 \%$ of the RA patients were in class I. By the end of the study, this number had declined to only $17 \%$. At the start of their study, only $3 \%$ of the patients were completely disabled. When the study was finished, $16 \%$ of the patients were in class IV. Duthie et al. (1964, p. 194-195) reported similar findings: "From the first assessment onwards there has been a gradual and progressive deterioration in the group as a wholle. Nevertheless, over 20 percent were still in Grade I at the fourth assessment and less then 12 percent had become entirely dependent on others. Rather more than 60 percent retained full functional capacity". By using several health assessment questionnaires several authors did find similar results (Fries et al., 1980* Meenan et al., 1984, Fries et al., 1982).

An individual's functional ability is determined by a complex interaction of physiological variables, psychosocial (e.g. coping skills, motivation, family support, socioeconomic status), and environmental factors (e.g., transportation, adaptive devices).

One of the areas of daily functioning in which the consequences of RA and its medical treatment become clear is the area of $\mathrm{ADL}$. A widely used instrument to investigate ADL was developed by Katz (1963). He and his collegues identified six functions (bathing, dressing, going to toilet, transferring, continence, and feeding) by which patients could be ranked according to their adequacy of performing ADL. Normal aging processes lead to a slight decrease in the possibilities to perform ADL-activities independently. Jette and Branch (1981) investigated the nature and magnitude of disability among non-institutionalised elderly. They found, as far as the independent performance of ADL was concemed, that "almost all respondents perform all six activities without assistance of any kind. For all activities, except eating, respondents 75-84 years of age are significantly more likely than their younger counterparts, to use help in accomplishing the activity. However, over 90 per cent of respondents being $75-84$ years of age, are still independent in these six ADLs". In order to investigate the ADL performance of patients with chronic conditions, several scales have been developed (Pincus et al., 1983; Fries, 1983b; Katz et al., 1963; Jette, 1980; Lee, 1973; Steinbrocker, 1949; Meenan et al., 1980; Convery et al., 1977). Due to the fact that the instruments used different kinds of items, added, or used less items then the Index of ADL, it is difficult to compare the results obtained by these in- 
struments. In most instances the investigation of ADL (as part of these instruments) was used to (Liang and Jette, 1981):

1. Evaluate the effect of an intervention;

2. Define needs for specific services or therapy, or

3. To monitor the longitudinal course of a disease.

In the Netherlands, few studies have been done to investigate the ADL of RA patients. Studying the performance of ADL of 200 RA patients Rasker (1984) found that patients experienced the most difficulties with dressing, bathing and walking stairs. Less problems were reported with eating and drinking, walking in the house, getting in and out of a bed or chair, and toiletting. It is possible that less problems were reported for these items because of the use of aids and appliances. Similar results were found by the Kruisvereniging Twente (1989), and Mostert (1987).

Two aspects of the treatment of RA can be of influence on the independent performance of ADL-activities, namely, the use of aids and appliances and a regimen of rest and activity.

In order to facilitate independent functioning the RA patient is advised to use aids and appliances. Aids and appliances are usually prescribed when patients are in functional class III and IV. In these stages it is not expected that functional capacity can be totally recovered (Van der Korst, 1980). Grennan (1984) and Van der Korst (1980) name as part of the management of RA occupational therapy. Occupational therapists can provide detailed functional assessments. They may also advise on the modification of work habits and the use of splints to prevent deformity. For patients with functional disabilities, occupational therapists can provide home aids to help with ADL and household activities (Grennan, 1984). Although aids and appliances are often necessary to be able to function independently, it is not always easy to obtain them. Within the Dutch social security system, procedures to obtain aids and appliances are often complicated and longlasting. The help of professionals is often needed (rheumatologist, Community Nursing Association). In addition, it is known that patients do not allways (know how to) use them or that assistive devices are inappropriate (Liang et al., 1983, Williams et al., 1987). Two factors might influence the use of assistive devices. First, the procedures are often complicated and longlasting. Between the application and the moment of actually getting the aid or appliance, the disease situation might have changed to the extent that the aid or appliance is no longer needed or has become inappropriate. Second, as Robinson (1988) writes, physical disabilities force the patient to reorder relationships with the physical environment. "Given their personal aim to re-create a tolerable normality, people with chronic conditions generate hypotheses about how this might be best achieved, frequently through lateral and innovative thinking, and test the degree of fit and different courses of action with their hypotheses and aims". In both instances the role of acceptance of the disease by the patient, as well as the immediate environment, play an important role.

Another aspect of the medical treatment, which is related to the earlier described problems, is regimen of rest and activity, which might be a cause of problems for the daily functioning of RA patients. Most RA patients are advised to alter their rest and activity pattern. Several authors give a description of these general advisements (Van der Korst, 1980; Koerner and Dickinson, 1983; Smith 
Pigg et al ., 1985). Smith and Polley (1978) conclude in their article on 'Rest therapy for rheumatoid arthritis' that most physicians subscribe to the general principle of a judicious balance between rest and activity in the treatment of RA, but the prescription is often vague and confusing. The principal determining factor for a favorable result, especially the minimising of articular damage, continue to be sufficient rest and appropriate physical therapy:

Basically all literature on the treatment of RA, especially that concerning the rest and activity pattern state that:

- RA patients need more rest, specifically systemic rest, articular rest and emotional rest;

- RA patients need exercise (basic isotonic exercise regimen to maintain function and strength);

- RA patients need to bring a different balance in their rest and activity pattern (alteration of rest and activity).

The meaning of rest and activity to the RA patient was investigated by Lorig et al. (1984). They asked 98 RA patients what they thought would be helpful to arthritis. Eighty percent of the patients answered exercise, and $41 \%$ answered rest. In responding to what made their arthritis worse $58 \%$ answered exercise, $42 \%$ answered prolonged activity or staying in one position, and $27 \%$ answered inadequate rest. Silver et al. (1985) assessed RA patients' general need for patient education. Among the topics which were rated as very important were prescribed exercises, stress reduction, and rest and relaxation.

As was mentioned earlier the advice given to the patient regarding rest and activity are of ten vague and confusing and patients consider "rest and activity' as an important part of the treatment of their disease. It can be concluded that because of the vagueness of the advice and the importance of rest and activity to the patient, it is often difficult for the RA patient to integrate rest and activity advice into every day life.

\subsubsection{Relational Functioning and RA}

Acceptance of the disease by the patient and the immediate environment plays an important role in the handling of RA and its medical treatment. Parker et al. (1988) state that "the pattern of uncertain disease progression, accompanied by difficulties in many areas of daily functioning, contributes to the extreme stressfulness of RA". Williams and Wood (1988) conclude that the process of coming to terms with chronic illness is largely one of negotiating autonomy. This involves more then complying with doctor's advice and instructions; it entails confronting challenges to personal identity on a number of levels, and finding some means of negotiating a viable form of life that gives the illness its due without alllowing it to undermine the moral economy of family relationships and friendships. It also means resisting or ignoring more negative attitudes in society which make people with disabilities feel uncomfortable.

From the start of the disease the RA patient has to learn to cope with the disease, its symptoms, medical treatment, and the unpredictable course of the disease which includes variable dependency on the immediate environment because of varying functional ability. Many studies refer to these problems of RA patients 
with regard to the consequences for the relationships of the RA patient (Weiner, 1975; Bird et al., 1985; Rasker, 1984; Rogers et al., 1982; Abram, 1972; Pollock, 1986; Vignos et al., 1971; Muhlenkamp et al., 1986; Mechanic, 1977; Marden and Burnight, 1969; Russel, 1981; Moulton, 1984; Mostert, 1987; Kruisvereniging Twente, 1989; De Witte et al., 1989). Problems which are most frequently mentioned refer to three categories of possible problems. All authors name problems concerning the self (decreased sense of self-worth, hopes for the future are shattered, loss of control on life, feelings of fear and depression). A second source of problems mentioned are problems which involve the consequences of the disease process (uncertainty about disease process, dependency, loneliness). A third group of problems concerns the relationships of the RA patient, such as a lack of understanding from partner and/or family, grief and stress in the family situation, and loss of social contacts.

\subsubsection{Loneliness and RA}

Whereas the physical deterioration may lead to a greater dependency between the RA patient and the immediate environment, the emotional and relational consequences of the disease may also have an influence on the development of feelings of loneliness. Loneliness was described as one of the consequences of changes in relational functioning of the RA patient. According to Van der Korst (1980) the lessening of the range of action of the patient could imply loss of social contacts. The experienced lack of social contacts is, according to De JonghGierveld (1985), a major component of loneliness. Using the loneliness-scale as developed by De Jongh-Gierveld, Mostert (1987) found that 23 RA patients (ARA functional class III and IV) who received community nursing care did have relatively high loneliness scores, indicating that RA patients in higher functional classes experience more feelings of loneliness. De Witte et al. (1989) found that 139 RA patients did experience feelings of loneliness within the same range as Van Tilburg (1988) found in a population study. Cantor (1976) found that elderly who were lonely or missed company did not share these feelings with their spouse or children but sought help by non-relatives. This could especially be evident for those RA patients who are dependent on their relatives that feelings of loneliness are not shared with people in the personal network.

\subsection{Factors Influencing the Problems of RA patients}

In the first part of this chapter the problems of elderly RA patients conceming daily activities have been discussed. In all instances the problems referred to were seen as 'outcomes' of the disease process and medical treatment. This direct relation between RA, its medical treatment, and the outcome of the disease process might be influenced by other factors as social position and attitudes and the care provided for by the immediate environment and professionals. These control factors will be explored in the following sections. 


\subsubsection{Social Position and Attitudes}

\subsubsection{Health Perception: the meaning of RA to the patient}

Safilios-Rothschild (1970) found, interviewing disabled persons, meanings and consequences associated with disability, which differed from more traditional 'illness' or "disease'. Blalock et al. (1988) state that differences in individuals" satisfaction with their physical abilities may account, in part, for the differences in levels of psychological well-being. In terms of health perception this means that chronically ill patients attribute stable meanings to their disease, which include consequences of the disease and its medical treatment for everyday functioning. Only a few Dutch studies have been done in which the RA patients were asked what the disease meant to them (Rasker, 1984; Kruisvereniging Twente, 1988; De Witte et al., 1989). Table 2.2 summerises the different meanings given to RA as reported in the three studies. Basically, three groups can be differentiated in the meanings given to the disease. In all three studies, the meanings in terms of the symptoms of the disease, play an important role to the patient. Similar results were found by Lorig et al. (1984). They found in their study involving $98 \mathrm{RA}$ patients, that $87 \%$ of the patients answered pain to the question "What first comes to mind when you think about arthritis". Among other disease related symptoms and consequences in terms of relationships, $72 \%$ of the patients answered immobility or disability and $21 \%$ answered deformity. Burckhart (1984) found in a study on the impact of arthritis on the quality of life, that patients who were experiencing severe pain from their arthritis were decidedly more negative about their disease.

Table 2.2: Answers to the question "What does RA mean to you" as given in studies done by Rasker (1984), Kruisvereniging Twente (1988). and De Witte et al. (1989).

What does RA mean to you:

No longer able to perform certain activities;

Restrictions in freedom of movement;

Pain;

Fatigue;

Bodily complaints;

Dependency;

Uncertainty about disease progression;

Lack of understanding from relatives;

Shattered future;

Feelings of fear and depression;

Loss of social contacts;

Grief and stress in the family situation;

Decreased sense of self-worth;

Loss of control in life;

Loneliness;

Financial limitations. 
A second group of meanings refer to the psychological effects of RA. Different studies were done investigating the impact of arthritis on the psychological problems of patients with arthritis. Lorig et al. (1984) found that 27\% of $98 \mathrm{RA}$ patients did express the experience of emotional and psychological problems. The different psychological consequences of RA which have been studied are depression (Muhlenkamp and Joyner, 1986; Smith and Peck, 1988; Turner and Noh, 1988), uncertainty (Weiner, 1975; Mishel and Braden, 1988), helplessness (Nicassio et al., 1985), lower self-esteem (Burckhart, 1984; Muhlenkamp and Sayles, 1986), anxiety (Muhlenkamp and Joyner, 1986), and grief (Moulton, 1984).

A third group of meanings concern dependency and the relationships of the patient. All three studies report that dependency and loss of social contacts are experienced as a significant meaning of RA. In general, both aspects are related to disease severity. The more disabled a patient becomes, the more dependent she will be on the immediate environment for help and the more the person will be restricted in actually meeting other people. This aspect will be further discussed in relation to personal network and professional help.

\subsubsection{Coping Behavior and RA}

A second aspect which influences the outcomes of RA is coping behavior. Much research has been done on the coping behavior in RA patients. Schreurs (1987) defines coping as: the efforts made by an individual, when demands are relevant to wellbeing (health, social functioning, and self-confidence), and if these demands appeal to an individual's adaptability.

Coping strategies which are often referred to, are: action strategies, such as information seeking; control strategies" escape strategies; optimism; fatalism; and interpersonal coping strategies. Craig and Edwards (1983) describe that the commonly used coping behaviors in chronic illnesses include the following:

- denying or minimising the seriousness of the loss;

- utilisation of personal and extra-personal resources;

- setting concrete goals and expectations, and

- utilisation of hope.

Schreurs et al. (1985) notice that coping behavior in chronically ill patients is not an individual concern, but can, dependent on the impact of the disease, be a matter of the entire social system of the chronically ill person.

Parker et al. (1988) found in their sample, a tendency towards the use of 'Wish Fulfilling Fantasy' as a coping strategy for arthritic patients. This strategy' was associated with higher levels of depression, higher levels of 'helplessness', an increase of daily stress, and greater psychological distress. The tendency to use 'Self-Blame' as coping strategy was also related to greater psychological distress. The use of 'Wish Fulfilling Fantasy' and 'Self-Blame' were both associated with greater functional impairment, while 'Cognitive Restructuring' was associated with less functional impairment, and not with psychological distress. These results are similar to the results of Felton et al. (1984). They studied four groups of patients with chronic conditions (hypertension, diabetes mellitus, RA, and systemic blood changes). They found that RA patients were more likely to use 'Wish-Fulfilling Fantasy' than did other patients, even after controlling for 
demographic variables. Viney and Westbrook (1984) found that chronically ill patients were more likely to use fatalism and optimism strategies than did nonpatients. In relation to uncertainty they concluded that patients who see themselves as using action strategies (which are often patients who are less disabled by their disease) were more likely to keep their uncertainty to a minimum, it is to say that if patients" uncertainty is minimal, they are then able to have a preference for action strategy.

\subsubsection{Social Position and RA}

A third aspect which might influence the outcomes in RA is social position. Weber argued that people in similar class situations share similar life chances (Lebenschancen), in that their economic position will directly affect their chances of obtaining those things defined as desirable in their society, for example access to higher education and acces to health care (Haralambos, 1980; Luischen et al., 1989). Several Dutch studies indicate that differences in the amount of problems with household and ADL activities and professional help asked for, exist between males and females, for patients in older age groups, with lower education level, and people in lower social classes (Rasker, 1984; Gorter, 1990; Frederiks, 1990; Kempen, 1990). This would mean that elderly female RA patients, with lower education levels and in lower social classes have more problems with daily functioning and less access to health care facilities. If patients have less access to health care facilities, the availability of people (spouse, housemates, and children) in the immediate environment becomes more important (dependent care facilities).

\subsubsection{Care Facilities and RA}

\subsubsection{Social Support and RA}

RA patients often become more dependent on the help of people in their immediate environment during the course of the disease process. Van der Korst (1980) notices that patients in stage II of the disease process (moderate limitations in movement) should not do heavy (household) work. On the other hand patients in stage IV need help for all ADL activities, and are therefore, dependent on the help of community nursing. In the first instance, however, patients are dependent on the help of people in the immediate environment (spouse, children, family, and friends). In a study by Knipscheer (1980), involving 455 elderly, he found that the mean size of the personal network was 10.5 people. Of these relations about seven persons were family members and about three were friends or neighbours. Knipscheer found that $42 \%$ of the children and $33 \%$ of the neighbours gave much instrumental support, less instrumental support was given by the group of brothers and sisters of the elderly. Children (69\%) and friends (65\%) were responsible for the greatest part of emotional support. De Witte et al. (1989) found that, about three quarters of 242 arthretic patients reported to receive much instrumental support from their spouse, while $9 \%$ reported to have little instrumental support from their spouses (see also Gorter, 1988). Fourty-four percent of 
257 respondents reported to receive much instrumental support from their child: ren (see also Knipscheer, 1980). Less instrumental support was provided for by family and neighbors $(17 \%)$. Eighty percent of the respondents reported to receive much emotional support from their spouses. Less emotional support was given by family, $50 \%$ of the patients did not receive much emotional support from their family. Patrick et al. (1986) state that social ties and psychosocial backing may be of particular importance for physically disabled people because support maintains or strenghtens individual coping behavior. Disabled people with high levels of support may have higher levels of self-esteem or morale. This helps them to cope with everyday problems of being disabled, like encouraging problem-solving and providing advice and access to professional services or selfhelp groups. However, psychosocial support may have little significance for people with established medical conditions or unavoidable limitations that follow a deteriorating course, such as RA.

Schiltmans (1988) found in a research done by 44 elderly RA patients a mean size of the personal network of about seven persons. She did not differentiate between instrumental and emotional support. She found that spouses were responsible for some $12 \%$ of the support given to the elderly, while family members (including children) gave $40.6 \%$ of the total support.

\subsubsection{Professional Help and RA}

Next to the help of the people in the immediate environment, RA patients use the help of health care professionals. Much has been written about the care for RA patients by health care professionals, for example, about patient education programs (Lorig, 1982; Le Gallez, 1985; Kaplan and Kozin, 1981; Mullen et al., 1987), community care programs (Liang et al., 1981; Liang et al., 1984; Levinson et al., 1982; Dickinson et al., 1980), and the use of specific arthritis care programs (Barney and Neukom, 1979; Vignos et al., 1971; Yelin et al., 1985). However, not much is known about the actual contacts between the RA patients and health care professionals in the open community. Some Dutch studies investigated the contacts between the RA patients and health care professionals (Rasker. 1984; Kruisvereniging Twente, 1988; De Witte et al., 1989). Table 2.3 summerises the results of the different studies. As can be seen in table 2.3 almost all RA patients do see their rheumatologist on a regular basis. The number of patients who have contact with their general practitioner differs in the studies. This applies also to the physiotherapist and occupational therapist. About $20 \%$ of the patients involved in these studies have contact with community nursing and home aid. It can be concluded that almost all RA patients do have contacts with either a rheumatologist or a general practitioner. In case of home aid and community nursing it can be said that it is possible that patients who are more dependent (ARA-functional classes III and IV) did ask for the help of these professionals. 

reported by Rasker (1984) (A), Kruisvereniging Twente (1988)

(B), and De Witte (1989) (C) (\%).

\begin{tabular}{|c|c|c|c|}
\hline & $A^{*}$ & $\underline{B}^{* *}$ & $C^{* * * *}$ \\
\hline Rheumatologist & 95 & 100 & 77 \\
\hline General practitioner & 35 & 22 & 63 \\
\hline Community nursing & 27 & 24 & 21 \\
\hline Home aid & 21 & 17 & 25 \\
\hline Physiotherapist & 76 & 26 & 59 \\
\hline Occupatioal therapist & 31 & & 11 \\
\hline Social worker & 18 & 1 & 9 \\
\hline Psychologist & 4 & & 3 \\
\hline Rehabilitation & & & 10 \\
\hline Hospital nursing & & & 19 \\
\hline Other specialists & & & 33 \\
\hline Social security offices & 28 & & 23 \\
\hline Priest & & 13 & 10 \\
\hline Other & & 4 & $\mathbb{1 1}$ \\
\hline
\end{tabular}

* All contacts prior to the study

** Contacts during two years prior to the study

*** Contacts during one year prior to the study

\subsection{Summary and Conclusion}

RA is a chronic systemic disease, involving the joints and extra-articular features. Major complaints of the RA patient include pain, fatigue, stiffness and a decrease of functional capacity (health deviation factors). Many studies describe pain, fatigue and stiffness as being important complaints of RA and hinder the patient in daily functioning. However, little is known about the consequences and the impact of these complaints on the performance of activities of daily functioning. Several longitudinal studies indicated that the functional capacity of the RA patient shows a gradual and progressive deterioration. Approximately $20 \%$ of the RA patients remain in ARA functional class $\mathbb{I}$, whereas approximately $10 \%$ becomes severely disabled.

The disease and its treatment will have consequences for everyday functioning of the RA patient. Areas of daily functioning in which the RA patient meets problems which have been described in the literature were ADL, obtaining and using aids and appliances, relational functioning, rest and activity pattern, and loneliness (outcome factors). The majority of ADL problems identified in the literature concerned dressing, bathing and walking stairs, less problems were identified concerning eating and drinking, walking in the house, getting in and 
out of bed or a chair, and toiletting. Aids and appliances can support independent (ADL) functioning of the RA patient. Procedures to obtain aids and appliances within the Dutch social security system are, however, complicated and longlasting. Next to this, several studies indicate that patients do not always (know how to) use assistive devices or find that assistive devices are inappropriate. The (uncertain) progression of the disease does not only cause problems in the area of $\mathrm{ADL}$ and obtaining aids and appliances, but can also cause problems in the area of relational functioning. Based on the literature, three categories of possible problems with relational functioning were identified: problems with the self, problems involving the consequences of the disease process and problems with relationships. Another possible outcome of the disease process is loneliness. Because of the decrease in functional capacity, the RA patient can be restricted in actually meeting other people, initiating or strengthening feelings of loneliness. Although many studies have investigated the problems of the RA patient in these areas of daily functioning, two questions remain unanswered. Firstly, the development of problems met by the RA patient during the course of the disease process concerning ADL, obtaining aids and appliances, relational functioning, the rest and activity pattern and loneliness. Secondly, the impact of pain, fatigue, stiffness and (a possibly changing) functional capacity on the development of these problems.

Up until now it has been argued that RA and its treatment have consequences for different areas of daily functioning. This direct relationship between RA, its treatment and the outcomes of the disease process can, however, be influenced by other factors such as social position and attitudes, and the care provided for by the immediate environment and professionals (control factors). Two attitudinal characteristics are described in the literature: health perception or the meaning of RA to the patient, and coping behavior. Several studies identified three categories of meanings of RA: the symptoms of the disease, the meaning of RA to the patient personally, and meanings concerned with dependency and relationships of the patient. No research has been done on the impact of the meaning of RA on the problems with daily functioning and the disease symptoms. An important personal characteristic described in the literature was coping behavior. Coping strategies used by RA patients were wish-fulfilling fantasy, self blame, fatalism and optimism. Several studies indicated that these strategies were related to higher levels of depression, helplessness, daily stress, psychological distress, and greater functional impairment. Cognitive restructering and action strategies were related to less functional impairment and lower levels of uncertainty. The remaining question concems the impact of coping behavior on the development of the problems with daily functioning.

The support a patient receives from the immediate environment and professionals is found to influence problems with daily functioning. Few studies investigated the instrumental and emotional support received by the RA patient. Much of the instrumental support is obtained from spouses, children and neighbors, whereas spouses are the group responsible for the greater part of the emotional support. As far as professional help is concerned, almost all RA patients receive help from a rheumatologist, or frequently visit their general practitioner. About $20 \%$ of the RA patients receive help from home aid or community nursing. Not 
much research has been done on the impact of the meaning of RA, coping, and social support on the development problems with daily functioning.

It can be concluded that health deviation factors (functional capacity, pain, fatigue and stiffness, duration of RA, and clinical data) have consequences for the outcome of the disease process (problems with daily functioning, rest and activity pattern, and loneliness). This relation might be influenced by control factors. Control factors identified in this chapter could be differentiated in two categories, namely social position and attitudes (meaning of RA, coping behavior, gender, and social position), and care facilities (personal network, and professional help). Within the next chapter these concepts will be further explored and presented in the research model. 


\section{RESEARCH QUESTIONS AND RESEARCH MODEL}

\section{Introduction}

In this chapter the research questions, the general model and the phenomena, which will be part of this study, are discussed, following the findings of the literature (chapter 2). The expected relations between the phenomena will be presented and will be used as a guide-line in presenting the results of this study. Finally some design issues will be discussed.

\subsection{General Research Model}

Becoming chronically ill often means that patients have to face changes in their everyday life. According to Smith Pigg, Webb Driscoll and Caniff (1985, p. 4) the impact of a chronic illness is that it: "can be a dramatic, unasked-for, permanent change in a person's life, with the occurance of varying degrees of loss in previously chosen and accepted styles of life". Several factors may influence these 'outcomes' of RA and can be divided into two broad categories (see figure 3.1):

- Health deviation variables,

- Control variables: social position and attitude, and care facilities (professional help and personal network).

The fact that health deviation variables influence outcome variables is widely accepted. Next to this relation the control factors (social position and attitudes, and care facilities) are expected to influence the health deviation and the outcome variables as well as the relation between these variables (section 2.5 ) (figure 3.1).

As previously mentioned, the emphasis of this study was on the care for patients with a chronic disease over a certain period of their patient career. When a person is diagnosed as having RA she will have to adjust to possible changes in life-style. Most changes will occur in the area of activities of daily functioning (Van der Korst, 1980). Disease symptoms, limitations in the range of motion (ROM) and loss of motion (LOM) of the joints lead to difficulties in performing activities necessary for daily functioning (outcome). 
CARE FACLITIES (professional help and personal network)

HEALTH DEVIATION VARIABLES

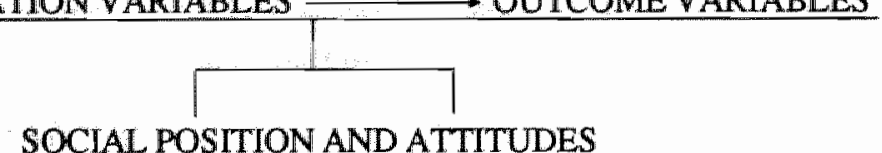

The central relation studied is the relation between health deviation and outcome variables. Health deviation variables (functional capacity, pain, fatigue, stiffness, duration of RA, and clinical data) influence problems of RA patients with daily functioning, rest and activity pattern, and feelings of loneliness (outcome variables) (chapter 2). Three possible relations exist between control, health deviation and outcome variables. Firstly, control variables influence the outcome variables, for example, the meaning of RA to the RA patient influences the problems with daily functioning. Secondly, control variables influence the health deviation variables, for example, the personal network factors influence the duration of morning stiffness. Finally, the control variables may influence the relation between health deviation and outcome variables, for example coping behavior influences the relation between pain and problems with daily functioning.

Prior to formulating research questions based on the relations as given in the general research model, descriptive questions are:

la Which problems do elderly RA patients, living in the community, meet in daily functioning, especially concerning ADL, obtaining and using aids and appliances, and relational functioning?

1b To what extent do elderly RA patients alter their rest and activity patterns, given the presciptions on rest and activity as part of the medical treatment?

1c To what extent do elderly RA patients experience feelings of loneliness?

1d Which changes concerning ADL, obtaining aids and appliances, relational functioning, rest and activity, and feelings of loneliness occur during the course of the disease process?

Relational research questions are:

2 Which influence do health deviation variables have on problems with daily functioning, rest and activity paitern, and feelings of loneliness?

3a To what extent do social position and attitudes, and care facilities influence problems with daily functioning, the rest and activity pattern, and feelings of loneliness?

$3 \mathrm{~b}$ To what extent do social position and attitudes, and care facilities influence health deviation?

$3 \mathrm{c}$ To what extent do social position and attitudes, and care facilities influence the relation between health deviation and problems with daily funclioning, the rest and activity pattern, and feelings of loneliness? 
4 Do changes concerning problems with daily functioning, the rest and activity pattern, and loneliness concur with:

- changes in health deviation

- changes in social position, attitudes and care facilities?

In the following sections each part of the general model will be further explored.

\subsection{Health Deviation Variables}

The majority of difficulties that the RA patient is confronted with concern activities of daily functioning and will greater develop due to the physical consequences of the disease process. In the research model these consequences are compiled in "health deviation variables" (figure 3.3), which can either be measured in terms of (Philipsen, 1969):

- 'disease', which refers to pathology (clinical data),

- 'sickness', which refers to dependency, or acceptance of the patient role (duration of RA, functional capacity) or in terms of

- 'illness', which refers to affective aspects related to the disease (pain, fatigue and stiffness).

The 'disease' and 'sickness' measures will give an indication of the extent to which the patient is limited in dailly functioning, as well as, the (in)stability of the disease process (for example: roentgenological changes of the joints, subcutanous nodules, number of joints involved, ESR) (Van der Korst, 1980; Bird et al., 1985). The clinical data, as used in this research, will provide an answer to the question: Which stage of the disease process the RA patient is in and will give an indication of the activity of the disease. The fourth research question (section 3.1) involves the influence of the changes in the disease process on the problems met by RA patients in daily functioning. By assessing the clinical data the question of the association between the disease activity and the changes concerning activities of daily living can be answered.

An indirect measure of sickness is the duration of RA. It can be hypothesised that the longer the disease lasts, the more disabled the patient will become. In a 15-year follow-up, Sherrer et al. (1986) found that an initial deterioration and recovery in the early years was followed by slow progression of functional loss (section 2.3.1). The duration of the disease gives an indication about the seriousness of the disability caused by the disease and the extent to which the disability has consequences for daily functioning and will therefore be part of this study.

A second measure of sickness is functional capacily. The quantification of functional ability may have several objectives, of which monitoring the (longitudinal) course of a disease is one (Liang \& Jette, 1981). Based on the (uncertain and unpredictable) activity and progression of the disease, the joints will ultimatly become affected and the functional ability of patients will decrease in time. Weiner (1975) differentiates three reductions in bodily functioning:

- a reduction of mobility;

- a reduction of skill;

- a reduction of energy.

All three kinds of reductions lead to the existence of difficulties in performing activities of daily functioning and, therefore, have consequences for dependency. 
Besides the bodily changes, which affect the dependency of the RA patient, the treatment of RA encloses different presciptions which are related to functional capacity and influence daily functioning. First of all, RA patients are advised to rest more and to realise more regular changes between rest and activity periods during the day. Second, patients are advised not to do heavy (house-hold) work (Van der Korst, 1980; Grennan, 1984). Furthermore, in most instances the treatment of RA will enclose the prescription of daily exercise programmes as well as the alteration of previous ways of accomplishing various tasks (Van de Korst, 1980; Smith Pigg et al., 1985). These presciptions are given to the RA patient in order to reduce inflammation and to prevent deformity.

An 'illness" aspect of the disease variables are the three major complaints of the disease (pain, fatigue and stiffness), which can cause problems with daily activities for the RA patient.

Stiffiness can be defined as the discomfort or restriction penceived by the patient when attempting the first part of easy movement of a joint after a period of inactivity (Smith Pigg et al., 1985) (section 2.2.1). Stiffness is often experienced after inactivity or after the maintenance of a single position for a lengthy period. Three types of stiffness can be differentiated. First, the short-lasting stiffness, which responds to limbering movements and is most noticable in ambulation, where it creates a temporary problem. This type of stiffness will hardly have any effect on the daily activities of a RA patient. A second type of stiffness of short duration (less than half an hour) occurs with structural joint diseases. This type of stiffness is related to overuse of the specific joint and can temporarily affect the activity pattern of a patient. The third type of stiffness is the early morning stiffness. The occurance of this type of stiffness is a prodromal sign of arthritis and is one of the diagnostic criteria in RA.

\section{Figure 3.2: Heallh deviation variables.}

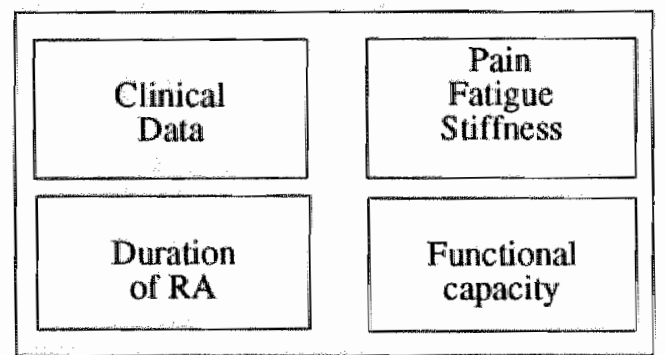

Pain is a second major complaint of RA. According to Mooney (1983): "the pain associated with arthritis is at times nondescript, at times sporadic in its intensity, at times chronic, but most arthritics will agree that it is present in some form for most of their lives". RA patients can have either acule or chronic pain. The function of acute pain is to give a warning that something is wrong within the system. Acute pain in RA is, apart from all normal causes, associated with flare-up's. Chronic pain is usually decribed as pain lasting six-months or longer that persists despite treatment or exists in absence of demonstratable disease (Taylor et al., 1984). The pain of an arthritic patient, however, differs from chronic pain in that 
the pain lasts longer than six months with a known source of the pain. Persistent arthritis pain (section 2.2.1) tends to be modest but long-lasting. Besides the persistant character of the pain, it can be characterised as variable and unpredictable. For example, pain may be present in the morning and gone by the end of the day, or it may be caused by certain activities.

Pain can also cause fatigue, which is the third major complaint of the disease. Smith Pigg and colleaques (1985) state that fatigue is an imprecise term. Fatigue is a subjective complaint of weariness, exhaustion, or lassitude, frequently associated with irritability, inefficiency, and a decreased capacity for work (section 2.2.1). Fatigue can be caused by anemia (associated with the systemic disease activity), muscle atrophy (result of a rheumatic disease), physical activity, emotional stress, or a lack of knowledge about the rest and the principles of personal energy conservation. (Bird et al., 1985; Smith Pigg et al., 1985).

\subsection{Outcome Variables}

The outcomes of the disease process can be approached from different perspectives. Much research, for example, has been done to assess quality of life and health care consumption in RA patients as outcomes of the disease (Liang et al., 1984; Nuki, 1972; Fries et all., 1980). They can also be described in terms of perception of illness (Jankowski et al., 1980; Arluke, 1980; Lorig et al., 1984; Potts et al., 1984) or dependency (Akhtar et al., 1973; Vignos et al., 1972; Rogers et al., 1982). Because the main objective of this study is the assessment of problems RA patients meet in daily functioning, as consequences of RA and its treatment, and the factors influencing these problems, the outcomes of the RA are studied in terms of dependency.

Chronic disease causes a patient to become more and more dependent on the help of others, often on fewer people (De Swaan, 1986). Williams \& Wood (1988, p. 130) argue that "the problem is not so much a change from independence to dependence in daily activities, although this may be how people express it, but of needing to re-establish a new basis for action and participation within a changing pattern of interdependence". The dependency of RA patients caused by the disease process and its treatment affect all parts of everyday life, which can be described as all activities necessary for daily functioning. In this research the outcomes of RA in terms of dependency were operationalised as (figure 3.3):

- difficulties performing activities;

- activity pattern, and

- loneliness.

\subsubsection{Difficulties Performing Activities}

To the RA patient dependency will, in the first instance, mean dependency in the area of daily activities. As already described in chapter 2, the majority of difficulties met by RA patients concern household activities, activities of daily living (ADL), obtaining and using aids and appliances, and difficulties concerning 
relationships. Three categories of daily activities will be differentiated in this research (see also section 1.3):

- Activities of Daily Living:

- obtaining and using alds and appliances, and

- relational functioning.

Household activities will not be a part of this study because if a patient is not able to perform ADL-activities she will also not be able to perform household activilies (Frederiks, 1990, section 4.2.2.1).

One of the main areas in daily functioning in which the dependency of the RA patient becomes manifest are the Activities of Daily Living (ADL). ADL-activities (bathing, dressing, going to the toilet, transfer, continence, and feeding) can be viewed as activities which people perform habitually and universally (Katz et al. 1963). According to Katz (1963) elderly people show a specific decrease in ADL-activities. He states that: "It might allso be hypothesised that, just as there is an orderly pattern of development, there is an ordered regression as part of the natural process of aging. It seems reasonable that loss of function would begin with those activities which are most complex and least basic, while those functions which are most basic and least complex could be retained to the last".

In a normal aging population problems with bathing and dressing will thus occur before problems like transfer and feeding (Branch et al., 1984 ; Katz et al., 1963; Katz ef al., 1979).

A second area of importance to the RA patient is obtaining and using aids and appliances. RA patients are confronted with loss of motion (LOM) which is a common manifestation of joint diseases. This LOM may either be permanent (due to joint deformity) or temporary (stiffness, pain). LOM affects not only mobility, but also increases difficulties with daily living skills (Smith Pigg et al., 1985). When LOM occurs palients are advised to use assistive devices. Because the application for aids and appliances is a complicated procedure, is long-lasting and not always clear (section 2.3.1), the patient often needs the help of the theumatologist or community nursing. Apart from difficulties in obtaining aids and appliances, it is known that patients do not always use them because they do not know how to use them or the assistive devise is inappropriate (Liang et al., 1983; Williams et al., 1988).

\section{Figure 3.3: Outcome variables.}

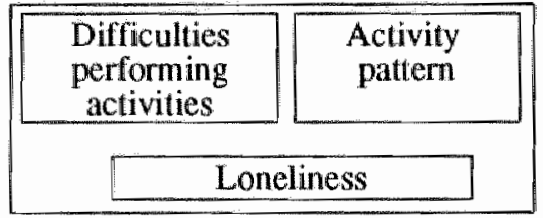

A final area in daily functioning which affects the dependency of the patient was identified as relational functioning. Apart from the possibility that the handicap(s) experienced by the patient may prevent her from actually meeting other people, the acceptance of the disease and its consequenses can play an important role within relationships of RA patients. The consequences of the disease on everyday life ask for the acceptance of the disease by the immediate environment of the 
patient (spouse, children, friends). Rogers et al. (1982) describes some common problems of RA patients as "loss of independence and self esteem, relations with family and friends, employment, and managment of pain". Dependent on the stage of the disease process and the functional status of the patient he or she will become dependent on the immediate environment. "Care-givers may find providing such support burdensome, particularly in the case of heavy time requirements. Such a burden thas been noted in providing support to Alzheimer patients, and is also likely in cases of severely disabling arthritis" (Moskowitz \& Haug, 1986).

\subsubsection{Rest and Activity Pattern}

Due to the disease outcomes and the medical treatment people with RA will have to face changes in the activity pattern. For instance, if the patient is advised to have more rest periods during the day she will not only have to fit in these periods within the daily activity pattern but she will probably have to reschedule normal activities. Generally, the activity pattern should show that RA patients have more rest and more rest periods during the day. Besides this the kind of activities of RA patients will differ from the activities of more healthy elderly people, in that the activity pattern of RA patients will contain less (physical) active, and more passive activities.

In this research the diary method will be used to measure the activities of daily functioning. In this way the amount of activities during the day can be measured.

\subsubsection{Loneliness}

Restriction in and difficulties with activities of daily living can lead to greater dependency of the RA patient. One of the outcomes of this process might be a loss of social relationships. Smith Pigg and collegues (1985, p. 299) state that: "Social. relationships are disrupted by impaiment of mobility, lessened energy, deformity, control of symptoms, and time required to carry out the treatment program". This disruption of social relationships may lead to the development of feelings of loneliness (De Jongh-Gierveld, 1985). As stated before, RA patients are often limited in their daily activities, which, in this case, means that a lack of opportunities in meeting other people may exist. Feelings of loneliness can be developed under these circumstances and therefore were part of this study.

\subsection{Control Variables}

The third part of the model are the control factors, which can be divided into two categories:

- social position and attitudes, and

- care facilities (health care and personal network). 
These control variables influence the outcome variables and health deviation variables. They also influence the relation between the outcome and health deviation variables. The general term 'control variables' is used here because the influence of the variables can either be determining, moderating or intervening. In the following sections the different control variables which will be part of the model are discussed.

\subsubsection{Health Perception: the meaning of RA}

Learning to live with the consequences of the disease implies that patients will hold certain feelings about these consequences. In other words, they attach a meaning to the different consequences of the disease. Although several studies contained a scale measuring the meaning of the disease, none of these studies investigated the relation between the meaning of RA and the difficulties with daily functioning of RA patients (Rasker, 1984; Kruisvereniging Twente, 1988; De Witte et al., 1989). In this study a difference will be made between the meaning which refers to the bodily consequences of the disease (i.e. pain, fatigue, loss of movement), and the psychological, social, or relational consequences of the disease (i.e. feelings of depression, loss of social contacts) (Figure 3.4). The differentation between the two categories is based on a study done by Rasker (1984). He asked 200 RA patients what they thought about having RA. Basically two kinds of answers were given. On the one hand, RA patients said that the symptoms of RA and the limitations in movement substantially influenced their lives and restricted them in daily activities (bodily meanings), while on the other hand, the disease meant more dependency on their immediate environment and that their relationships changed (relational meanings).

\subsubsection{Coping Behavior}

Patients with a chronic illness have to cope with illness associated fears, such as pain and loss of body integrity. Furthermore, Viney \& Westbrook (1984) stated that with chronic illness, patients have more long term concerns: about the future, loss of usual social roles, maintaining self-esteern and a need to develop a new lyfe-style.

Figure 3,4.1: Control Variables: social position and attitudes.

\begin{tabular}{|c|c|c|}
\hline Meaning of RA & Coping Behavior & Social position \\
\hline $\begin{array}{c}\text { Bodily } \\
\text { Relational }\end{array}$ & $\begin{array}{l}\text { Action directed } \\
\text { Seeking social support } \\
\text { Awaiting/avoiding }\end{array}$ & $\begin{array}{c}\text { Gender } \\
\text { Social class } \\
\text { Dependent care } \\
\text { facilities }\end{array}$ \\
\hline
\end{tabular}




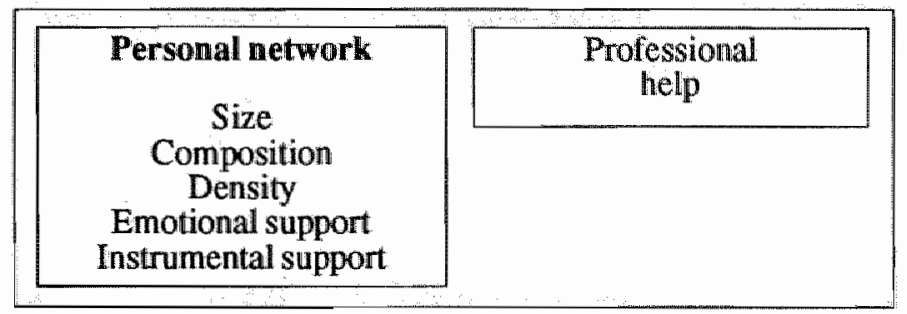

Based on the literature (Lazarus, 1980; Pearlin \& Schooler, 1978; Schreurs et al., 1985) three different coping strategies can be differentiated:

a Instrumental coping or behavior that is primarily concemed with changing the threatening situation (action directed behavior).

b Cognitions and emotions used to influence the perception and evaluation of a problem or threatening situation (seeking social support).

c Behavior that is directed to reduce the experience of physical and emotional stress (awaiting/avoiding).

The fact that RA patients have a chronic and potentially crippling disease may lead to an alteration of their coping style. Coping behavior also plays an important role in controlling the disease symptoms and level of disability.

\subsubsection{Social Position}

\subsubsection{Age and Gender}

As described in section 2.1.1, both the incidence and prevalence of RA are influenced by age and gender, being increasingly common in older age groups and females (Kirwan \& Silman, 1987; Van der Korst, 1980; Linos et al., 1980). The incidence and prevalence of RA is not influenced by social class, race, climate, or lifestyle (see section 2.1.1) (Kirwan \& Sillman, 1987; Van der Korst, 1980; Grennan, 1984).

As was stated in section 2.4.1.3, gender, as an aspect of social position, influences the problems with daily functioning and access to health care facilities.

Age was not part of the model because duration of RA was included in the health deviation variables component.

\subsubsection{Social Class}

A second operationalisation of social position is social class. Patients in different social classes are believed to have different life chances (see section 2.4.1.3). Several Dutch studies indicate that patients who have a lower education level, and are in lower social classes have more problems concerning daily functioning and have less access to health care facilities (Frederiks, 1990; Kempen 1990). 
Dependent care facilities is a third operationalisation of social position. It is already mentioned that in many instances the RA patients need help for ADLactivities. In the first instance, the immediate environment will be the primary source of help. Professional help will only be asked for if the people in the immediate environment can no longer provide the help needed. Different studies have shown (Rasker, 1984; Mostert, 1987; Kruisvereniging Twente, 1988; De Witte et al., 1989) that only a few patients use professional care facilities. Thus, dependent care facilities are essential to the majority of the RA patients and, therefore, were part of this study, next to professional help.

\subsubsection{Personal Network}

In the mobilisation of care the social network of the elderly with RA plays an important role. Mitchell $(1969$, p.2) defines social network as: A specific set of linkages among a defined set of persons with the additional property that the characteristics as a whole may be used to interpret the social behavior of the person involved. Considering the purpose of the study different aspects of a social network can be studied (total network, partial network, sub-system of the network) (Knipscheer, 1980). In this study the primary or personal network is of interest. The primary network contains all persons who have a direct relation to a certain individual. Two groups of personal network characteristics can be distinguished (Knipscheer, 1980; Mitchell, 1969):

- morphological characteristics, and

- interactional characteristics.

Mitchell (1969) describes anchorage, reachability, range and density as the morphological characteristics, which refer to the relationship or patterning of the links. Content, directness, durability, intensity and frequency are the interactional characteristics of the social network, which refer to the nature of the links.

\subsection{Relations in the Research Model}

The purpose of this study is to gain insight into the (development of) problems of elderly RA patients with daily functioning, the rest and activity pattem and feelings of loneliness and the influence of heal th deviation variables on the problems. Conirol factors are believed to influence the outcome variables, the health deviation variables as well as the relation between health deviation and control variables. Given the phenomena described in this chapter, several relations can be hypothesised.

Deteriorations in functional capacity will lead to an increase in the number of problems related to daily functioning. In particular, the number of ADL problems will show an increase. The number of problems obtaining and using aids and appliances will increase when functional capacity decreases. RA patients in the higher ARA functional classes will, probably, have most problems with obtaining 
and using aids and appliances, because in this stage of the disease process, most of the procedures required to obtain aids and appliances will have been started.

No influence of a decrease in functional capacity is expected conceming relational problems. Adjustment to a changing situation is a process which continues throughout the disease process and is not particularly associated with a certain disease period.

Duration of morning stiffness is proportional to the amount of disease activity and has (great) influence on the activities of the patient. Activities which are usually performed during the morning are impeded (for example, getting in and out of bed, dressing, and bathing) and specific activities take a lot more time to be finished for a RA patient than for a healthy person.

Pain affects many parts of daily living. It can interfere with mobility. It can be a barrier for the patient to carry out activities of daily living, and the performance of these tasks, on their turn, can cause pain (Smith Pigg et al., 1985). Thus, the more pain a patient experiences, the more difficulties she will have performing ADL-activities. The amount of pain can also influence the problems with relational functioning. The way in which patients cope with pain or the extent to which pain influences the patiens' mobility, body image and self-esteem can be detrimental to their personal relationships. Pain can disrupt social interaction and can result in social isolation.

Fatigue interferes with the ability to cope with the disease and affects the activities of daily functioning as well as the relationships with family and friends. In this study it is expected that outcome variables are influenced by the meanings RA patients attach to their disease. For example, the more negative meanings that are given to RA, the more difficulties with the activities of daily functioning can be expected. If patients attribute more meanings to RA it is possible that they also have more feelings of pain and fatigue.

The number of problems experienced with daily functioning, independent of functional capacity, might be different for patients using different coping styles.

Gender differences exist in daily activities. The amount of household activities, for example, will be higher in females than in males, consequently the amount of rest will be lower. It is likely that the amount of reported pain, fatigue and stiffness will be higher in females because a relation exists between the amount of activity and the three complaints of RA. Based on traditional role differentiations, the help RA patients need with activities of daily living is expected to be higher in males than in females. Combining the expected relations between gender and activities and gender and the help received by the RA patients, fernale RA patients will experience more feelings of loneliness than male patients.

The more dependent care facilities, the less problems with daily functioning, and feelings of loneliness are expected. If patients have more dependent care facilities they will have more access to help from the immediate environment and in this respect will experience less difficulties with daily functioning.

Patients who experience more problems with daily funclioning will also have more professional help.

A similar influence on the activities of daily functioning is expected in relation to the personal network. It is expected, that RA and its treatment will have an influence on giving and receiving emotional and instrumental support. 


\subsection{Design issues}

This cohort study has a longitudinal character. This kind of research has, in patient studies, several disadvantages due to the nature of research and the research population (elderly RA patients). Problems might occur concerning sampling and analyses of the results.

First, research into the problems of elderly $\mathbb{R A}$ patients concerning daily functioning, rest and activity, and loneliness requires a comparison to a healthy population. In this way it can be ascertained which problems are specific to RA and cannot be attributed to normal aging processess. Obviously, large differences will exist between RA patients and a healthy elderly population, differences concerning control variables might exist. Therefore, in addition to a RA patient group, a reference group of healthy elderly will be involved in this study.

There are some specific problems concerning defining and selecting the population of RA patients and references. It is known that, especially patients who experience only minor symptoms of the disease, will not see a doctor or seek medical advise (Kirwan and Silman, 1987). In this study only those patients who frequent a rheumatologist are included. As a consequence a systematic underpresentation of RA patients in ARA functionl class I will exist.

Another problem which might occur is underrepresentation or overrepresentation of certain patient groups because of non-response and non-completion. Patients with severe RA might not want to participate or might not complete the study. Mortality, flare ups, surgery, or admission to a hospital or nursing home might play a role in non-response and non-completion. It is, therefore, possible that not as many patients as expected will participate in the study, and that patients who do participate represent a relatively 'healthy' population.

Secondlly, patients and references are familiar with the general objectives of the study. The study was not blinded. It is possible that, in relation to dependent and independent variables, respondents might, during the first measurement period, unconsciously, for example, exaggerate their problems with daily functioning, while in the third interview they might understate their difficulties.

Thirdly, the disadvantages of longitudinal designs are its costs and the duration of the research. The intervals between measurement moments were planned at six months. This means that the data gathering period would be approximately one and a half to two years.

Analyses of the results will be transversal as well as longitudinal. Advantages of longitudinal designs are that trends or changes over time can be detected, causality of relations can be examined, as well as, stability of relations, and that relations can be studied at various stages of the disease process. However, the assessment of changes in dependent and independent variables may pose problems. Differences in dependent and independent variables probably exist from the start of the study, and a number of RA patients presumably are in a relatively stable phase of their disease. Expected changes might therefore be small and unreliable. 


\subsection{Summary}

In this chapter the research model and questions have been presented, which will serve as a guide for the analyses. The elaborated model is presented of which the concepts will be further operationalised in chapter 4 .

The first research question, as stated in section 3.1, concerns the transversal and longitudinal description of the outcome variables. Other research questions deal with the relation between outcome, health deviation and control variables. Hypotheses concerning the relations between variables have been described in this chapter and are summarised in the eleborated research model (figure 3.5).

As can be seen in figure 3.5 a direct relationship between the 'outcome' variables and 'health deviation' variables is expected. This means that difficulties with ADL, obtaining and using aids and appliances, and relational functioning, as well as changes in the activity pattern and the existence of feelings of loneliness, are directly influenced by the different identified health deviation variables. Next to this relation it is expected that the control variables (personal characteristics and care facilities) have either a determining, moderating, or intervening effect on both the outcome and health deviation variables as well as the relation between the outcome and health deviation variables. 


\section{POPULATION AND METHODS}

\section{Introduction}

Given the purpose of this study, a longitudinal cohort study with three measurement moments was designed, using interviews and diaries. In this chapter the sampling procedure of the RA patients and references, the response, and the general characteristics of the population will be described. In addition, the data collection methods will be discussed.

\subsection{Population}

\subsubsection{The RA Patient Population}

This study was prepared in cooperation with the Community Nursing Association of Breda. The number of elderly RA patients, who received community nursing care from the Community Nursing Association of Breda, however, was small, and had recently participated in a study about the consensus between RA patients and community nurses on the community nursing care for these patients (Mostert, 1987). Therefore, a rheumatologist, working in one of the local hospitals, was asked for his cooperation to select RA patients who would be willing to participate in this study. Advantages of the participation of the rheumatologist are, among other things, that the treatment of and the information given to the RA patients will be approximately constant with respect to different subgroups in terms of consequences of the disease for daily life. After consensus on the research questions and the design was reached, the medical director of the hospital was asked for permission to take a systematic sample of RA patients.

Before sampling took place, criteria for inclusion was ascertained (table 4.1). All respondents had to be between 55 and 80 years of age. The RA patients had to be diagnosed as having classical or definite RA (Van der Korst, 1980) and none of the respondents were to have a known history of other disorders of the musculo-skeletal system. Criteria four and five were part of the selection procedure because we wanted the population to be as homogeneous as possible for the employment and family phase. Having a job or having children younger than 18 years of age and living at home, might for example, influence the problems associated with daily functioning and the activity pattern. 
RA patients References

\begin{tabular}{llll}
\hline 1 & 55 to 80 years of age & + & + \\
2 & Classical or definite RA & + & + \\
3 & $\begin{array}{l}\text { No other (chronic) disorders of the } \\
\text { musculo-skeletal system }\end{array}$ & + & + \\
4 & $\begin{array}{l}\text { No children up to the age of } 18 \text { being part } \\
\text { of the same household }\end{array}$ & + \\
5 & + & + \\
\hline
\end{tabular}

The sampling resulted in 100 RA patients. A letter was sent requesting patients to participate in the study. The letter contained an explanation of the purpose of the study and the procedures to be followed, and a consent form. Patients were asked to return the consent form if they were willing to participate (first response $58 \%$ ). Three letters were returned wherein the applicable RA patient had recently died. Therefore, only 97 RA patients, of the original 100, remained. Three weeks after the initial letter, a reminder was sent to the patients who had not yet reacted. The total response was $67 \%$.

\subsubsection{The Reference Group}

A reference group was matched to the RA patients, by using the following procedure. Within two weeks after the RA patients returned their consent form, they were interviewed at their homes. When the interview was finished they were asked if they knew anyone in their environment, of the same age (maximum difference: 5 years), the same gender, and living in the same neighbourhood, who would be willing to participate in the study. Persons who agreed to participate had to meet the same inclusion criteria as the RA patients (table 4.1). Eighteen of the RA patients suggested a person. Either through the interviewer or through the RA patient, a written explanation of the purpose of the study and the research procedure, was given to the reference person, before they agreed to take part in the study. Total response of references who were approached through RA patients was 18. Local Community Nursing Associations and local organisations of elderly were approached and then presented with the question of whether or not they could help in finding elderly people willing to participate. A list containing gender, age and neighbourhood of the RA patients who did not, or could not name a reference was given to these organisations. Besides this, they were informed about the inclusion criteria. Through local Community Nursing Associations and local organisations of the elderly 32 references were obtained. Finally, a total of 50 references, willing to participate, were found. 


\subsubsection{Response}

There were three interview periods. During the first interview period 65 RA patients were interviewed. During the second interview period nine RA patients withdrew from the study, and one patient withdrew during the third interview period (table 4.2). The response after three interview sessions was 55.

During the first interview period, a reference group totalling 50 persons existed. The second interview period consisted of 47 references, and 45 in the third interview period.

Table 4.2: Reasons for withdrawal of RA patients and references.

\begin{tabular}{lcc}
\hline & RA patients & References \\
\hline Moved to another part of the country & 1 & \\
Moved to nursing home & 1 & \\
Acute flare-ups & 2 & 1 \\
Surgery & 4 & 2 \\
Died & 1 & 2 \\
No specific known reason & 1 & \\
\hline
\end{tabular}

The number of RA patients and references who returned a diary differed markedly from the response to the interviews. Respectively: 53,43 and 41 RA patients returned a diary in the first, second, and third interview period, of which 41,36 and 40 proved to be useful. In the reference group: 43,37 and 39 people returned a diary, of which 38,35 and 32 were useful. Finally, 29 RA patients and 25 references returned a diary in all three study periods (table 4.3).

At the start of the study all references were matched to a RA patient by using distribution matching. Another matching procedure was performed at the end of the data gathering period. This time the RA patients were matched to the 45 references on the basis of age, gender and neighborhood (precision matching).

In the case where all the 45 references and 45 RA patients had participated in three interviews, not all of these respondents returned three diaries. The second matching procedure concerning the diaries resulted in 22 matched pairs of RA patients and references who returned three diaries. 
Table 4.3: Response of RA patients and references in three interview periods and times of the two matching procedures.

\begin{tabular}{|c|c|c|c|c|c|c|}
\hline & $\begin{array}{l}\text { Random } \\
\text { sample }\end{array}$ & $\begin{array}{c}\text { Response } \\
t^{*} 1 \\
M * 1\end{array}$ & 2 & t 3 & $\begin{array}{l}\text { Three } \\
\text { interviews } \\
\text { and diaries }\end{array}$ & M2 \\
\hline RA patients & $\begin{array}{c}100 \\
97\end{array}$ & & & & & \\
\hline Interview & & 65 & 56 & 55 & & 45 \\
\hline Diary & & 41 & 36 & 40 & 29 & 22 \\
\hline \multicolumn{7}{|l|}{ References } \\
\hline Interview & & 50 & 47 & 45 & & 45 \\
\hline Diary & & 38 & 35 & 32 & 25 & 22 \\
\hline
\end{tabular}

* t=interview period; ${ }^{* *} M=$ matching procedure performed.

Next to the total RA patient group ( $N=45)$, and the reference group $(N=45)$, the study population will, when necessary, refer to the RA patient diary group $(\mathrm{N}=22)$ and the reference diary group $(\mathrm{N}=22)$ with three interviews and diaries.

\subsubsection{Time Schedule}

All RA patients and references were interviewed in their homes and were asked

Figure 4.1: Time schedule of the interviews of the RA patients and references.

\begin{tabular}{|c|c|c|c|c|c|c|}
\hline & 1988 & & 1989 & & 1990 & \\
\hline & $\mathrm{RA}$ & Ref & RA & $\operatorname{Ref}$ & RA & $\operatorname{Ref}$ \\
\hline january & & & & & & \\
\hline february & & & & & & \\
\hline march & & & & & & \\
\hline april & & & & & & \\
\hline may & & & & & & \\
\hline june & & & & & & \\
\hline july & & & & & & \\
\hline august & & & & & & \\
\hline september & & & & & & \\
\hline october & & & & & & \\
\hline november & & & & & & \\
\hline december & & & & & & \\
\hline
\end{tabular}


to keep a diary for one week recording their activity pattem three times. The intervals between measurement moments were initially planned for half a year. The first interwiew period (February to October 1988) was longer, because completing the reference group took more time than originally planned. The second interview took place between November 1988 and July 1989, the last period was between June 1989 and February 1990, the intervals between the interviews were, therefore, approximatly 8 months in duration (figure 4.1 ). Mean interviewing time was 2.5 hours (range 1 to 4.5 hours).

\subsection{Methods}

\subsubsection{Data Collection}

As stated in the introduction, two data collection methods were used, the structured face-to-face interview and the diary technique.

The face-to-face interview technique has several advantages. 'It can obtain a great deal of information, is flexible and adaptable to individual situations and can often be used when no other method is possible or adequate" (Kerlinger, 1964 , p. 480 ). Interviewing raises the response rate. Although a face-to-face situation might obtain more accurate information, it can be a source of information bias (Pollit \& Hungler, 1987, p. 243). In the case of RA patients who often have problems writing, interviewing is preferred to written questionnaires.

The largest disadvantage of interviewing is the time investment it needs, and the costs (Kerlinger, 1964; Pollit \& Hungler, 1987; Swanborn, 1981). Another disadvantage is the possibility of socially desirable answers, and the fact that the respondent is not anonymous to the interviewer(s).

Prior to the start of the first interview period, the questionnaire was pretested. Four interviews with RA patients from an outpatient clinic in Maastricht were conducted by the researcher. The main purpose of these interviews was to test the length of the interviewing time, and to check the intellegibility of the questions. The four RA patients interviewed consisted of one woman and three men, between 55 and 69 years of age. These patients represented all ARA functional classes.

The second technique used in this study was the diary technique. An advantage of the diary technique in comparison to the interview technique is that the recail of events and details are more accurate (Higgins et al., 1985). Major disadvantages are stated by Rachmann and Lopatka (1988) as: 'Diaries seem to be as flexible and, in principle, as widely applicable research instruments as questionnaires. The issue is not their feasibility, but their relatively high cost, the greater degree of cooperation required from the respondent, and the vastly increased work involved in a complete analysis of all the data collected' (see also Allen et al., 1954; Higgins et al., 1985; Rochmann, 1972).

All interviews in the first and second period with the RA patients were held by a research assistant. The interviews with the reference group were partly done by the researcher. Half of the interviews in the third period were conducted by the research assistant, the other half were conducted by the researcher. 
Prior to each interview period, the questionnaires were carefully discussed in order to prevent interviewer and interviewing bias. After the first week of interviewing these discussions were repeated to find out if there were any difficulties with questions or with precoded answers. Likewise, the possibilities of social desirable answers were discussed. This resulted, for example, in an adjustment within the professional help scale where special attention was given to the help given by spouses.

To reduce the refusal rate for the diaries, verbal and written instructions were given to the respondents, immediatly following the interview. Respondents were advised to fill in the diary two to three times a day as a way of increasing the completeness of the information asked for. If the RA patients had a problem with writing they were advised to ask for help, e.g. from their spouses. After the completion of the first diary the respondent was asked to phone the interviewer, who would then collect the diary. The second and third diary could be returned via a postage-paid envelope.

\subsubsection{The Interview}

Table 4.4 presents a summary of the questionnaire used in the different interviews. Some scales and tests were part of all three interviews whereas the scales concerning the control variables were part of two or only one interview, because these variables were considered relatively stable in time.

Table 4.4: Variables in three questionnaires.

\begin{tabular}{lccc}
\hline & Interview & & \\
& 11 & 12 & 13 \\
\hline $\begin{array}{l}\text { Difficulties performing activities } \\
\text { Loneliness }\end{array}$ & + & + & + \\
& + & + & + \\
Functional capacity & + & + & + \\
Duration of RA & + & $(+)$ & ++ \\
Clinical data & + & + & + \\
& & & + \\
Meaning of RA & + & & + \\
Coping behavior & + & & + \\
Social Position & + & + & + \\
Personal network & & & + \\
Professional help & & & + \\
\hline
\end{tabular}

In the following sections each scale or test will be discussed. 


\subsubsection{Activities of Daily Functioning}

The scale used to investigate difficulties performing activities of daily functioning, originated from a study by Mostert (1987) who investigated the (dis)agreement between 23 elderly RA patients and their community nurses about the need for help and the community mursing care given to these patients. Respondents were asked if they did or did not have a problem performing certain activities. If they had a problem performing an activity they were asked if they needed help. Several answers could be given to this question:

- No, I do not have a problem, therefore, I do not need any help (code 0);

- No, I do have a problem performing this activity, but I do not need any help (code 1);

- Yes, I need help: referral, advise, or mediation (code 2);

- Yes, I need help: support, or help with ... (code 3);

- Yes, I need help: take-over (code 4).

The original scale, as used by Mostert (1987), consisted of 11 categories of daily functioning (table 4.5). In this study the number of items was reduced using the internal consistency of each subscale, measured with Cronbach"s $\alpha$. Sub-scales with an alpha less than .60 were excluded for further analyses (bodily dysfunctioning, problems concerning medical regimen, problems concerning leisure). Second, four other categories were left out of the analysis. "Household activities' because the ability to perform household activities is closely related to the ability to perform $\mathrm{ADL}$ activities and because the medical regimen often includes restrictions in the performance of household activities. 'The use of social services' and 'problems with living surroundings' were excluded from the scale. Both categories were related to the aids and appliances category. Finally, the category 'problems with not being able to work' because one of the inclusion criteria of the study was not working at the start of the study.

Three subscales were formed with the remaining categories: activities of daily living ( $\mathrm{ADL}$ ), obtaining and using aids and appliances, and relational functioning. In each category some items were left out. In the ADL subscale the questions 'do you have problems with walking and/or walking up and down stairs' (comparable to questions within the aids and appliances subscale), and "do you have problems with activities like washing your hair and cutting your nails' (did not show any variance in the initial study) were deleted. The subscale ADL finally consisted of seven items. In the 'obtaining and using aids and appliances' subscale, the questions concerning household and leisure activities were left out. Finally, the subscale consisted of four items. For the 'relational functioning' subscale, only those items referring to acceptance of the disease by the patient herself and relatives and contacts with other persons were included. Finally, the scale consisted of 5 items.

The final scale consisted of 16 items (annex I) divided into three sub-categories: $\mathrm{ADL}$; aids and appliances; and relational functioning. The questions asked on each item were of the same format as the original questions (see above).

Due to the fact that only a few respondents answered with codes 1,2 , or 4 , each item was dichotomised into:

- No, I do not have a problem therefore I do not need any help (original code 0);

- Yes, I have a problem performing this activity (original code 1 to 4). 
Table 45: Categories of daily functioning, number of items in the scales used by Mostert (1987) and in this study.

\begin{tabular}{|c|c|c|}
\hline & \multicolumn{2}{|c|}{ Number of Items } \\
\hline & $\begin{array}{c}\text { Mostert } \\
(1987) \\
\end{array}$ & $\begin{array}{l}\text { This } \\
\text { study }\end{array}$ \\
\hline $\mathrm{ADL}$ & 9 & 7 \\
\hline Bodily dysfunctioning & 4 & \\
\hline Household activities & 6 & \\
\hline Aids & 3 & $2-$ \\
\hline Appliances & 4 & 2 \\
\hline Use of social services & 4 & \\
\hline Problems concerning medical regimen & 4 & \\
\hline Problems concerning living surroundings & 3 & \\
\hline Relational problems & 3 & 4 \\
\hline Problems accepting the handicap & 3 & 1 \\
\hline Problems with not being able to work & 2 & \\
\hline Problems concerning leisure & 4 & \\
\hline
\end{tabular}

Internal consistency of the different subscales was tested with Cronbach's $\alpha$. A scale which shows an between .60 and .90 is considered to have good internal consistency (Pollit \& Hungler, 1983). Cronbach"s $\alpha$ "s of the subscales in three measurement moments are presented in table 4.6. Except for aids and appliances and relational functioning in the first interview, all Cronbach's $\alpha$ 's were between .60 and .90 .

Table 4.6: Internal consistency (Cronbach's $\alpha$ ) of the sub-scales difficulties performing activities $A D L$, aids and appliances and relational functioning in three interviews for the RA patients $(N=45)$.

\begin{tabular}{lcccc}
\hline & \multicolumn{4}{c}{ Interview } \\
& $\mathrm{t}$ & $\mathrm{t} 2$ & $\mathrm{t}$ \\
\hline $\mathrm{ADL}$ & .83 & .73 & .82 \\
aids and appliances & .47 & .80 & .93 \\
relational functioning & .37 & .61 & .73 \\
\hline
\end{tabular}

To test the stability of the ADL, aids and appliances and relational functioning subscales test-retest reliabilities between the different measurement moments were calculated. In the case of ADL $(11-12: .45, \mathrm{p}\langle .01 ; \mathrm{t} 2-\mathrm{t} 3: .47, \mathrm{p}\langle .01)$ and relational functioning $(\mathrm{t} 1-\mathrm{t} 2: .35, \mathrm{p} \times .01 ; 12-\mathrm{t} 3: .38, \mathrm{p} \times .01)$ problems were expected to change over time, which influences the stability of the instrument (Pollit and Hungler, 1983). In case of obtaining aids and appliances test-retest reliability was small $(11-12:-.01 ; 12-13:-13)$. Based on the nature of this phenomenon and the distribution (section 5.2.1) test-retest reliablity is not adequate. 
In this study, loneliness was measured by the loneliness scale developed by De Jongh Gierveld (1985). This Rasch-type scale has 11 items, 6 positively and 5 negatively formulated. The scale is a 5 -point scalle. Possible answers are Yes! (1), Yes (2), mone or less (3), No (4), and No! (5). Individual scores can range from 0 to 11 , where 0 indicates no feelings of loneliness and 11 indicates extreme feelings of loneliness.

In section 2.3.3 loneliness was defined according to De Jongh Gierveld (1985). She considers the nature and intensity of missing relationships as the most essential to loneliness (1985, p.290). Reliability and validity have been tested in different populations (De Jongh Gierveld, 1985; Van Tilburg, 1988; Mostert, 1987). In this study reliability was tested with Cronbach's $\alpha(.83, .82$, .83 in the respective measurements). Stability of the instrument was tested with Pearson correlations $(11-12: .76, p(.01 ; 12-13 * .79, \mathrm{p}(.01)$ and can be considered sufficient.

\subsubsection{Functional Capacity}

A number of instruments can be used to measure functional capacity. Next to medical indicators, several questionnaires have been developed. In a review by Liang and Jette (1981), three types of instruments which follow the ICIDHclassification (injuries, disabilities, and handicaps) were differentiated.

In this study functional capacity was operationalised as the ability to move certain joint-groups. This means that functional capacity was seen as an indicalor of the level of disability according to the ICIDH-classification.

Functional capacity was then measured according to Lee's Functional Index (Lee, 1973). This structured test consists of 17 items stated in terms of daily activities (f.e. Can you lift a full teapot; Can you walk). Each question can be answered with (a) yes, I can; (b) yes, I can despite difficullies due to pain or sliffness; (c) no, I cannot. All questions have a score between 0 and 2, except for the question 'Can you walk' which has a score of 18 . If a person is not able to walk, six additional questions concerning the lower extremeties are than no longer relevant (for example: are you able to walk up a flight of stairs). Scores can range between 0 and 40. A low index indicates good functional capacity an a high index poor capacity. In line with the ARA functional classes, the following categories can be advanced: 0-5 good functional capacity, 6-12 moderate functional capacily, 13-18 poor functional capacity, and 19-40 very poor functional capacity (Lee, 1973; Makisara et al., 1982).

Reliability and validity were tested (Lee, 1973; Liang et al., 1983; Makisara et al., 1982) with test-retest reliabilities and comparison to different other instruments. In this study reliability was tested with Cronbach's $\alpha(.93, .93, .94)$, stability of the instrument with Pearson correlations $(11-12: .79, p(.01 ; 12-13: .64, p(.01)$.

\subsubsection{Duration of RA}

Duration of RA was assessed by asking the RA patients how long they did have RA. Patients were asked to estimate the time from the first appearance of disease 
symptoms, because the time between the appearance of the first symptoms of RA and going to a general practitioner and/or going to a rheumatologist might be very long.

\subsubsection{Clinical Data}

Several clinical data can be used to provide information about the stage of the disease process (roentgenological changes in the joints, subcutanous nodules, number of joints involved, erythrocyte sedimentation rate, etc.)(Van der Korst, 1980; Bird et $\mathrm{al}_{\text {, }}$ 1985). In this study, an attempt was made to find ARA classifications and erythrocyte sedimentation rate measures in the patient records of the RA patients involved in the study, as closely to the interviewing date as possible. Unfortunately, it was not possible to trace the information within the patient records. Patients did attend their rheumatologist on a regular base, but not synchronic with the interviews. ARA classification as used in this study are based on Lee's functional index (section 4.2.2.3). Clinical data were, therefore, not a part of this study.

\subsubsection{The Meaning of RA}

It was shown that RA patients attribute several meanings to their disease (section 2.4.1.1). Sixteen of these meanings (Rasker, 1984; Kruisvereniging Twente, 1988; De Witte et al. 1989) were put together in a scale. RA patients were asked for example: "Does RA mean pain to you?". The answers could either be yes or no. Factor analysis (annex II) revealed two factors, one component with bodily meanings of RA (i.e. pain, fatigue), another with relational meanings of RA (i.e. loss of social contacts, financial problems). Internal consistency of the two subscales was tested with Cronbach's $\alpha$ (Bodily meanings $.67,78$ respectively on $t 1$ and 13 ; Relational meanings $.81, .78$ respectively on $t 1$ and $t 3$ ). Test-retest reliabilities were used to test the stability of the two-subscales (bodily meanings of $\mathrm{RA}, \mathrm{t1}-\mathrm{t} 3: .65, \mathrm{p}\langle .01$; relational meanings of $\mathrm{RA}, \mathrm{t1}-\mathrm{t}: .69, \mathrm{p}\langle .01)$.

\subsubsection{Coping Behavior}

Coping behavior was measured with the 'Utrechtse Coping Schaal' (UCL) developed by Schreurs et al. (1984). The original scale consisted of 47 items. A shortened version of 26 items was used in this study. The UCL is a 4-point Likert type scale. Respondents were asked to say if they normally seldom/never, sometimes, often, or very often reacted in the way described in each item (i.e. showing one's anger with those responsible for the problem; trying to avoid difficult situations as much as possible; considering different solutions to the problem).

Based on a factor analysis of the original 47 item scale, Schreurs developed the 26 item version. Factor analysis on the 26 item version with 1226 respondent from different cohorts showed three factors of 6 items each (annex III). Based on the literature (Lazarus, 1980; Pearlin and Schooler, 1978) these categories could be classified as (section 2.4.1.2):

- action directed behavior,

- seeking social support, 
- awaiting, avoiding.

The internal consistency of the subscales was tested with Cronbach's $\alpha$ (table 4.7). Internal consistency appeared to be sufficient for action directed and seeking social support, but the internal consistency of awaiting, avoiding was low in both studies. The sub-scale will, however, be part of further analyses because of the theoretical importance.

Table 4.7: Internal consistency of the 26 item version of the UCL in two studies. $(N=1226 ; N=90)$.

\begin{tabular}{lrcr}
\hline & \multicolumn{3}{c}{ Cronbach's $\alpha$} \\
& $\mathrm{N}=1226$ & $\begin{array}{c}\text { This study } \\
\mathrm{t}\end{array}$ & $\mathrm{t}$ \\
\hline Action directed & .78 & .76 & .80 \\
Seeking social support & .73 & .61 & .69 \\
Awaiting, avoiding & .62 & .34 & .42 \\
\hline
\end{tabular}

Test-retest reliability was used to test the stability of the three subscales (action directed t1-t3: .49 , $\mathrm{p}\langle .01$; seeking social support $\mathrm{t1}-13$ : .52, $\mathrm{p}\langle .01$; awaiting, avoiding t1-13: .32, p(.05).

\subsubsection{Dependent Care Facilities}

Being able to appeal to people in the immediate environment for help can be very important to elderly people. Dependent care facilities was, therefore, operationalised as:

- having a spouse and/or,

- having a housemate(s) and/or,

- having daughters (in law) living less than 15 minutes travelling time.

A scale was constructed of these three items in which having access to one of the three items was coded as 1, having access to two of the items was coded as 2 , having access to all three facilities was coded as 3 .

\subsubsection{Education Level and Social Class}

Social position was operationalised as education level and social class. In the case of education level, respondents were asked which was their highest completed level of schooling. Three categories were distinguished, lower (primary school and lower vocational education), middle (secondary education and intermediate vocational education), and higher education (higher vocational education and university education).

A second operationalisation of social position was social class. Patients were asked what was their latest occupation. According to the ITS classification (Instituut voor Toegepaste Sociologie, 1975) six social classes were distinguished: unskilled labor (including housewifes), skilled labor, lower employee, small tradesman, middle employee, and higher professions. 
Analyses of education level and social class (table 4.8 ) revealed that only a few patients did have higher education or were in higher social classes, the majority of the RA patients did have a lower education and could be classified in the lower social classes. This means that an underrepresentation of the higher social classes existed. Because of the homogeneity in case of social class and education level. these variables were no longer part of the study.

Table 4.8: Education level and social class of RA patiems $(N=45)$.

\begin{tabular}{lclc}
\hline Education & N & Social class & N \\
\hline Lower & 23 & Housewife/unskilled labor & 11 \\
Middel & 16 & Skilled labor & 6 \\
Higher & 6 & Lower employee & 15 \\
& & Small tradesman & 2 \\
& & Middle employee & 10 \\
& & Higher professions & 1 \\
\hline
\end{tabular}

\subsubsection{Personal Network}

Persons with a chronic disease will encounter changes in their personal network, especially concerning instrumental and emotional support, given and received.

Mitchell (1969) described two characteristics of the personal networks, namely, the morphological and the interactional characteristics. Relationships and patteming of the links in the network in respect to one another refer to morphological characteristics, they are: anchorage, density, reachability and range.

Interactional characteristics refer to the nature of the links themselves and are: the content, directedness, durability, intensity and frequency of the interaction in the links.

Because the focus of this study was on the care facilities for RA patients over a period of their patient career ${ }_{4}$ on the mobilisation of informal and professional care, and coping with the potential discontinuity of lay and professional culture, and of hospital and primary health care facilities the aspects of the personal network which are used in this study are size and density of the personal network (morphological characteristics), and composition, instrumental and emotional support (interactional characteristics). In relation to size, the respondents were asked to name the persons which were most important to them. Density of the network was measured by asking to what extent the persons in the network knew each other. Composition was measured by asking the respondents which people in the network were relatives or non-rellatives. In the case of instrumental and emotional support two questions were asked:

- How much instrumental and emotional support do you receive from the different persons in the personal network?, and

- How much instrumental and emotional support do you give to the different persons in the personal network?

Scores on these questions can range between 0 (I do not receive or give any support to this person) to 5 (I do receive or give a lot of support to this person). Afterwards, the balance in instrumental and emotional support was calculated by 
subtracting the support received by the respondents of the persions in the network from the support given by the respondents to the persons in the network. Theoretically, scores could then have a range between -5 and +5 . Three categories were differentiated:

- positive balance, scores between -5 and -1 , in which case the people in the network give more support than the respondent,

- equal, scores between $-\mathbb{1}$ and $\mathbb{1}$, support given by the respondents and the people in the network are approximately equal, and

- negative balance, scores between +1 and +5 , the respondent gives more support than the people in the network.

\subsubsection{Professional Help}

The scale concerning professional help received by the RA patients, contained the same items as the list concerning the difficulties performing activities. Questions asked on each item were:

1 Do you receive help concerning eating?, answer yes or no;

2 If yes, who do you receive help from?

3 Do you receive help from anyone else?

If a patient received community nursing care they were asked:

4 What kind of help does she give?

5 What kind of help was asked for?

6 Who asked for community nursing care?

The answers which could be given to questions 2,3 and 6 were later recoded into 'non professional help' (code 0) and 'professional help' (code 1). The reason for this recoding was that the majority of the help given to the RA patients stemmed from their spouses. However, during the first interview period the spouse was hardly ever mentioned as being the one who gave help. Within the second and third interview period special attention was given to this problem. Several RA patients were asked why they did not mention their spouse as a help giver. It appeared that in most instances the help of the spouse was considered as a form of extended self-care.

Internal consistency of the different subscales was tested with Cronbach's $\alpha$ (Table 4.9). Because none of the references received professional help, analyses were only performed with the RA patient group. Almost no professionall help was reported within the RA patient group for relational functioning, therefore, no Cronbach's $\alpha$ was calculated.

Table 4.9: Internal consistency of professional help given for $A D L$, and obtaining and using aids and appliances in three interviews $(N=45)$.

\begin{tabular}{lccc}
\hline & \multicolumn{3}{c}{ Interview } \\
& $\mathbb{1}$ & $\mathbb{1} 2$ & $\mathbb{B}$ \\
\hline ADL & .94 & .90 & .95 \\
Aids and appliances & .85 & .61 & .90 \\
\hline
\end{tabular}


Test-retest reliablity was used to measure the stability of the total instrument (t112: 66, p $\{.01 ;, 12-13 ; .31, p(.05)$. Based on the nature of this phenomenon and the distribution (section 5.4.4) test-retest reliablity is less adequate.

\subsubsection{The Diary}

In addition to the interviews the RA patients and references were asked to keep a diary of their activity patterns for one week, following each interview. The need for a more complete insight into the activity pattern of RA patients and reference group was the reason for choosing the diary approach. The diary consisted of the following items:

- main activity per quarter-of-an-hour;

- pain level per hour;

- level of fatigue per hour;

- duration of morning stiffness.

Each item in the diary will be further discussed in the following sections.

\subsubsection{Main Activity Per Quarter of an Hour}

All respondents were asked to record their main activity for each quarter-of-anhour. Activities were not pre-coded. After the diaries had been returned and proved to be useful, the stated activities were coded into the following categories:

- no activity named;

- rest;

- activities connected with eating:

- self-care activities;

- household activities;

- passive leisure activities at home;

- active leisure activities at home;

- social activities at home;

- necessary and usefull activities outdoors;

- passive leisure activities outdoors;

- active leisure activities outdoors;

- social activities outdoors.

After recoding, the mean time spent on each activity per week was calculated. Stability of the category 'rest' was calculated by Pearson correlations (t1- $t 2 * .52$, $\mathrm{p}(.01 ; \mathrm{t} 2 \mathrm{-13}: 82, \mathrm{p}(.01)$.

\subsubsection{Pain Level Per Hour}

In section 2.2.1 five kinds of pain were distinguished (Escobar, 1985):

- acute pain;

- sub acute pain;

- recurrent acute pain;

- continous pain, and

- chronic pain. 
Recurrent acute pain can also be described as persistent arthritis pain (Ehrlich, 1980). This type of pain tends to be modest but longlasting. Although the pain is generally low grade, when sustained over long periods, it becomes increasingly unbearable.

Pain levels were measured by asking the respondent to note the intensity of the pain per hour with a number between 0 (no pain at all) and 10 (pain is very, very heavy). Afterwards, painscores were calculted as a pain-score per hour that a person was active. The same method was used by Fordyce et al. (1984) and Follick et al. (1984) who both used the diary technique to measure chronic pain. Only Follick (1984) reported reliability and validity measures. In this study test-retest reliabilities were: first and second diary $r=.62(p<.01)$, second and third diary $\mathrm{r}=.68$ (p〈.01).Considering the nature of this phenomenon a reasonable correlation.

\subsubsection{Level of Fatigue}

The level of fatigue was measured by the same procedure as pain. For each hour, patients were asked to score their fatigue between 0 (not at all fatigued) and 10 (extreme fatigue). In accordance with painscores, fatigue-scores were calculated per hour that a person was active. Test-retest reliabilities were: first and second diary $r=.70(p\langle .01)$, second and third diary $r=.66(p<.01)$.

\subsubsection{Duration of Morning Stiffness}

Patients were asked to report the duration of their morning stiffness in quartersof-an-hour each day. RA patients were not asked to rate the severity of their stiffness because several authors state that severity of stiffness and pain are closely related (Rhind et al., 1987; Smith Pigg et al. 1985; Bird et al., 1985). As for pain and fatigue test-retest correlations were calculated: first and second diary $\mathrm{r}=.64$ ( $p\langle .01)$, second and third diary $r=.55(p<.01)$.

\subsection{Non-response and Noncompletion Analysis}

As already mentioned, 32 of the 97 RA patients did not respond in the first instance. A non-response analysis was performed to detect significant differences between these groups. ANOVA revealed no main effects for either gender or age, nor an interaction effect (table 4.10). Although no significant differences were found, table 4.10 shows that older females especially refused to participate in the study. Possibly, older female RA patients were more handicapped because of their disease. In that case, the refusal of older female RA patients could mean healthy patient selection. Differences between the groups concerning the stage of the disease process and the functional capacity could not be traced (section 4.2.2.5). 
Table 4.10: Mean age and gender in the response and nonresponse groups of the RA patients.

\begin{tabular}{lccc}
\hline & & \multicolumn{2}{c}{ Response Nonresponse } \\
& & $(\mathrm{N}=27)$ & $(\mathrm{N}=17)$ \\
\hline Age males & mean & 67.2 & 68.2 \\
& s.d. & 6.1 & 6.1 \\
\hline & & $(\mathrm{N}=38)$ & $(\mathrm{N}=1.5)$ \\
\hline Age females & mean & 67.7 & 74.2 \\
& s.d. & 6.1 & 7.4 \\
\hline
\end{tabular}

Ten patients withdrew from the study during the research period. After the second matching procedure $45 \mathrm{RA}$ patients and 45 references were left. Therefore, the non-completion within the RA patient group rose up to 20 . To find out if selection had taken place in the RA patient group a non-completion anallysis was performed using chi-square and t-tests for the variables of the research model. No significant differences were found between the RA patients completion and RA non-completion group (annex IV), which does not necessarily mean that selection bias concerning dependent and independent variables could have been present. 


\section{DESCRIPTIVE RESULTS OF OUT- COME, HEALTH DEVIATION, AND CONTROL VARIABLES}

\section{Introduction}

In this chapter the results of the outcome, health deviation, and control variables will be described, transversal as well as longitudinal. ${ }^{1}$ For those variables, which were measured in more then one interview, MANOVA repeated measurements were used to find group, time, or interaction effects. T-tests were used to test the significance of differences between mean scores for those variables which were measured once.

In the first section an overview of MANOVA and t-tests will be given. Based on the group, time, or interaction effects found, the separate variables of the research model will be discussed in the next sections. Within each section the following order will be held in presenting the results concerning the different groups: the RA patient group ( $\mathrm{N}=45)$ separatly and in comparison to the reference group $(\mathrm{N}=45)$. The $\mathrm{RA}$ patient diary group $(\mathrm{N}=22)$ and reference diary group $(\mathrm{N}=22)$ will be used as far as the results of the diaries are concerned.

\subsection{Overview of MANOVA and T-test Analyses for Outcome, Health Deviation, and Control Variables}

In table 5.1 the results of the MANOVA and t-test analyses for the outcome, health deviation and control variables for the RA patient group, and the comparison between the RA patients and reference group are presented. Several group, time and interaction effects were found for the outcome and health deviation variables, only few effects were found for the control variables (annex $V$ ).

1 Annex XI contains an overview of scores of the RA palients on outcome, heal th deviation, and control variables. 
Table 5.1: MANOVA and t-test analyses* of the variables of the research model for the $R A$ patients $(N=45)$, and $R A$ patients and reference group $(N=45)$.

\begin{tabular}{llll} 
Effecits: & group & time & Interaction \\
\hline Outcome vartables & & & \\
Difficulies performing activities & & & \\
ADL & RA>ref & increase & - \\
Aids and appliances & RA>ref & - & - \\
REL & RA>ref & increase & RA stronger
\end{tabular}

Rest and activity pattem

$\begin{array}{lll}\text { Rest }^{2} & \text { RA }>\text { nef } & \text { increas } \\ \text { Activity }^{2} & \text { RA>ref } & \text { increas }\end{array}$

Loneliness

decrease

\section{Health devlation varlables}

Punctional capacity

RA $>$ ref

Pain $^{2}$

Patigue $^{2}$

Stiffness ${ }^{2}$

RA $>$ ref

Controll varlables

Meaning of RA:

Bodily

RA decrease

Relational

RA decrease

Coping behavior:

action directed

seeking social support

awaiting favoiding

dependent care

facilities

professional help

$R A>$ ref

personal network

size

density

relatives

non-rellatives

balance in support:

-instrumental

RA $<$ ref

-emotional

RA $>$ ref

RA $>$ ref

* : results are presented only if $p<, 05_{;}{ }^{2}, \mathrm{~N}=22$ 


\subsection{Outcome Variables}

\subsubsection{Difficulties Performing Activities of Daily Functioning in the RA patient Group}

Difficulties in performing activities of daily functioning were investigated within three areas of daily functioning: ADL, obtaining and using aids and appliances, and relational functioning (chapter 2). As can be seen in table 5.2 in all three interviews, the majority of difficulties reported by the RA patient group concerned the ADL-subscale (mean 3.2,3.0, and 3.8), next to the relational functioningsubscale (mean .3, .9, .8), and the aids and appliances-subscale (mean .3, .4, .3).

Dressing was the problem most frequently mentioned. Other often mentioned difficulties were bathing, eating, and getting in or out of a chair. These results are similar to the results found by other authors (Rasker, 1984; Kruisvereniging Twente, 1989; Mostert, 1987), allthough Rasker found less problems with eating and getting in and out of a chair.

When loss of motion or changes in the range of motion occur, patients are advised to use assistive devices. Only few patients experienced difficulties in obtaining and using aids and appliances. They appeared to be rather constant in all interviews $(8.2 \%, 8.7 \%, 6.8 \%)$. In section 4.2 .2 .1 it was seen that all RA patients already had several aids and appliances. Besides this test-retest reliabilities showed that the aids and appliances subscale were unstable between the different measurement periods, while entering the procedures to obtain aids and appliances appeared, in general, to be based on coincidence.

Difficulties in relational functioning increased in time (table 5.1). In three interviews $8.2 \%, 21.5 \%$ and $15.3 \%$ of the total number of difficulties mentioned, concerned this subscale, which may be influenced by the fact that the RA patients were more acquaintened with the interviewer and interviewing procedures in the second and third interview period (information bias). As can be seen in table 5.2 most difficulties with relational functioning, concerned problems of acceptance by the patients themselves or by their spouses. Difficulties in relation to sexuality and contacts with friends were less frequently mentioned.

\subsubsection{Difficulties Performing Activities of Daily Functioning of the RA Patients and Reference Group}

As expected, most difficulties reported by the RA patients and the reference group were found within the ADL-subscale (table 5.3). MANOVA revealed a group and time effect (table 5.1). RA patients reported more difficulties performing ADL-activities than did the references. The amount of difficulties increased in time, especially between the second and third interview period (figure 5.2). 
Table 5.2: Number of RA patients with difficulties (in absolute numbers) performing activities of daily functioning in three interview periods $(N=45)$.

\begin{tabular}{|c|c|c|c|}
\hline $\mathrm{ADL}$ & 11 & 12 & $\mathrm{t} 3$ \\
\hline dressing & 33 & 25 & 32 \\
\hline bathing & 23 & 23 & 26 \\
\hline eating & 21 & 19 & 29 \\
\hline in/out bed & 21 & 16 & 23 \\
\hline in/out chair & 18 & 25 & 26 \\
\hline washing & 16 & 21 & 25 \\
\hline tolletting & 10 & 7 & 12 \\
\hline total & 142 & 136 & 173 \\
\hline mean & 3.2 & 3.0 & 3.8 \\
\hline$\underline{s d}$ & 2.4 & 2.1 & 2.4 \\
\hline \multicolumn{4}{|c|}{ aids and appliances } \\
\hline ADL & 5 & 6 & 5 \\
\hline small appliances & 5 & 4 & 3 \\
\hline walking & 3 & 5 & 4 \\
\hline house & 1 & 2 & 3 \\
\hline total & 14 & 17 & 15 \\
\hline mean & 0.3 & 0.4 & 0.3 \\
\hline sd & 0.7 & 0.9 & 1.0 \\
\hline \multicolumn{4}{|c|}{ relational functioning* } \\
\hline \multicolumn{4}{|c|}{ acceptance by: } \\
\hline self & 8 & 17 & 13 \\
\hline partner & 2 & 9 & 8 \\
\hline children & 2 & 7 & 4 \\
\hline sexuality & 2 & 6 & 3 \\
\hline contact & 0 & 3 & 6 \\
\hline total & 14 & 42 & 34 \\
\hline mean & 0.3 & 0.9 & 0.8 \\
\hline sd & 0.6 & 1.2 & 1.2 \\
\hline
\end{tabular}


Figure 5.2: Mean difficulties performing ADL-activities for RA patients $(N=45)$ and reference group $(N=45)$ in three interview periods.

Mean number of difficulties 4.0 performing ADL of the RA patients $(A)$, and reference group (B)

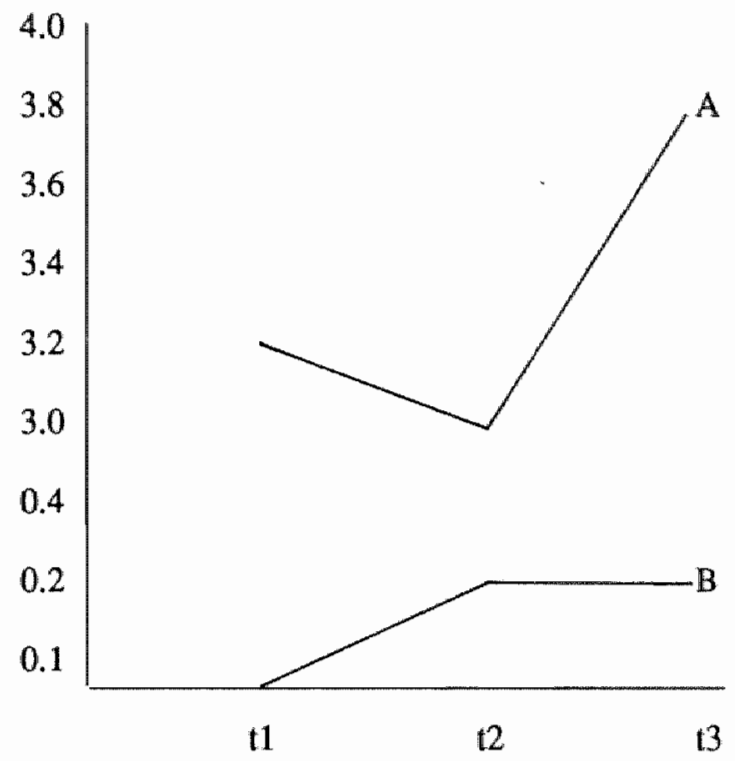

The mean number of difficulties performing ADL activities in three interview periods (table 5.3) mentioned by the RA patients, was $3.2,3.0$ and 3.8 , whereas the reference group mentioned $0,0.2$ and 0.2 problems (table 5.3). The increase of problems in the reference group, indicates that in a more healthy population of elderly, the number of problems with ADL-activities will show a certain increase with age. This result shows that RA and its medical treatment influence the number of problems experienced in daily living.

For obwious reasons, the reference group did not mention any difficulties in obtaining and using aids and appliances.

The fact that the reference group did not mention any problems concerning relational functioning was less comprehensible. It was expected that the reference group and the RA patients should show some identical problems inherent to aging. 
Table 5.3: Mean number of difficulties performing activities of daily functioning as mentioned by RA patients $(N=45)$ and reference group $(N=45)$.

\begin{tabular}{|c|c|c|c|c|c|c|}
\hline \multirow[t]{2}{*}{$\mathrm{ADL}$} & \multicolumn{2}{|c|}{ RA patients } & \multicolumn{4}{|c|}{ references } \\
\hline & $\mathbb{1 1}$ & -2 & 13 & $\mathfrak{t 1}$ & 12 & t3 \\
\hline mean & 3.2 & 3.0 & $3.8^{*} \#$ & 0.0 & 0.2 & $\overline{0.4}$ \\
\hline sd & 2.4 & 2.11 & 2.4 & 0.0 & 0.8 & 1.1 \\
\hline \multicolumn{7}{|c|}{ Aids and appliances } \\
\hline mean & 0.3 & 0.4 & $0.3^{*}$ & 0. & 0. & 0 . \\
\hline sd & 0.7 & 0.9 & 1.0 & 0. & 0. & 0. \\
\hline \multicolumn{7}{|c|}{ relational functioning } \\
\hline mean & 0.3 & 0.9 & $0.8 * @$ & 0. & 0. & 0 . \\
\hline sd & 0.6 & 1.2 & 1.2 & 0. & 0. & 0. \\
\hline
\end{tabular}

* p<.01 group effect; \# p<.05 time effect; @ p<.01 interaction affect

\subsubsection{Rest and Activity Pattern of RA Patients Diary Group and Reference Diary Group}

RA patients are advised to alter their rest and activity pattern as part of the (basic) medical treatment. The resulting changes depend either on the disease activity. and/or on the rules as prescribed by the rheumatologist. MANOVA analysis revealed a difference in the amount of activities between the RA patients and the reference group (table 5.1) (annex VI). In a few cases Pillai's criterion (pooled effect variances) was used instead of univariate $F$, because Box"s $M$ tests proved to be significant, in which case robustness is not guaranteed (Tabachnick \& Fidell, 1989).

RA patients spent approximately four hours more resting than references do, and are, therefore, less active (table 5.1). As can be seen in table 5.4, there are minor increases and decreases in the number of hours spent resting or being active between the three measurements in the RA patients, and reference group. 
Table 5.4: Rest and activity pattern in $R A$ patients $(N=22)$ and reference group ( $N=22$ ), (hours per day).

\begin{tabular}{|c|c|c|c|c|c|c|c|}
\hline & & \multicolumn{3}{|c|}{ RA patients } & \multicolumn{3}{|c|}{ refarence group } \\
\hline & & 11 & 12 & 13 & $t 1$ & 12 & 13 \\
\hline \multirow[t]{2}{*}{ no activity named 1) } & mean & .9 & .0 & .0 & 1.8 & .0 & .0 \\
\hline & sid & 1.9 & .0 & .0 & 1.6 & .0 & .0 \\
\hline \multirow[t]{2}{*}{ rest 2 ) } & mean & 14.4 & 14.7 & 15.0 & 10.8 & 11.9 & 11.5 \\
\hline & $\mathrm{sd}$ & 2.3 & 1.9 & 1.8 & 1.6 & 1.0 & 1.0 \\
\hline \multirow[t]{2}{*}{ activity 3 ) } & mean & 8.7 & 9.3 & 9.0 & 11.4 & 12.1 & 12.5 \\
\hline & sd & 2.8 & 1.9 & 1.9 & 1.5 & 1.0 & 1.0 \\
\hline Total & & 24 & 24 & 24 & 24 & 24 & 24 \\
\hline \multirow[t]{2}{*}{ 1). RA-reference } & \multirow{2}{*}{\multicolumn{4}{|c|}{$\begin{array}{l}\text { Pillai's }=4 \quad p<.01 \\
\text { approximate } \mathrm{F}=12.7 \mathrm{df}=2\end{array}$}} & & \multicolumn{2}{|c|}{ time effect } \\
\hline & & & & & & & \\
\hline \multirow[t]{3}{*}{ 2) RA-reference } & \multicolumn{2}{|c|}{$F(2,42)=57.3$} & \multicolumn{2}{|c|}{$P<.01$} & & \multicolumn{2}{|c|}{ group effect } \\
\hline & \multirow{2}{*}{\multicolumn{3}{|c|}{ approximate $\mathrm{F}=3.9 \mathrm{df}=2$}} & & & \multicolumn{2}{|c|}{ time effect } \\
\hline & & & & & & \multirow{2}{*}{\multicolumn{2}{|c|}{ time effect }} \\
\hline \multirow{4}{*}{ RA-reference } & \multicolumn{2}{|c|}{$F(1,20)=5.8$} & \multicolumn{2}{|c|}{$\mathrm{p}=.05$} & & & \\
\hline & \multicolumn{2}{|c|}{$\mathrm{F}(2,42)=51.3$} & \multicolumn{2}{|l|}{$p<.01$} & & \multicolumn{2}{|c|}{ group effect. } \\
\hline & \multicolumn{2}{|c|}{ Pillain's=2 } & $p<05$ & & & \multicolumn{2}{|c|}{ time effect } \\
\hline & \multicolumn{4}{|c|}{ approximate $F=3.7 \mathrm{df}=2$} & & & \\
\hline
\end{tabular}

To find out which specific activities were responsible for the differences found in the activity pattern, the categories of activities as presented in section 4.2.3.1 were re-ordered into four different activity groups:

- rest (no activity named, rest, passive leisure in and outdoors);

- activity (eating, selfcare, household activities, active leisure, necessary activities, and social activities);

- selfcare (eating, selfcare, household activities), and

- leisure (passive-, active-, social-, necessary leisure).

Profile analyses were performed on each of the four activity categories. Table 5.5 shows the patterns of these activities three times. The major question to be answered by profile analysis, is whether or not profiles of groups differ on a set of measures (Tabachnik \& Fidell, 1989). Three tests are of interest:

- parallelism of profiles (do different groups have parallel profiles);

- overall differences between groups (does one group, on avarage, score higher or lower on rest and activity than another), and

- flatness of profiles (similarity of response to rest and activity, independent of groups).

In all four activity categories the tests of parallelism revealed significant differences in profiles between the RA patients and the reference group. For the group hypothesis, significant differences were found for rest and activity only. An overall difference in the profiles of both groups was found for the activity pattern, which means, in general, that RA patients spent more time resting and are less active than the reference group. The amount of time spent on selfcare and leisure 
activities differed slightly between the two groups. RA patients spent less time on these activities than references do. No further attention was given to the flatness test, because this test is less interesting if groups have no parallel profiles.

Table 5.5: $\quad$ Profile analysis of the activity categories rest, activity, selfcare, and leisure of $R A$ patients $(N=22)$ and reference group $(N=22)$ in three interview periods (hours per day).

\begin{tabular}{|c|c|c|c|c|c|c|c|}
\hline \multirow[t]{2}{*}{$\begin{array}{l}\text { Activity } \\
\text { (mean) }\end{array}$} & & \multirow[b]{2}{*}{ tl } & \multirow[b]{2}{*}{12} & \multicolumn{4}{|c|}{$\begin{array}{l}\text { Hotelling T2 } \\
F(2,42)\end{array}$} \\
\hline & & & & 13 & 11 & 12 & $B$ \\
\hline \multirow[t]{2}{*}{ rest } & RA & 14.4 & 14.7 & 14.9 & $.7^{x}$ & $1.0^{\circ}$ & $1.3^{* *}$ \\
\hline & reference & 11.5 & 11.9 & 11.7 & $20.3^{\prime}$ & $20.8^{\prime}$ & $54.3^{\prime \prime}$ \\
\hline \multirow[t]{2}{*}{ activity } & RA & 8.6 & 9.3 & 9.0 & $1.5^{\prime}$ & $1.3^{\prime}$ & $1.7^{3}$ \\
\hline & reference & 11.4 & 12.0 & 12.2 & $21.7^{\prime}$ & $36.4^{\prime}$ & $53.8^{\prime}$ \\
\hline \multirow[t]{2}{*}{ selfcare } & RA & 5.2 & 5.7 & 5.2 & $.2^{\prime \prime}$ & $.2 "$ & $.6^{\prime}$ \\
\hline & reference & 5.5 & 5.9 & 5.9 & & & \\
\hline \multirow[t]{2}{*}{ leisure } & $\mathrm{RA}$ & 7.8 & 8.2 & 8.3 & $1.3^{\prime}$ & $1.2^{\prime}$ & 1.6 \\
\hline & reference & 8.2 & 9.1 & 9.2 & & & \\
\hline
\end{tabular}

* test of parallelism; \# overall differences between groups.

"p $\mathrm{x} .01 ; " \mathrm{p}\langle .05$

It can be concluded that activity profiles for rest, activity, selfcare, and leisure together, differ between RA patients and the reference group, probably due to RA, its medical treatment, and the presciptions given by the rheumatologist to the RA patients to alter their rest and activity pattern.

Although no differences were found in the time RA palients and references spent on selfcare and leisure, it is possible that differences exist in the separate activities of these categories. Next to the difference between selfcare and leisure, differences were found between the separate leisure activities. Table 5.6 shows that significant group differences were found for all forms of leisure (at home, outdoors; passive, active, and social). The amount of time spent on the several leisure categories do not differ much in the reference group in contrast to the RA patient group where more time is spent on activities at home and passive leisure activities. 
Table 5.6: Number of hours spent on leisure at home, outdoors and bodily passive, active and social leisure by $R A$ patients $(N=22)$ and reference group $(N=22)$ in three diaries.

\begin{tabular}{|c|c|c|c|c|c|c|c|}
\hline \multirow[t]{2}{*}{ leisure } & & \multicolumn{3}{|c|}{ RA patients } & \multicolumn{3}{|c|}{ reference group } \\
\hline & & $t 1$ & 12 & 13 & $\mathrm{tl}$ & 12 & 13 \\
\hline \multirow[t]{2}{*}{ at home 1) } & $\mathrm{m}$ & 5.7 & 5.8 & 6.0 & 4.3 & 4.8 & 4.8 \\
\hline & sd & 2.0 & 1.8 & 2.0 & 1.2 & 1.5 & 1.5 \\
\hline \multirow[t]{2}{*}{ outdoors 2) } & $\mathrm{m}$ & 2.0 & 2.2 & 2.3 & 4.0 & 4.3 & 4.4 \\
\hline & $\mathrm{sd}$ & .8 & 1.0 & 1.0 & 1.6 & 1.5 & 1.4 \\
\hline \multirow[t]{2}{*}{ passive 3) } & $\mathrm{m}$ & 4.3 & 4.0 & 4.3 & 2.4 & 2.9 & 2.7 \\
\hline & sd & 1.9 & 1.5 & 1.6 & $1 . \mathbb{1}$ & .7 & .8 \\
\hline \multirow[t]{2}{*}{ active 4) } & $\mathrm{m}$ & 1.9 & 2.4 & 2.4 & 3.5 & 3.4 & 3.5 \\
\hline & sd & 1.1 & 1.3 & 1.2 & 1.5 & 1.4 & 1.3 \\
\hline \multirow[t]{2}{*}{ social 5) } & $\mathbf{m}$ & 1.5 & 1.6 & 1.6 & 2.4 & 2.8 & 3.0 \\
\hline & sd & 1.0 & 1.1 & .9 & .9 & 1.4 & 1.5 \\
\hline 1) RA-reference & & $F(2,42)=7.7$ & $\mathrm{p} x<01$ & & \multicolumn{3}{|c|}{ group effect } \\
\hline 2) RA-reference & & $F(2,42)=44.3$ & $p<01$ & & & peffect & \\
\hline \multicolumn{2}{|l|}{ RA-reference } & $F(2,42)=18.7$ & $p<.01$ & & \multicolumn{3}{|c|}{ group effect } \\
\hline RA-reference & & $F(1,43)=7.7$ & $P\{01$ & & \multicolumn{3}{|c|}{ interaction } \\
\hline \multirow{4}{*}{ 4) $\begin{array}{l}\mathrm{RA} \\
\mathrm{RA} \text {-reference } \\
\mathrm{RA} \text {-reference }\end{array}$} & & $F(1,20)=5.8$ & $\mathrm{p}\langle 05$ & & \multicolumn{3}{|c|}{ time effect } \\
\hline & & $\mathrm{F}(2,42)=51.3$ & P\{to1 & & \multirow{2}{*}{\multicolumn{3}{|c|}{$\begin{array}{l}\text { group effect } \\
\text { time effect }\end{array}$}} \\
\hline & & Pillai $s=.2$ & p $\langle .05$ & & & & \\
\hline & & \multicolumn{3}{|c|}{ approximate $\mathrm{F}=3.7 \mathrm{df}=2$} & & & \\
\hline 5) RA-reference & & $\mathrm{F}(2,42)=22.1$ & $p<.01$ & & \multicolumn{3}{|c|}{ group effect } \\
\hline
\end{tabular}

\subsubsection{Loneliness}

Limitations in movement do not only have consequences for activities of dailly functioning but can also cause feelings of loneliness. Table 5.8 shows the mean loneliness scores of the RA patients. MANOVA analysis revealed a significant decrease in feelings of loneliness for both patients and references (table 5.1). Two possible explanations for the decrease found could be that the studly was not blind. Respondents knew about the purpose of the study. It is also possible that respondents, uncounsciously, exaggerate their feelings of loneliness in the first interview in a negative way, and positively in the third interview.

The mean loneliness scores of RA patients were slightly higher than those of the reference group except in the second interview where the scores of both groups were almost equal, meaning a (temporary) increase in the feelings of loneliness in the reference group. The mean loneliness scores in the first and second interview of the RA patients are comparible to the results of De Wilte et al. (1989), who found a mean loneliness score of 2.6, and Van Tilburg (1988), who 
found a mean score of 3.1. Mostert (1987) found a mean loneliness score of 4.7, but investigated RA patients in ARA functional classes III and IV. Loneliness scores found in the third interview were lower than the results found in other studies. In the first instance, no explanation for this phenomenon could be found.

Table 5.7: Mean loneliness scores of RA patients $(N=45)$ and reference group $(\mathrm{N}=45)$ in three interviews.

\begin{tabular}{lrrrrrr}
\hline Loneliness* $^{*}$ & \multicolumn{2}{c}{ RA patients } & \multicolumn{4}{c}{ references } \\
& $\mathbf{t 1}$ & $\mathbf{1 2}$ & $\mathbf{1 3}$ & $\mathrm{t1}$ & $\mathbf{2}$ & $\mathbf{t 3}$ \\
\hline mean & 2.9 & 2.6 & 2.2 & 2.2 & 2.6 & 1.5 \\
sd & 3.1 & 3.0 & 2.8 & 2.2 & 2.8 & 2.1 \\
\hline
\end{tabular}

* plol; time effect

\subsubsection{Relations Between the Outcome Variables}

Table 5.8 presents the pearson correlations between the outcome variables in the RA patient group on three measurements. (Pearson correlations for the separate outcome variables on three measurements were presented in chapter 4 , and annex VII). It is shown in the table that only a few relations were found. In the third measurement a positive relation was found between $\mathrm{ADL}$ and abtaining and using aids and appliances. This is opposite to the first and second measurement. It is possible that during the research period more patients did apply for aids and appliances because of a deterioration in functional abilities or they were given information as to how one obtains and uses aids and appliances by the interview or interviewer.

A second positive relation was found between ADL and relational functioning in the third measurement. The majority of the problems with relational functioning concerned problems with the acceptance of the disease by the patient herself or by the spouse. The relation found might implicate that problems with the acceptance of the disease increase when the number of difficulties with ADL increase.

More feelings of loneliness are experienced if patients have more difficulties performing ADL ( $t 1$ en $B$ ) and if patients have more difficulties with relational functioning ( $t 1$ and $t 2)$. 
Table 5.8: Pearson correlations between the outcome variables for the $R A$ patients ( $N=45$ ) in three measurements.

\begin{tabular}{cccccc}
\hline & & ADL & A\&A & REL & Rest $^{2}$ \\
\hline Aids and & $\mathrm{t} 1-\mathrm{t} 1$ & .19 & & & \\
appliances & $\mathrm{t} 2-\mathrm{t} 2$ & .01 & & & \\
& $\mathrm{t} 3-\mathrm{t} 3$ & $.27 \#$ & & & \\
Relational & $\mathrm{t} 1-\mathrm{t} 1$ & .19 & -.01 & & \\
functioning & $\mathrm{t} 2-\mathrm{t} 2$ & .13 & -.20 & & \\
& $\mathrm{t} 3-\mathrm{t} 3$ & $.30 \#$ & .04 & & \\
& & & & & \\
Rest $^{2}$ & $\mathrm{t} 1-\mathrm{t} 1$ & .28 & .25 & .29 & \\
& $\mathrm{t} 2-\mathrm{t} 2$ & .19 & -.18 & .19 & \\
& $\mathrm{t} 3-\mathrm{t} 3$ & .06 & -.05 & -.16 & \\
& & & & & \\
Loneliness & $\mathrm{t} 1-\mathrm{t} 1$ & $.47 *$ & .15 & $.42 *$ & .02 \\
& $\mathrm{t} 2-12$ & .16 & .02 & $.30 \#$ & .16 \\
& $\mathrm{t} 3-13$ & $.30 \#$ & .05 & .08 & -.11 \\
${ }^{2} \mathrm{~N}=22 ;{ }^{*} \mathrm{p} x .01 ; \# \mathrm{p}(.05$ & & & &
\end{tabular}

\subsection{Health Deviation Variables}

\subsubsection{Functional Capacity}

The ability to move as measured by Lee's Functional Index, is an important indicator of disability. As was expected, MANOVA analysis revealed that the functional capacity of RA patients decreased significantly in time (table 5.1). Table 5.9 presents the number of RA patients in the different ARA functional classes in three interviews. It can be seen that the number of patients in functional class I especially decreased in contrast to the number of patients in class IV. These results are similar to the results found by Sherrer et al. (1986), and Duthie et al. (1964) (section 2.3.1). 
Table 5.8: Number of RA patients ( $N=45)$ in the different ARA Functional Classes in three interviews.

\begin{tabular}{lccc}
\hline ARA Functional & \multicolumn{3}{c}{ RA patients } \\
Classes & 11 & $\mathbf{1}$ & $\mathbf{t}$ \\
\hline not limited & 7 & 7 & 3 \\
moderatly limited & 19 & 18 & 18 \\
severely limited & 11 & 12 & 12 \\
dependent & 8 & 8 & 12 \\
\hline
\end{tabular}

* $p \nmid 05$, time effect

Table 5.10 summarises the changes in functional capacity in time with the ARA functional classification of the first interview as point of departure. The median score on functional capacity of the RA patients increased from 11.0, in the first and second interview, to 13.0 in the third interview. The functional capacity scores of the RA patients in all different ARA functional classes increased in time (table 5.10). The reference group could almost entirely be classified in ARA functional class I in all three interview periods. A large difference, therefore, exists between the reference group and the RA patients, caused by the disease.

Table 5.10: Changes infunctional capacity based on the classification in the first interview of RA patients (median scores) $(N=45)$.

\begin{tabular}{lcrrr}
\hline Functional & & \multicolumn{3}{c}{ RA patients } \\
Classes & $\mathrm{N}$ & $\mathrm{t1}$ & $\mathrm{t} 2$ & $\mathrm{t} 3$ \\
\hline I & 7 & 2.0 & 5.0 & 8.0 \\
II & 19 & 9.0 & 9.0 & 11.0 \\
III & 11 & 16.0 & 15.0 & 16.0 \\
IV & 8 & 21.0 & 22.5 & 23.0 \\
\hline Total & 45 & 11.0 & 11.0 & 13.0 \\
\hline
\end{tabular}

\subsubsection{Pain, Fatigue and Duration of Morning Stiffness}

Three major complaints of RA investigated through diaries were: pain, fatigue and duration of moming stiffness. Table 5.11 presents the mean pain scores per hour. The presented numbers were calculated by dividing the mean amount of pain per day by the mean number of hours a respondent was active. MANOVA analysis revealed a significant group effect between the RA patients and reference group ( $\mathrm{N}=22)$ (table 5.1). Table 5.11 shows the difference in mean pain scores between the RA patients and reference group. Both groups show a slight increase in pain levels over time.

RA patients did also experience more fatigue during the day than references did (table 5.1). (The mean scores were derived in the same way as pain scores). Fatigue is similar to pain in that the scores of both the RA patients and reference group increased in time. 
As for the duration of morning stiffness, which is presented in the number of quarters-of-an-hour, RA patients reported to have longer duration of moming stiffness than references did, the same results were found for both pain and fatigue (table 5.1).

Table 5.11: Mean pain, and fatigue scores per active hour and duration of morning stiffness in quarters-of-an-hour of RA patients ( $N=22$ ) and reference group $(N=22)$ in three diaries.

\begin{tabular}{lcrrrrr}
\hline Pain* & \multicolumn{3}{c}{ RA patients } & \multicolumn{4}{c}{ References } \\
& $\mathbf{t} 1$ & $\mathbf{t}$ & $\mathfrak{t} 3$ & $\mathrm{t} 1$ & $\mathbf{2}$ & $\mathbf{1}$ \\
$(\mathrm{N}=$ & 20 & 20 & 22 & 22 & 22 & $22)$ \\
mean & 3.5 & 4.3 & 4.3 & 0.7 & 0.9 & 1.1 \\
sd & 2.8 & 3.1 & 3.0 & 1.5 & 1.6 & 1.7 \\
\hline Fatigue* & & & & & & \\
$(\mathrm{N}=$ & 18 & 19 & 22 & 22 & 22 & $22)$ \\
mean & 2.7 & 3.1 & 3.3 & 0.7 & 0.7 & 1.0 \\
sd & 2.6 & 3.1 & 2.4 & 1.2 & 1.1 & 2.5 \\
Stiffness* & & & & & & \\
$(\mathrm{N}=$ & 18 & 17 & 22 & 22 & 22 & $22)$ \\
mean & 6.2 & 5.7 & 4.7 & 0.1 & 0.6 & 0.2 \\
sd & 3.6 & 3.5 & 3.4 & 0.4 & 2.0 & 0.6 \\
\hline
\end{tabular}

${ }^{*}$ p $\mathbf{x} .01$, group effect

In summary, the RA patients and the reference group did show differences in the amount of pain, fatigue and moming stiffness experienced. The fact that RA is responsible for the three complaints explains the differences found between both groups. Within the RA group the amount of experienced pain, fatigue and duration of morning stiffness did not markedly increase in time.

\subsubsection{Duration of RA}

In section 3.2 it was argued that the duration of the disease might give an indication of the disability caused by the RA. The mean duration of RA in this study for the RA patient group was 14.5 years (sd 12.0), with a range of 1 to 46 years. However, a significant relation between the ARA classification and the duration of RA was found only in the third measurement $(-.28, p(.01)$. This means that, in the third measurement, patients with a shorter duration of RA did have worse functional capacity. The RA patient group was not homogeneous in relation to duration of RA. It is possible that patients with a longer duration of RA were more stable in functional class than patients with shorter duration of RA. 


\subsubsection{Relations Between the Health Deviation Variables}

Significant relations were found between functional capacity, pain, fatigue and duration of morming stiffness (table 5.12). It appears that having poorer functional capacity is related to having more pain, fatigue and stiffness. Having poorer functional capacity might indicate that patients who have loss of motion and a poorer range of motion also have more feelings of pain, more feelings of fatigue and have a longer duration of morning stiffness.

Rhind et all. (1987) and Smith Pigg et al. (1984) point out that RA patients do not always make a clear differentiation between pain, fatigue, and morning stiffness (section 2.2.1). In this study, high positive correlations were found between pain and fatigue in all three interviews. No significant correlations were found between pain and moming stiffness and fatigue and morning stiffness. Due to the fact that strong relations were found between pain and fatigue, a new variable was created, pf-complaints, by calculating the mean pain and fatigue scores per hour a patient was active.

A negative relation was found between functional capacity and the duration of RA, meaning that patients with a longer duration of RA did have better functional capacity. This result was, however, found only in the third interview period.

Finally, a relation was found between fatigue and the duration of RA in the first measurement period, after which it disappears.

Table 5.12: Pearson correlations between the health deviation variables for the $R A$ patients $(N=45)$ and the $R A$ patient diary group $(N=22)$ on three measurement moments.

\begin{tabular}{|c|c|c|c|c|c|}
\hline \multirow{2}{*}{ Pain } & \multicolumn{2}{|c|}{ Functional capacity } & \multirow[t]{2}{*}{ Pain $^{2}$} & \multirow[t]{2}{*}{ Fatigue $^{2}$} & \multirow[t]{2}{*}{ Stiffness ${ }^{2}$} \\
\hline & t1-t1 & $.48 \#$ & & & \\
\hline & $12-12$ & $.57^{*}$ & & & \\
\hline & $13-13$ & $.55^{*}$ & & & \\
\hline \multirow[t]{3}{*}{ Fatigue } & $t 1-t 1$ & $.58 *$ & $.93^{*}$ & & \\
\hline & $12-12$ & $.59 *$ & $.89^{*}$ & & \\
\hline & $13-13$ & $.60^{*}$ & $.79 *$ & & \\
\hline \multirow[t]{3}{*}{ Stiffness } & $\mathrm{t} 1-\mathrm{t} 1$ & $.48 \#$ & .24 & .31 & \\
\hline & $12-12$ & .02 & .11 & .03 & \\
\hline & $13-13$ & $.41 \#$ & .29 & .34 & \\
\hline \multirow{3}{*}{$\begin{array}{l}\text { Duration of } \\
\text { RA }\end{array}$} & t1-t 1 & .01 & .33 & $.43 \#$ & .25 \\
\hline & $2-12$ & -.07 & .37 & .32 & .31 \\
\hline & $t 3-13$ & $-.28 \#$ & .01 & .05 & .03 \\
\hline
\end{tabular}




\subsection{Control Variables}

\subsubsection{Meaning of RA}

RA patients attribute several meanings to their disease (section 2.4.1.1), which can be differentiated in a bodily and a relational component (section 4.2 .2 .6 ). MANOVA analysis revealed a significant decrease in the mean number of meanings attributed to RA for both subscalles (table 5.1). The mean number of meanings attributed to the bodily component decreased from 4.5 to 4.0 (range 0-5) (table 5.13).

This means that, in general, RA patients reported 1 meaning less in the third interview than they did in the first interview. Comparible to the bodily meanings given to RA are the relational meanings given to the disease. The mean number of meanings attributed to the relational component decreased from 5.0 to 4.0 (range 0-11) (table 5.1).

Table 5.13: Meaning of RA (bodily and relational) to RA patients $(N=45)(t$ and (3).

\begin{tabular}{lcc}
\hline Bodily* & RA patients & \\
& $\mathrm{t} 1$ & $\mathrm{~B}$ \\
$\mathrm{~N}=$ & 45 & $45)$ \\
mean & 4.5 & 4.0 \\
sd & 1.1 & 1.5 \\
\hline Relational** & & \\
\hline mean & 5.0 & 4.0 \\
sd & 3.0 & 3.0 \\
\hline
\end{tabular}

${ }^{*} p<.05 ;{ }^{* *} p<.01$ time effects

\subsubsection{Coping Behavior}

A second control variable was coping behavior, which was part of the first and third interview. Three major groups of coping behavior were identified in section 4.2.2.7, as action directed behavior, seeking social support, and awaiting, avoiding behavior. No differences were found for the three components of coping behavior between the RA patients and reference group. Mean scores for action directed behavior were 2.5 and 2.7 for the RA patients, and two times 2.8 for the references in interview 1 and 3. Mean seeking social support scores in the first and third interview were 1.8 and 1.9 for the RA patients, and 2.0 and 1.9 for the references. Finally, RA patients scores for awaiting, avoiding behavior were two times 2.4 , and references did in both interviews have a mean score of 2.3 . 


\subsubsection{Dependent Care Facilities}

When RA patients need help they are often dependent on their immediate environment (section 2.4.1.3). The amount of dependent care facilities was measured to find out to what extent the RA patients have access to these facilities. No differences were found between RA patients and references concerning dependent care facilities. The majority of respondents (26 RA patients and 17 references) did have a spouse and/or a daughter(s) (in law) living less than 15 minutes traveling and/or had a housemate(s), in their immediate environment who would be able to give help. Only few patients and references did report to have no dependent care facilities ( 8 and 4 ).

\subsubsection{Professional Help Given to the RA Patients}

In most instances when RA patients expressed to having difficulties performing activities of daily functioning, they also expressed a need for help. If a need for help was expressed, the most likely person to give help was the spouse. The second group to give help to the RA patients were the professionals. The majority of professional help (table 5.14) given to the RA patients, concerned obtaining and using aids and appliances. Due to the fact that aids and appliances can only be obtained through community medical services, the patients will either turn to their rheumatologist or to the community nursing association for advice or help.

In addition to the help given concerning aids and appliances, help was given for $\mathrm{ADL}$ activities. The largest amount of help given to the RA patients, was help with bathing and dressing. With the exception of the third interview, no professional help was reported concerning relational problems.

In addition to the question if RA patients received professional help, they were asked which professionals were involved. Almost all the professional help given in case of difficulties with performing ADL was given by community nurses $(9,11,13)$. Different professions are of help in obtaining aids and appliances, but the majority of help was given either by the rheumatologist $(1,12,8)$ or the community nurse $(11,7,2)$. As mentioned before, professional help concer-

Table 5.14: Number of RA patients with professional help $(N=45)$ in three measurements.

\begin{tabular}{|c|c|c|c|c|c|c|c|}
\hline \multicolumn{4}{|l|}{ ADL } & \multicolumn{4}{|c|}{ Aids and appliances } \\
\hline & $t 1$ & $\mathrm{t} 2$ & 13 & & t1 & 12 & 13 \\
\hline eating & 0 & 0 & 1 & walking. & 4 & 5 & 4 \\
\hline in/oul bed & 1 & 1 & 2 & ADL & 4 & 7 & 5 \\
\hline toiletting & 1 & 1 & 2 & small & 6 & 10 & 3 \\
\hline in/out chair & 1 & 1 & 2 & house & 2 & 3 & 2 \\
\hline dressing & 3 & 3 & 4 & & & & \\
\hline washing & 1 & 1 & 2 & & & & \\
\hline bathing & 3 & 4 & 4 & & & & \\
\hline
\end{tabular}


cerning problems with relational functioning was only reported in the third interview by 1 patient who received help from a social worker.

\subsubsection{Personal Network}

The RA patients did have an average personal network size of 9.3 persons, of which approximately 6 persons were relatives (table 5.15). The personal network size of the RA patients did not significantly differ from the personal network size of the reference group. This was also true for the number of relatives in the personal network of RA patients (6.2) and the reference group (7.2). The number of people in the personal networks of RA patients and references found in this study are slightly lower than the results found by Knipscheer (1980) who found a mean personal network size of 10.5 , with 7.2 relatives and 3.3 nonrelatives.

Table 5.15: Personal network: total network size and number of the relatives and non-relatives in the network of $R A$ patients $(N=45)$ and reference group $(N=45)(t 3)$.

\begin{tabular}{lrr|rrrr}
\hline \multicolumn{2}{c|}{ Size } & & \multicolumn{2}{c}{ Relatives } & \multicolumn{2}{c}{ Non-relatives } \\
& RA patients & references & RA & Ref & RA & Ref \\
\hline mean & 9.3 & 9.9 & 6.2 & 7.1 & 3.1 & 2.8 \\
sd & 4.7 & 5.2 & 3.7 & 4.5 & 4.0 & 3.1 \\
\hline
\end{tabular}

The majority of RA patients had a very high density in their personal network (19 persons reported that everybody in the network knew each other and had contact on a regular basis). No differences were found in density between the RA patients and reference group.

A last aspect of the personal network is the amount of instrumental and emotional support given by, and to, the RA patients and the reference group. As was described in section 3.4.4 it was expected that a chronic illness and its medical treatment would have an effect on the balance in giving and receiving instrumental and emotional support. Table 5.16 presents the results of the balance in instrumental support. T-test analysis revealed significant differences between the balance of instrumental support between all groups (table 5.1). The majority of RA patients (35) received more instrumental support than they gave support (mean support received 2.9, given 2.2), opposite to the reference group (21) who gave more support than they received (mean support given 2.3, received 2.2). 
Table 5.16: Balance in instrumental support of $R A$ patients and reference group $(N=45)$ in the third interview period.

\begin{tabular}{|c|c|c|c|c|}
\hline & \multicolumn{4}{|c|}{ Balance in instrumental support } \\
\hline & positive & equal & negative & \\
\hline RA patients* & 16 & 24 & 4 & 44 \\
\hline references & 4 & 26 & 14 & 44 \\
\hline total & 20 & 50 & 18 & 88 \\
\hline
\end{tabular}

No differences were found for the balance in emotional support. RA patients gave a little more emotional support (mean 4.0) than they received (3.8), whereas the reference group received a little more (3.8) than they gave (mean 3.7).

\subsubsection{Relations Between the Control Variables}

As can be seen in table 5.17 several intercorrelations exist between the control variables. Positive relations exist between the bodily and relational meaning of $\mathrm{RA}$ on $\mathrm{t} 1$ and $\mathrm{t} 3$, meaning that consequences of the disease are translated by the RA patients to both physical and relational meanings.

Action directed coping behavior is negatively related to the bodily meaning of RA on $t 1$, to the relational meaning of RA on $\mathbf{B}$, and to the balance in instrumental support. A positive relation exists between action directedness and professional help. Negative relations were found between awaiting, and avoiding, and professional help, size of the personal network and the number of family members in the network. This indicates that RA patients with less awaiting, avoiding behavior do have more professional help, and larger personal networks, with more family members.

RA patients with more dependent care facilities do also have a higher density in the personal network, their networks also contain more relatives and less nonrelatives.

Female RA patients do attribute more bodily and relational meanings to RA. They also receive more professional help than their male counterparts. Male R.A patients, in this study, did have larger personal networks and did receive more instrumental support than female RA patients.

RA patients with a high density of the personal network did have less professional help.

Size of the personal network was related to all other network variables. A larger network means more relatives and non-relatives in the network. It also means that patients receive more instrumental support than they give. On the other hand, a larger network means lower density and receiving less emotional support. 
Table 5.17: Pearson correlations between the outcome variables for the RA patients $(N=45)$ in three measurement periods. 
In this chapter the transversal and longitudinal results for the separate outcome, health deviation, and control variables were described.

\section{Outcome Variables.}

The majority of difficulties experienced in performing activities of daily functioning for the RA patients, were found in the ADL subscale in all three interviews $(83.6 \%, 69.8 \%$, and $77.9 \%)$. A group and time effect was found through MANOVA analysis in the number of difficulties performing ADL between RA patients and references. RA patients reported to have more difficulties with $A D L$ than the references, and the number of difficulties increased during the research period. These results are congruent with other research findings. Only a few difficulties were mentioned by the RA patients concerning the aids and appliances subscale $(8.2 \%, 8.7 \%$, and $6.8 \%)$, references did not mention any problems concerning this subscalle. A final area of daily functioning was the difficulties with relational functioning. The amount of difficulties reported for the relational functioning subscale increased significantly in the second interview and decreased a little in the third interview $(8.2 \%, 21.5 \%$, and $15.3 \%)$. Group effects were found between the RA patient and reference group, in that the references did not mention any problems concerning relational functioning. It can be concluded that RA patients, on the average, have more difficulties with daily functioning than the references. The impact of RA and its medical treatment on the daily functioning of RA patients, seems quile substantial and will be further explored in the following chapters.

A second outcome variable was the rest and activity pattern. Due to the disease process and the alterations in the rest and activity pattern as prescribed by the rheumatologist, it was expected that rest and activity patterns would differ between RA patients and the references. It was found that RA patients, in general, have approximately four hours of rest more than the references, and RA patients were, therefore, less active. RA patients and references spent about the same amount of time on selfcare and leisure, although RA patients spent significantly more time on passive leisure activities at home.

A final outcome variable was loneliness. Mean loneliness score as found in this study for RA patients $(2.9,2.6,2.2)$, and the reference group $(2.2,2.6$, and $1.5)$ are comparible to the results found in other studies. However, MANOVA analysis revealed a significant decrease in the feelings of loneliness of both the RA patients and references.

Health Deviation Variables.

An important factor is functional capacity. A significant decrease of functional capacity was found for the RA patients. The number of patients in ARA functional class I decreased, whereas the number of patients in functional IV increased. Based on the ARA classification in the first interview, the mean scores on Lee's Functional Index increased for all functional classes. This result is similar to other research findings. Due to the fact that almost all references could be classified in ARA functional class I, MANOVA analysis showed significant group effect between RA patients and references. 
A second group of health deviation variables included pain, fatigue and duration of moming stiffness. For all three variables MANOVA analyses showed significant group differences between the RA patients diary group and the reference diary group. These differences can be explained by the fact that pain, fatigue and stiffness are three major complaints of RA. The amount of experienced pain, stiffness and the duration of moming stiffness of RA patients were approximately equal in all three diaries.

A final health deviation variable investigated was the duration of RA. The mean duration of RA for the RA patients was 14.5 years, with a range of 1 to 46 years.

Control Variables.

Two groups of control variables were investigated: social position and attitudes (meaning of RA, coping behavior, and dependent care facilities), and care facilities (professional help, and personal network).

In relation to the two subscales of the meaning of RA, significant time effects were found. For both the bodily and the relation meanings the RA patients attributed approximatelly one meaning less in the third interview $(4.0,4.0)$ than they did in the first interview $(4.5,5.0)$.

Coping behavior of RA patients and references was relatively stable in time. No differences were found between RA patients and references for the three coping behavior subscales: action directed, seeking social support, and awaiting, avoiding.

The presence of dependent care facilities is important in relation to care. Only a few patients and references reported not to have dependent care facilities $(8,4)$. Next to dependent care facilities, professional help can be important to the RA patient. The majority of the professional help given to the patients concerned obtaining and using aids and appliances, followed by ADL. No professional help was reported in relation to relational functioning, except for the third interview. The reference group received no professional help, therefore, significant group differences were found between the patient and reference groups. The rheumatologist (aids and appliances), and the community nurse (ADL, and aids and appliances) were responsible for the majority of the help given to RA patients.

Finally, the personal network of the respondents was investigated in the third interview period. No differences were found between the personal network of RA patients and references in relation to network size (mean 9.3, and 9.9), densily of the network, number of relatives $(6.2,7.1)$, and nonrelatives $(3.1,2.8)$, and the balance in emotional support. A difference was found concerning instrumental support. RA patients, generally, received more instrumental support than they gave, opposite to the references, who, in general, gave more support than they received. 


\section{THE IMPACT OF HEALTH DEVI- ATION ON OUTCOME VARIABLES}

\section{Introduction}

A decrease in functional abilities, the almost constant presence of pain, feelings of fatigue and the existence of early moming stiffness often cause difficulties in activities of every-day life (section 3.2). Aids and appliances may contribute to at least a part of the solution of these problems, but are often hard to get and not always easy to use. The burden of RA can also put a strain on the interpersonal relations of the RA patient (section 5.2.1). In terms of dependency (section 3.3) this means that the RA patient becomes more dependent on the persons in the immediate environment.

In this chapter the question to answer is: What impact does health deviation variables have on outcome variables? First, the relationships between the health deviation variables and each separate outcome variable will be presented. Due to of the high individual stability of the variables between the different measurement moments (annex VII), and because only few changes were found for the health deviation and outcome variables between the first and third interview (chapter 5), the results presented refer to mean scores derived from the scores of the first and third interview.

The longitudinal analysis will describe the covariation of changes in the health deviation variables on changes in the outcome variable between the first and third interview.

The RA patient group ( $N=45)$ will be subject of analysis. The results of the the RA patient diary group $(\mathrm{N}=22)$ will be presented where results of the diaries are concerned.

\subsection{Health Deviation and Outcome Variables}

\subsubsection{General Results}

Significant relations were found between heallh deviation and ADL, relational functioning, and loneliness (table 6.1) (annex VIII). No relations were found between the health deviation variables and obtaining and using aids and appliances, the number of hours rest, and between the duration of RA and the outcome variables. Therefore no further analyses were performed concerning these variables. 
Table 6.1: Pearson correlations of the health deviation and outcome varia bles for the RA patients ( $N=45$ ), and RA patients diary group $(N=22)(t+13)$.

\begin{tabular}{|c|c|c|c|c|c|}
\hline \multirow{2}{*}{$\begin{array}{l}\text { Health deviation } \\
\text { variables }\end{array}$} & \multicolumn{5}{|c|}{ Outcome variables } \\
\hline & ADL & $\begin{array}{l}\text { Aids and } \\
\text { appliances }\end{array}$ & $\begin{array}{l}\text { Relational } \\
\text { functioning }\end{array}$ & $\operatorname{Rest}^{2}$ & Loneliness \\
\hline Functional capacity & $.68^{*}$ & .19 & $.39 \#$ & -.04 & $.35^{*}$ \\
\hline Duration of RA & -.09 & -.22 & -.21 & -.22 & .07 \\
\hline Pf-complaints ${ }^{2}$ & $.47 \#$ & .28 & $.52 \#$ & -.05 & $.74^{*}$ \\
\hline Stiffness ${ }^{2}$ & $.41 \#$ & .30 & .09 & -.01 & .33 \\
\hline
\end{tabular}

${ }^{2} \mathrm{~N}=22 ; * \mathrm{p}\langle .01 ; \# \mathrm{p}\langle .05$

\subsubsection{The Impact of Health Deviation on ADL}

$\mathrm{ADL}$ is the main area in which the dependency of the RA patient becomes evident (section 5.2)(see also: Rasker, 1984; Mostert, 1987; Kruisvereniging Twente, 1988; De Witte et al., 1989). The extent to which the patient is hindered in ADL-activities is dependent on functional capacity, pf-complaints, and stiffness, but not on the duration of RA (table 6.1).

\subsubsection{Functional Capacity and ADL}

RA leads to reduced mobility. On the one hand, the disease progresses and as a consequence, the functional ability of the patient decreases. On the other hand medical treatment tries to prevent inflammation and deformity, and to maintain the ROM of the affected joint as large as possible through prescription of rest, restrictions in heavy (household) work and a daily exercise programme (Van der Korst, 1980; Grennan, 1984). As shown in table 6.1 the deterioration of functional capacity leads to an increase in the number of difficulties with ADL. Table 6.2 shows the mean number of problems with $A D L$ for the different ARA functional classes. The functionall class as measured in the first interview was taken as point of departure. (Because of small numbers, and because it is difficult to make a clear distinction between classes I and II they were taken together). As can be seen, the mean number of difficulties with $A D L$ increased from approximately 3 problems for the RA patients in ARA class I and II to 6 problems in ARA class IV.

Table 6.2: $\quad$ Mean number of difficulties with ADL for the different $A R A$ functional classes for the RA patients $(N=45)(t I+t 3)$.

\begin{tabular}{lrrr}
\hline ARA functional classes & $\mathrm{N}$ & ADL (mean) & $\% \geq 4$ difficullies \\
\hline I + II & 26 & 2.8 & 26 \\
III & 11 & 3.4 & 54 \\
IV & 8 & 6.0 & 100 \\
\hline
\end{tabular}


Not only the number of difficulties with $A D L$, but also the order in which problems with ADL occur, gives insight in the difficulties of RA patients in the different stages of the disease process. Katz (1963) hypothised (section 2.3.1) that there was an orderly regression of ADL activities in an aging population. Table 6.3 shows the order in which the ADL activities of the RA patients decreased compared to the suggested decrease by Katz. It can be seen that a different order was found than Katz did in his studies of mobility in the elderly. RA patients in this study did have problems with dressing, bathing and (sometimes) feeding in all ARA functional classes. Problems with transferring and toiletting seemed to cause problems in ARA functional classes III and did cause problems in ARA functional class IV. However, it is possible that RA patients in functional classes I, II, and III used an assistive device for toiletting, in which case, no problems were reported during the interviews.

Table 6.3: Difficulty rank-order of ADL-activities as put forward by Katz and as found in this research.

\begin{tabular}{ll}
\hline Katz & $\begin{array}{l}\text { This research } \\
(t 1+13)\end{array}$ \\
\hline bathing & dressing \\
dressing & bathing \\
toiletting & feeding \\
transferring & transferring \\
continence & - \\
feeding & toiletting \\
\hline
\end{tabular}

\subsubsection{Pf-complaints, Duration of Moming Stiffness and ADL}

Pain affects many aspects of daily living. Smith-Pigg and colleagues (1985) argued that pain can be a barrier for the patient to carry out activities of daily living, but also the performance of these activities can cause pain. Fatigue was defined by Smith Pigg et al. (1984) as a subjective complaint of weariness, exhaustion or lassitude, frequently associated with irritability, inefficiency, and a decreased capacily for work.

Table 6.4: The relation between pf-complaints, duration of morning stiffness and the mean number of difficulties performing $A D L$ for the $R A$ patient diary group $(N=22)(t I+t 3)$.

\begin{tabular}{lrrrrr} 
& \multicolumn{2}{c}{ Pf-complaints } & \multicolumn{2}{c}{ Stiffness } \\
& less & equal/higher & \multicolumn{1}{c}{ less } & equal/higher \\
& $(\mathrm{N}=9)$ & $(\mathrm{N}=9)$ & $(\mathrm{N}=9)$ & $(\mathrm{N}=9)$ \\
\hline $\mathrm{ADL}$ mean & 2.7 & 3.7 & 2.4 & 4.1 \\
$\%>4$ & 33 & 55 & 30 & 75 \\
\hline
\end{tabular}


In this analysis, the group was divided into two subgroups (less and equal/higher) using the mean pf-complaints-score and stiffness score (table 6.4). RA patients with equal/higher pain and fatigue had, on the average, 1 difficulty with $A D L$ more than patients with less pain and fatigue. The fact that some activities have to be performed, despite pain or fatigue, due to RA or its treatment, could explain the low difference in scores. The number of problems with ADL differ a great deal between RA patients with longer or shorter duration of morning stiffness. In section 5.2.1 it was seen that RA patients did experience most difficulties with dressing, bathing, eating, and getting in and out of bed. Activities which are, at least partly, considered to be morning activities. Therefore, patients who are suffering from longer-lasting morning stiffness will experience more difficulties performing these activities than patients with a shorter duration of moming stiffness.

\subsubsection{Changes in ADL and Changes in Health Deviation}

One of the research problems, as stated in chapter 3, was: Do changes concerning the problems with daily functioning occur if there are changes in the health deviation variables? In chapter 5 , the changes in the separate variables were described. Change scores between the third and first interview were calculated for all health deviation and outcome variables. The change scores in the health deviation variables could either represent the categorie: decrease, equal, or increase. In the case of difficulties with ADL-activities, three categories were differentiated:

- decreased, meaning that the score of the patient was 2 or more than 2 less in interview 3 than in interview 1;

- equal, meaning that the score of the patient was between 1 and -1 , or

- increase, meaning that the score of the patient was 2 or more than 2 higher in the interview 3 than in interview 1.

Pearson correlations were used to explore the relation between the changes in the health deviation variables and difficulties performing ADL (table 6.5). The number of difficulties performing ADL changed when the functional capacity of the RA patient improves or decreases, as well as when the duration of morning stiffness increases or decreases.

Table 6.5: Pearson correlations between the change scores of the health deviation variables and $A D L$ for the $R A$ patients $(N=45)$ and $R A$ patient diary group $(N=22)(t 3-t l)$.

Changes in: functional capacity pf-complaints ${ }^{2}$ stiffness ${ }^{2}$

ADL

RA patients

$.32 \#$

RA patients diary group

${ }^{2} \mathrm{~N}=22 ; \# \mathrm{p}$.05

Lambda's were calculated to find out if predictive associations existed between changes in health deviation and outcome variables (Everitt, 1977). The reduction in error predicting difficulties with ADL from the functional class for the RA group was $13 \%$, for pf-complaints and ADL for the RA patient diary group $14 \%$, 
and for duration of moming stiffness and ADL for the RA patient diary group $22 \%$.

Table 6.6: Changes in functional capacity and changes in difficulties with $A D L$ for the RA group $(N=45)$, and changes in stiffness and changes in difficulties with $A D L$ for the RA patient diary group $(N=22)$.

\begin{tabular}{lrrrr}
\hline $\begin{array}{l}\text { Functional } \\
\text { capacity }\end{array}$ & decrease & $\begin{array}{r}\text { Difficulties with ADL } \\
\text { equal }\end{array}$ & increase & total \\
\hline better & 2 & 5 & 0 & 7 \\
equal & 3 & 15 & 4 & 22 \\
worse & 2 & 7 & 7 & 16 \\
& & & & \\
tolal & 7 & 27 & 11 & 45 \\
\hline Stiffness & 2 & 5 & 2 & 9 \\
decrease & 0 & 4 & 5 & 9 \\
equal/increase & & & & \\
& 2 & 9 & 7 & 18 \\
total & & & &
\end{tabular}

Table 6.6 shows that patients with better functional capacity did show a decrease in the number of difficulties performing ADL, whereas patients with poorer functional capacity did have an increase in the number of difficulties performing $A D L$. The decrease in functional capacity led to an increase in difficulties with $A D L(+3.2)$ and vice versa (-3.5). The RA patients with equal functional capacity scores did show a slight increase in the number of difficulties performing ADL $(+.07)$. This result is congruent with the medical literature which states that RA patients deteriorate in time (Van der Korst, 1980; Bird et al., 1985).

Although only two patients did have a decrease in the number of problems performing $A D L$, these patients also reported a decrease in the duration of morning stiffness. An increase in the duration of morning stiffness was accompanied by an increase in the number of difficulties perofrming ADL. Possibly, patients who have longer duration of moming stiffness have more problems with moming activities like bathing, dressing, and getting in and out of bed.

In general, it can be concluded that a decrease in functional capacity or an increase in the duration of morning stiffness leads to more difficulties performing ADL.

\subsubsection{Health Deviation and Relational Functioning}

The consequences of the disease and the medical treatment can lead to acceptance problems of the patient, as well as, the environment. As can be seen in table 6.1 positive correlations were found between functional capacity, pf-complaints, and the number of problems with relational functioning. The number of problems 
with relational functioning increased in time (section 5.2.1), although in general, in absolute numbers, these problems are on a low level. It should be noted, however, that information bias may be the cause that no problems with relational functioning were mentioned during the first interview. The following analyses have to be interpreted in this light.

\subsubsection{Functional Capacity and Relational Functioning}

Actually meeting other people might prove to be a problem for the RA patient. The physical inabilities which are inherent in the case of RA, often limit the patient to go out-doors. Besides this, the unpredictability and uncertainty (Weiner, 1975) of the disease can play a role in the maintenance of relations. The acceptance of the consequences of the disease by the RA patient herself and by the persons in the immediate environment are important to relationships of the patient, especially when considering the dependency of the patient in relation to instrumental and emotional support (Rogers et al., 1982; Moskowitz \& Haug, 1986; Moulton, 1984).

Table 6.7: $\quad$ Mean number of problems with relational functioning for different ARA functional classes of the RA patients $(N=45)(t 1+t 3)$.

\begin{tabular}{lrrr}
\hline & & \multicolumn{2}{c}{ Relational Functioning } \\
ARA functional classes & $\mathrm{N}$ & mean & range \\
I + II & 26 & .3 & $0-2.5$ \\
III & 11 & .9 & $0-2.0$ \\
IV & 8 & .7 & $0-2.5$ \\
\hline
\end{tabular}

As described in section 3.2 it was not expected that functional class would have a relationship with the number of relational problems. Adjustment to a changing situation is a process which continues thoughout the disease process and is not particularly connected with the ARA functional classes. However, as shown in table 6.1, a relation between the functional capacity and the number of problems existed. The mean number of problems with relational functioning per ARA functional class in three interviews, is presented in table 6.7. RA patients in ARA functional class I and II mentioned the least number of problems with relational functioning. It is likely that RA patients in functional class II and II do not ex-m perience difficulties with the acceptance of RA because they are not or moderately limited in their functional abilities. On the other hand it can be expected that if the functional capacity of these patients deteriorates, acceptance problems will become more dominant given the increase in difficulties with relational functioning of RA patients in functional classes III and IV.

\subsubsection{Pf-complaints, Duration of Morning Stiffness and Relational Function- ing}

Erlich (1980) stated that it is not the intensity but the persistance of the pain that makes arthritis unbearable. Arthritis pain is generally low-grade, sustains over 
long periods of time, but is unpredictable, present at one time and gone at another. This may confuse the patient and those around the patient. Smith Pigg et al. (1984) argue that the extent to which pain influences the patients' mobility, body image and self-esteem can be detrimental to the interpersonal relationships. In addition to pain, fatigue influences the interpersonal relationships of the RA patient. The lack of energy experienced by the patients affects the relationships with family and friends (section 3.2). As can be seen in table 6.8, patients with low pf-complaints scores did report less problems with relational functioning than patients with high pf-complaints scores. This supports the relationship between pain, fatigue and relational functioning as found in the literature.

Table 6.8 shows that the mean number of problems with relational functioning did not differ much between the patients with low or high duration of early morning stiffness.

Table 6.8: Pf-complaints, duration of morning stiffness and the mean number of difficulties with relational functioning for the RA patient diary group $(N=22)(t I+t 3)$.

\begin{tabular}{lrrrrr}
\hline $\begin{array}{l}\text { Relational } \\
\text { functioning }\end{array}$ & \multicolumn{2}{c}{$\begin{array}{r}\text { Pf-complaints } \\
\text { high }\end{array}$} & low & $\begin{array}{r}\text { Stiffness } \\
\text { high }\end{array}$ \\
\hline RA patient & mean & .3 & .7 & .5 & .6 \\
& range & $0-2.0$ & $0-2.5$ & $0-2.0$ & $0-2.5$ \\
\hline
\end{tabular}

\subsubsection{Changes in Health Deviation and Changes in Relational Functioning}

Table 6.9 presents Pearson correlations between changes in the health deviation variables and changes in the number of problems with relational functioning between the first and third interview. As can be seen, no significant correlations were found. Comparing the correlations found for the changes between the health deviation variables and $\mathrm{ADL}$ and those found for relational functioning, it can be said that a certain resemblance exists, although the relations between health deviation variables and relational functioning are less clear. Due to the fact that no significant correlations were found no further analyses were performed.

Table 6.9: Pearson correlations between changes in health deviation and changes in the number of problems with relational functioning for the $R$ A patients $(N=45)$, and $R A$ patient diary group $(N=22)(t I-$ (3).

Relational functioning Functional capacity Pf-complaints Stiffness

\begin{tabular}{llll}
\hline RA patients & .14 & & \\
RA patients diary group & & -.24 & .11 \\
\hline
\end{tabular}




\subsubsection{Health Deviation and Loneliness}

The experienced lack of social contacts is one of the major components of loneliness as defined by De Jongh-Gierveld (1985). The limitation in daily activities due to the disease and its medical treatment can cause a lack of opportunities for the RA patient to actually meet other people. As shown in table 6.1, several significant correlations were found between health deviation and loneliness. These will be discussed in the following sections.

\subsubsection{Functional Capacity and Loneliness}

As Smith Pigg and colleagues (1984) argued, a loss of social relations can be caused if mobility is impaired, patients have less energy, deformilies exist, time required for the treatment program and controlling the health deviation process. As previously mentioned, De Jongh-Gierveld defined the experienced lack of social relations as one of the aspects of loneliness. Therefore, it was expected that patients with RA experienced feelings of loneliness is partly due to their limited functional capacity.

Table 6.10: Mean loneliness scores in four functional capacity classes for the RA patients $(N=45)(t 1+t 3)$.

\begin{tabular}{lrrr}
\hline $\begin{array}{l}\text { ARA functional } \\
\text { class }\end{array}$ & $\mathrm{N}$ & Loneliness & $\%>$ median \\
\hline I + II & 26 & mean & $(2.5)$ \\
III & 11 & 1.7 & $30 \%$ \\
IV & 8 & 3.4 & $100 \%$ \\
\hline
\end{tabular}

In table 6.10, an increase in loneliness scores for the different ARA functional classes is shown. Mean loneliness scores of RA patients in functional class I and II are low compared to the result found by Van Tilburg in a open population study (3.1). Notable, is the increase of loneliness scores between functional class I, II and III. According to the ARA classification RA patients in cllass II are "able to conduct normal activities despite handicap or discomfort or limited mobility of one or more joints", while patients in class III "are adequate to perform only few or none of the duties of usual occupation or of self care" (Steinbrocker, 1949). Patients in functional class I and II are less limited in their mobility, less restricted in their activities and not as dependent on the help of other people in their daily activities as RA patients in functional class III (and IV). It can be concluded that the extent to which a person is limited in functional capacily is related to the degree in which a person experiences feelings of loneliness. These results are comparable to the results found by Mostert (1987), who found a mean loneliness score of 4.7 , in a study done with RA patients in ARA functional classes III and IV. 
It is obvious that pain often causes difficulties in performing the activities of daily life and vice versa. However, pain can also influence mobility and can therefore be detrimental to interpersonal relationships of the RA patient. Similar conclusions can be drawn in relation to fatigue. As can be seen in table 6.11, patients who experience more pain and fatigue do have more feelings of loneliness. The hypothesis as mentioned above, is therefore, supported by the results. Although the relation between the duration of morning stiffness and feelings of loneliness is not as clear as the relation between pf-complaints and loneliness, it can be seen in table 6.11, that patients with a shorter duration of moming stiffness experienced less feelings of loneliness than patients with a longer duration of morning stiffness.

Table 6.11: Mean loneliness scores in relation to pf-complaints, and duration of morning stiffness for the RA patient diary group diaries $(N=22)(t l+t 3)$.

\begin{tabular}{lcccc}
\hline Loneliness & \multicolumn{2}{c}{ Pf-complaints } & \multicolumn{2}{c}{ Stiffness } \\
& $\begin{array}{c}\text { low } \\
(\mathrm{N}=9)\end{array}$ & $\begin{array}{c}\text { high } \\
(\mathrm{N}=9)\end{array}$ & $\begin{array}{c}\text { low } \\
(\mathrm{N}=9)\end{array}$ & $\begin{array}{c}\text { high } \\
(\mathrm{N}=9)\end{array}$ \\
\hline RA patient & & & & \\
diary group mean & 0.8 & 3.6 & 2.0 & 3.4 \\
$\%>$ median (2.5) & $0 \%$ & $44 \%$ & $30 \%$ & $37.5 \%$ \\
\hline
\end{tabular}

\subsubsection{Changes in Health Deviation and Changes in Loneliness.}

If changes in feelings of loneliness were accompanied by changes in health deviation, were tested by Pearson correlations. As can be seen in table 6.12, no significant correlations were found between loneliness and health deviation. Therefore, no further analyses were performed.

Table 6.12: Pearson correlations for changes in loneliness scores and changes in health deviation for the RA patients $(N=45)$, and the RA patient diary group $(N=22)(t 3-t 1)$.

\begin{tabular}{lccc}
\hline Loneliness & Functional capacity & Pf-complaints & Siffness \\
\hline RA patients & .09 & & \\
RA patients diary & & .11 & .00 \\
\hline
\end{tabular}




\subsection{Conclusions and Discussion}

The central question in this chapter was: What impact did health deviation have on the outcome variables, and the influence of changes in health deviation on changes in the outcome variables? Several relations were found and will be discussed per outcome variable.

Activities of Daily Living.

The number of difficulties performing ADL increased with decreasing functional capacity. RA patients in ARA functional class I and II did have approximately 3 problems, RA patients in functional class IV approximately 6 . This result is similar to the results found in other studies (Rasker, 1984; Mostert, 1987; Kruisvereniging Twente, 1988; De Witte et al., 1989). The ability to move joints is essential in the performance of ADL, therefore, a decreased functional capacity will cause a decreased ability to perform ADL-activities.

Pain, fatigue and duration of morming stiffness are symptoms of RA which may have many concequences for daily functioning. Patients with more pain and fatigue (pf-complaints), as well as patients with longer duration of morning stiffness, did have the most problems with ADL. In the case of pf-complaints the difference between patients with lower or higher than the mean score was small. Possibly, the small difference in difficulties performing ADL, can be explained by the fact that some activities have to be done despite pain or fatigue. Patients with a longer duration of moming stiffness did experience more difficulties with ADL. Looking at the kind of activities with which RA patients did have most difficulties, it can be seen that these activities were, in general, early morning activities. Patients with a longer duration of morning stiffness probably have more difficulties performing these activities than patients with a shorter duration of morning stiffness.

The duration of RA did not influence the number of difficulties performing ADL.

Changes in the number of difficulties were accompanied by changes in functional capacity and with changes in the duration of morning stiffness. A decrease in functional capacity led to an increase in the number of difficulties performing ADL. Patients with equal functional capacity did have a slight increase in the number of difficulties performing ADL and vice versa. These results are congruent with the medical literature. Shorter duration of morning stiffness meant less difficulties with $A D L$ and vice versa.

\section{Aids and Appliances.}

No relations were found between health deviation and obtaining and using aids and appliances. During the first interview all patients mentioned to already have several aids and appliances. It is, therefore, possible that only a few RA patients did enter the procedures obtaining aids or appliances, independent of health deviation.

Relational Functioning.

Although the number of problems with relational functioning was very small, decreasing functional capacity led to an increase in the number of these prob- 
llems. The majority of the RA patients mentioned acceptance of RA by themselves and their spouses in relation to problems with relational functioning. It is possible that with deteriorating functional abilities these acceptance problems become more dominant.

Next to functional capacity, the number of problems with relational functioning increased when patients experienced more pain and fatigue. Having more pain and fatigue, possibly, will force the patient to spend more time and energy on these feelings, which means that less time and energy can be given to the people in the environment. This might impede relationships with family and friends.

Changes in health deviation were not related to changes in the number of problems with relational functioning.

Rest.

No relation was found between health deviation variables and rest. It is possible that, RA patients do rest more because of their disease and because of the regimen in rest and activity as prescribed by the rheumatologist and is not dependent on functional capacity, pain, fatigue, duration of morning stiffness or the duration of the disease.

\section{Loneliness.}

Feelings of loneliness increased with an increase in ARA functional class. RA patients in functional class III and IV did have more feelings of loneliness than patients in functional classes I and II. The experienced lack of social relations is an important aspect of loneliness (De Jongh-Gierveld, 1985). Patients with limited abilities to move are often more dependent on their immediate environment and are limited in actually meeting other people. This might explain the difference in feelings of loneliness between patients in the different ARA functional classes.

Similar to the relation between loneliness and functional capacity is the relation between loneliness and pain and fatigue.

Changes in loneliness were not accompanied by changes in health deviation. 


\section{THE IMPACT OF CONTROL VARI- ABLES ON HEALTH DEVIATION AND OUTCOME VARIABLES}

\section{Introduction}

In section 2.4 it was argued that social position, attitudes and care facilities could influence activities of daily functioning, health deviation variables. Social position, attitudes, and care facilities might also influence the relation between outcome and health deviation variables in terms of being moderating, intervening or determining.

In this chapter an answer will be given to the question of the impact of control variables on the health deviation and outcome variables. Bivariate rellationships of the control variables with the health deviation variables, and outcome variables will be presented through Pearson correlations. Next, in the longitudinal analyses the influence of changes in the control variables on changes in the outcome or health deviation variables will be reported. Finally, multiple regression analyses will be used to investigate the multivariate relationship between outcome variables (dependent) and health deviation and control variables (independent).

The RA group will be subject of analysis. Results of the RA patient diary group will be presented when the results of the diaries are concemed.

\subsection{The Impact of Control on Health Deviation}

Table 7.1 gives Pearson correlations between control variables and health deviation variables ${ }^{1}$. It can be seen that several significant relations were found. No relations were found between coping behavior, almost all of personal network variables and health deviation variables. Also no relations were found between the duration of RA and the control variables, therefore, no further analysis will be performed with these variables. 
Table 7.1: Pearson correlations of the control variables and the health deviation variables for the $R A$ patients $(N=45)$ and $R A$ patient diary group $(N=22)(t 1+13)$.

\begin{tabular}{|c|c|c|c|c|}
\hline & $\begin{array}{r}\text { Functional } \\
\text { capacity }\end{array}$ & $\begin{array}{r}\text { Duration } \\
\text { of RA }\end{array}$ & $\begin{array}{r}\text { Pf- } \\
\text { mplaints }\end{array}$ & Stiffness \\
\hline Social Position and Attitudes & $(\mathrm{N}=45)$ & $(N=45)$ & $(N=22)$ & $(N=22)$ \\
\hline \multicolumn{5}{|l|}{ Meaning of RA } \\
\hline Bodily & $.52^{*}$ & -.06 & $.55^{*}$ & .26 \\
\hline Relational & $.50^{*}$ & -.01 & $.67^{*}$ & .21 \\
\hline \multicolumn{5}{|l|}{ Coping behavior } \\
\hline Action directed & -.12 & .04 & .03 & -.17 \\
\hline Seeking social support & -.07 & -.21 & .35 & .17 \\
\hline Awaiting, avoiding & -.10 & .12 & .13 & .17 \\
\hline Gender & $.27 \#$ & .22 & .34 & -.11 \\
\hline Dependent care facilities & -.09 & -.23 & -.36 & $-.56^{*}$ \\
\hline \multicolumn{5}{|l|}{ Care facilities } \\
\hline Professional help & $.40^{*}$ & -.15 & .13 & .35 \\
\hline \multicolumn{5}{|l|}{ Personal network } \\
\hline Size & -.20 & .04 & -.06 & .22 \\
\hline Density & .00 & .01 & -.38 & $-.43 \#$ \\
\hline Relatives & -.06 & -.10 & -.20 & .11 \\
\hline Non relatives & -.18 & .14 & .11 & .20 \\
\hline Instrumental support & -.12 & -.06 & .15 & .19 \\
\hline Emotional support & -.04 & -.02 & .04 & -.20 \\
\hline
\end{tabular}

* $\mathrm{p}<.01 ; \# \mathrm{p}<.05$

In the next sections the relations found between social position, attitudes, and care facilities, and functional capacity, pf-complaints and duration of moming stiffness will be discussed.

\subsubsection{Social Position, Attitudes and Health Deviation}

More meanings are attributed to RA (bodily and relational) if patients have worse functional capacity (table 7.1). Figure 7.1 shows the number of bodily and relational meanings attributed to RA in the different ARA functional classes. 
Figure 7.1: Mean number of bodily and relational meanings attributed to $R A$ in the different ARA functional classes $(n+B)$.
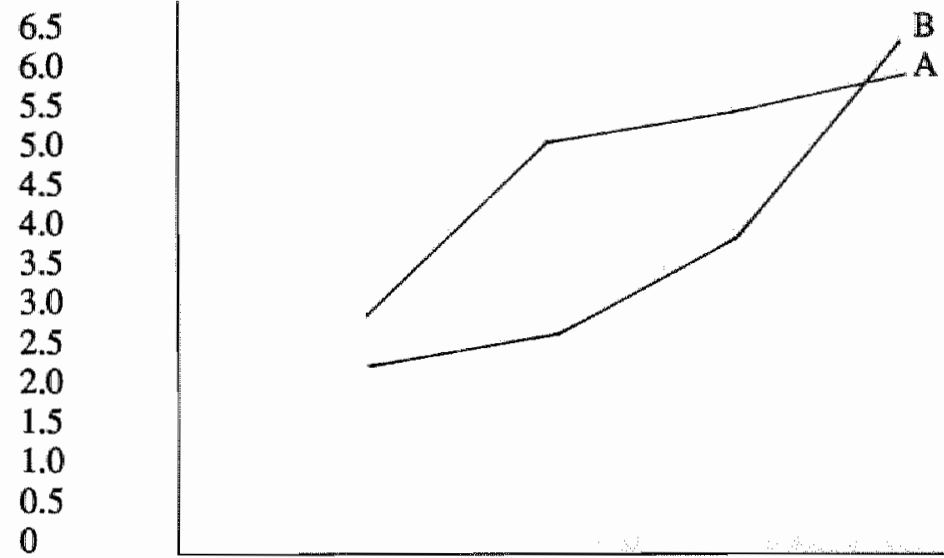

$1(\mathrm{~N}=6) \quad 2(\mathrm{~N}=24)$

ARA functional classes

It is conceivable that with decreasing functional ability RA patients are confronted with more restrictions in daily functioning, or with the symptoms of their disease and in this respect attribute more meanings to RA.

A similar relation was found between the bodily and relational meanings of RA and pf-complaints. Patients with lower than the mean pf-complaints-score (5.7) did attribute approximately four bodily, and two relational meanings to RA. Patients with equal or higher pf-complaints-score did attribute about five bodily meanings, and four relational meanings to RA. This means that patients who experience more pain and fatigue as outcome of their disease express their feelings partly through attributing more meanings to RA.

The functional ability of the female RA patients is worse than the abilities of the male RA patients (table 7.1).

Morning stiffness is mainly caused by the fact that during sleep the joints are hardly moved. In order to reduce the duration of moming stiffness RA patients are advised to do exercises and to take a hot shower or to take a bath in the morning. It is possible that patients with less dependent care facilities are less supported with these activities than patients with more dependent care facilities and therefore, have longer duration of morning stiffness. In this study, a negative relation was found between the duration of morning stiffness and dependent care facilities (table 7.1). RA patients with a spouse and/or a housemate and/or daughters (in law) living at less than $\mathbf{1 5}$ minutes travelling time do have a shorter duration of morning stiffness.

\subsubsection{Care Facilities and Health Deviation}

As could be expected, a strong positive relation was found between professional help given if problems with daily functioning exist and functional capacity. In 
case of difficulties with daily functioning, RA patients in functional class IV did receive professional help for approximately two of these difficulties, whereas patients in functional class I did not receive help from professionals for difficulties with daily functioning.

\subsubsection{Changes in Control Variables and Changes in Health Deviation}

Attention is turned now to the relation between changes in the health deviation variables and changes in the control variables. The relation between changes in the health deviation variables and personal network will not be explored because the personal network was only a part of the third interview. Therefore no information about the changes in the network are available. Table 7.2 shows that three significant relations were found. Changes in the duration of morning stiffness lead to changes in the number of bodily meanings given to RA. An increase in the duration of morning stiffness implies that patients are more hindered in their ability to perform certain activities of daily functioning which may lead to an increase in the number of bodily meanings attributed to RA and vice versa.

Changes in functional capacity are related to changes in the amount of professional help given to the RA patients.

Table 7.2: Pearson correlations between changes in the health deviation variables and changes in the control variables for the RA patients $(N=45)$ and $R A$ patient diary group $(N=22)$ $(13-11)$.

\begin{tabular}{|c|c|c|c|}
\hline & Functional capacity & $\begin{array}{l}\text { Changes in: } \\
\text { Pf-complaints }\end{array}$ & Stiffness $^{2}$ \\
\hline Gender & .05 & $.43 \#$ & -.23 \\
\hline \multicolumn{4}{|l|}{ Meaning of RA } \\
\hline bodily & .11 & .01 & $.40 \mathrm{~A}$ \\
\hline relational & .08 & -.00 & .02 \\
\hline \multicolumn{4}{|l|}{ Coping behavior } \\
\hline action directed & .08 & .13 & .05 \\
\hline seeking social support & -.06 & .15 & .11 \\
\hline awaiting, avoiding & -.10 & .21 & .11 \\
\hline Dependent care facilities & .08 & -.36 & .07 \\
\hline Professional help & $.36^{*}$ & .13 & -.17 \\
\hline
\end{tabular}


Patients with a decrease in functional abilities will probably have more difficulties with activities of daily functioning, in which case more help will have been asked from professionals.

In case of pf-complaints, male RA patients reported a decrease in the amount of pain and fatigue, which is opposite to the female RA patients who reported to have an increased amount of pain and fatigue.

Because hardly any significant correlations were found between the changes in the control variables and the changes in the health deviation variables no further analyses were performed.

\subsection{The Impact of Control Variables on Outcome Variables}

The Pearson correlations between the control variables and the outcome variables are presented in table $7.3^{2}$. In the following sections the significant relations found will be further explored.

Table 7.3: Pearson correlations of the control and outcome variables for the $R A$ patients ( $N=45)$, and $R A$ patient diary group $(N=22)(t+1+13)$.

\begin{tabular}{|c|c|c|c|c|c|}
\hline & $\mathrm{ADL}$ & $\begin{array}{l}\text { Aids and } \\
\text { appliances }\end{array}$ & $\begin{array}{l}\text { Relational } \\
\text { functioning }\end{array}$ & Rest2 & $\begin{array}{l}\text { Lone- } \\
\text { liness }\end{array}$ \\
\hline \multicolumn{6}{|l|}{ Meaning of RA: } \\
\hline . bodily & $.53^{*}$ & .03 & .22 & -.29 & .24 \\
\hline . relational & $.56^{*}$ & .17 & $.49 *$ & -.13 & $.55 *$ \\
\hline \multicolumn{6}{|l|}{ Coping behavior } \\
\hline . action directed & .00 & .10 & $-.32 *$ & .25 & -.03 \\
\hline seeking social support & -.12 & .17 & -.04 & -.00 & .02 \\
\hline . awaiting, avoiding & $-.25 \#$ & -.16 & $.25 \#$ & .02 & $.30 \#$ \\
\hline Gender & $.26 \#$ & .22 & -.03 & $-.52^{*}$ & $.30 \#$ \\
\hline \multicolumn{6}{|l|}{ Dependent care } \\
\hline facilities & $-.25 \#$ & .03 & .19 & .24 & $-.50^{*}$ \\
\hline Professional help & $.48^{*}$ & $.41^{*}$ & -.07 & -.29 & .02 \\
\hline \multicolumn{6}{|l|}{ Personal network: } \\
\hline size & $-.27 \#$ & .14 & -.15 & .07 & $-.42 *$ \\
\hline density & -.14 & $-.36^{*}$ & -.03 & .25 & $-.37 *$ \\
\hline relatives & $-.26 \#$ & .18 & -.01 & .07 & $-.48^{*}$ \\
\hline non relatives & .00 & -.16 & .01 & -.04 & -.18 \\
\hline instrumental support & $-.25 \#$ & .24 & .24 & .21 & -.09 \\
\hline emotional support & .12 & -.06 & .06 & -.06 & .19 \\
\hline
\end{tabular}

${ }^{2} \mathrm{~N}=22 ;{ }^{*} \mathrm{p}<.01 ; \# \mathrm{p}<.05$

2 Annex $X$ contains pearson correlations bet ween control and outcome variables on $t 1, t 2$ and $t 3 . t$ 


\subsubsection{Social Position, Attitudes and ADL}

Strong positive relations were found between $A D L$ and the bodily and relational meaning of RA. More difficulties performing ADL existed if more bodily and relational meanings were attached to RA. Patients who attributed less than the mean number of bodily meanings to $\mathrm{RA}(\mathrm{N}=18)$ did have approximately two difficulties performing $\mathrm{ADL}(\%>4: 22)$. RA patients with equal or more than the mean number of bodily meanings attributed to RA ( $N=27)$, did have about four difficulties performing ADL ( $\%>4: 63$ ). In the case of relational meanings attributed to RA (mean 3.6), patients with less than the mean number of meanings $(\mathrm{N}=18)$ did have about two difficulties performing $\mathrm{ADL}(\%>4: 26)$, and patients with equal or more than the mean number of meanings did have approximately four difficulties performing ADL ( $\%>4: 68$ ). This result is congruent with the relation found between functional capacity and the meaning of RA (section 7.1.1).

Patients with less than the mean 'awaiting, avoiding'-score $(\mathrm{N}=23)$ did have about four difficulties performing ADL (\% $\% 4: 56)$, whereas patients with equal or more than the mean score $(\mathrm{N}=21)$ did have approximately three difficulties performing ADL ( $\%>4: 33)$. It is probable that the existence of more ADL problems forces the patient to no longer deny or turn away from the existing problems. On the other hand, no significant correlations were found for 'action directed" or 'seeking social support". It seems that being impaired in daily functioning does not mean that patients show more 'action directed' or 'seeking social support' behavior.

Table 7.4: $\quad$ Mean number of difficulties performing $A D L$ for male and female RA patients $(N=45)(t l+13)$.

\begin{tabular}{lccc}
\hline Gender & $\mathrm{N}$ & \multicolumn{2}{c}{ Difficulties performing ADL } \\
\hline & & Mean & $\% \geq 4$ \\
\hline male & 15 & 2.7 & 27 \\
Semale & 30 & 3.8 & 57 \\
\hline
\end{tabular}

A positive relation was also found beiween gender and difficulties performing ADL. Female patients did have more difficulties performing ADL activities than male RA patients (table 7.4).

As was expected, a negative relation was found between dependent care facilities and the number of difficulties with ADL (table 7.3), meaning that if more dependent care facilities are available, less difficulties with ADL are experienced. It seems likely that, if certain ADL activities are taken care for by the spouse, or a housemate, or daughters (in law) the RA patient no longer experiences the activity as being problematic.

\subsubsection{Care Facilities and ADL.}

The assumption that more difficulties performing ADL lead to more professional help, was supported by a significant positive correlation (table 7.3). 
Table 7.5: Mean number of difficulties performing ADL for RA patients with less and equal or more persons and relatives in the personal network $(N=45)(B)$.

\begin{tabular}{|c|c|c|c|}
\hline \multirow[t]{2}{*}{ Size } & \multirow[t]{2}{*}{$\mathrm{N}$} & \multicolumn{2}{|c|}{ Difficulties performing $\mathrm{ADL}$} \\
\hline & & mean & $\% \geq 4$ \\
\hline$<$ mean & 26 & 4.4 & 69 \\
\hline$\geq$ mean & 19 & 3,1 & 42 \\
\hline \multicolumn{4}{|l|}{ Relatives } \\
\hline$<$ mean & 26 & 4.0 & 62 \\
\hline$\geq$ mean & 19 & 3.6 & 53 \\
\hline \multicolumn{4}{|c|}{ Ballance in instrumental support } \\
\hline positive & 16 & 4.6 & 69 \\
\hline equal/negative & 28 & 3.5 & 50 \\
\hline
\end{tabular}

RA patients with less than the mean size of the personal network did experience more difficulties performing ADL, than people with an equal or larger size of the network (table 7.5). This was also true for the patients with less than the mean number of relatives in the personal network (table 7.5). It is probable that, if patients do have a larger size of personal network and more relatives in the network, certain $\mathrm{ADL}$ activities are taken care of by these people. In which case, the patients no longer experience difficulties with these activities.

Finally, a negative relation was found between the balance of instrumental support and difficulties performing ADL (table 7.5). In general, there is a tendency that RA patients $(\mathrm{N}=16)$ receive more support than they give (section 5.4.5). As can be seen from table 7.5, patients with a positive balance do have more difficulties performing ADL. This means that patients who receive more instrumental support than they give, do have more problems with ADL.

\subsubsection{Care Facilities and Obtaining and Using Aids and Appliances}

A positive relation was found between obtaining and using aids and appliances and professional help (table 7.3). This supports the supposition that the help of professionals is often needed in obtaining aids and appliances, because the application for aids and appliances is complicated, long in duration and that procedures are not always clear (see section 2.3.1). On the other hand, certain characteristics of the personal network might facilitate not to use aids and appliances because certain activities of daily functioning are taken care for by people in the personal network. This supposition might be supported by the fact that patients with a high density in the personal network experience less difficulties oblaining and using aids and appliances (table 7.3). 


\subsubsection{Social Position, Attitudes and Relational Functioning}

RA patients who attribute equal or more than the mean number of relational meanings to $\mathrm{RA}(\mathrm{N}=23)$ do have more difficulties with relational functioning $(.7$, range $0-2.5$ ), than patients with less than the mean number of relational meanings attached to RA $(.3$, range $0-1.0)$

Between coping behavior and relational functioning two relations were found. A negative relation exists between action directed behavior and problems with relational functioning, while a positive relation exists between awaiting, and avoiding behavior and difficulties with relational functioning (table 7.3).

\subsubsection{Social Position, Attitudes and Rest}

Only one relation was found for the number of hours rest and control variables. A difference was found for the number of hours rest between males (mean 15.8, range $13.3-17.2$ ) and females (mean 13.9, range $11.1-16.3$ ) (table 7.3). There is a tendency that female RA patients do have less resting time than male RA patients (table 7.6). Given the traditional role differentiation between males and females it is likely that female RA patients spend more time doing household activities than male RA patients, despite their disease.

Table 7.6: Number of male and female RA patients with equal or more and less then the mean number of hours rest $(N=22)\left(t t+t^{3}\right)$.

\begin{tabular}{|c|c|c|c|}
\hline \multirow[t]{2}{*}{ Gender } & \multicolumn{3}{|c|}{ Rest } \\
\hline & $<$ mean & $\geq$ mean & total \\
\hline male & 2 & 7 & 9 \\
\hline female & 8 & 5 & 13 \\
\hline total & 10 & 12 & 22 \\
\hline
\end{tabular}

Fisher's exact $\mathrm{p}<.09$

\subsubsection{Social Position, Attitudes and Loneliness}

Loneliness was found to be related to the relational meaning of RA. Table 7.7 presents the mean loneliness score for patients with less or equal and more than the mean number of relational meanings of RA.

The mean loneliness score for the RA patients who attribute more relational meanings to RA is approximately twice as high as the mean loneliness score for the patients with less than the mean number of relational meanings attributed to RA. This result indicates that RA patients partly translate their feelings of loneliness in attributing relational meanings to their disease. 
Table 7.7: Mean loneliness-score for RA patients with less or equal and more then the mean number of relational meanings given to $R A$ $(N=45)(t l+t 3)$.

\begin{tabular}{|c|c|c|c|}
\hline \multirow{2}{*}{$\begin{array}{l}\text { Relational } \\
\text { meaning of RA }\end{array}$} & \multirow[t]{2}{*}{$\mathrm{N}$} & \multicolumn{2}{|c|}{ Loneliness } \\
\hline & & mean. & $\%>$ median \\
\hline$<$ mean & 23 & 1.7 & 17 \\
\hline$\geq$ mean & 22 & 3.5 & 54 \\
\hline
\end{tabular}

A second positive relation was found between loneliness and awaiting, and avoiding behavior (table 7.3). The mean loneliness score for patients with less than the mean avoiding, awaiting score was 2.3 (sd 2.5), the mean loneliness score for patients with equal or more than the mean awaiting, avoiding score was 2.9 (sd 3.0). This small difference is similar to that found between relational functioning and action directed behavior.

Female RA patients experience more feelings of loneliness (mean 3.1, sd 1.9) than their male counterparts (mean 1.4, sd 2.9) (table 7.5).

A strong negative relation was found between loneliness and dependent care facilities (table 7.3). Patients with more dependent care facilities do have less feelings of loneliness $(\mathrm{N}=37$, mean 1.9 , sd 2.5), than patients with no dependent care facilities $(\mathrm{N}=8$, mean 5.3 , sd 2.4).

\subsubsection{Care Facilities and Loneliness}

Negative relations were found between loneliness and size of the personal network, density of the network and the number of relatives in the network (table 7.8). In all instances patients with less than the mean size, density, and number of relatives in the personal network do experience more feelings of loneliness. An important aspect of loneliness (De Jongh-Gierveld, 1985) is the experienced lack of social contacts. In this respect, patients with a smaller size and a low density in the personal network, as well as patients with fewer relatives in the network, might experience this lack of social contacts and, therefore, have more feelings of loneliness. 
Table 7.8: Mean loneliness-scores for RA patients with less and equal or more then the mean size, density, and number of relatives in the personal nerwork $(N=45)(13)$.

\begin{tabular}{|c|c|c|c|}
\hline \multirow[t]{2}{*}{ Size } & \multirow[t]{2}{*}{$\mathbf{N}$} & \multicolumn{2}{|c|}{ Loneliness-score } \\
\hline & & mean & $q_{0}>$ median \\
\hline$<$ mean & 26 & 3.0 & 42 \\
\hline$\geq$ mean & 19 & 1.1 & 10 \\
\hline \multicolumn{4}{|l|}{ Density } \\
\hline$<$ mean & 18 & 3.4 & 44 \\
\hline$\geq$ mean & 27 & 1.4 & 18 \\
\hline \multicolumn{4}{|c|}{ Relatives } \\
\hline$<$ mean & 26 & 3.0 & 42 \\
\hline$\geq$ mean & 19 & $1 . \mathbb{1}$ & 10 \\
\hline
\end{tabular}

\subsubsection{The Relation Between Changes in Control Variables and Changes in Outcome Variables}

The question under consideration here is: Are the changes in control variables related to changes in the outcome variables? As can be seen in table 7.9, several relations were found between the control and outcome variables.

Table 7.9. $\quad$ Pearson correlations between changes in the control variables and changes in the number of difficulties with $A D L$ for the $R A$ patients $(N=45)$, and $R A$ patient diary group $(N=22)(t 3-t 1)$.

\begin{tabular}{|c|c|c|c|c|c|}
\hline Changes in: & ADL & $\begin{array}{r}\text { Aids and } \\
\text { appliances }\end{array}$ & $\begin{array}{l}\text { Relational } \\
\text { functioning }\end{array}$ & Restiton & $\begin{array}{r}\text { eline } \\
\text { Ss } \\
\end{array}$ \\
\hline \multicolumn{6}{|l|}{ Meaning of RA: } \\
\hline Bodily & .10 & .11 & .05 & .01 & .04 \\
\hline Relationall & .09 & $-.27 \#$ & -.00 & .29 & .14 \\
\hline \multicolumn{6}{|l|}{ Coping behavior: } \\
\hline Action directed & .09 & -.03 & -.15 & -.02 & .01 \\
\hline Seeking social support & .11 & $.31 \#$ & .05 & .03 & $-.33 \#$ \\
\hline A waiting, avoiding & .05 & $.29 \#$ & $-.26 \#$ & -.11 & .110 \\
\hline Gender & .04 & -.16 & -.01 & .20 & .07 \\
\hline Dependent care facilities & .11 & .08 & $.28 \#$ & -.10 & .06 \\
\hline Professional help & $.32 \#$ & $-.77^{*}$ & .04 & $.54 *$ & .19 \\
\hline
\end{tabular}

${ }^{2} \mathrm{~N}=22 ; * \mathrm{p}<.01 ; \# \mathrm{p}<.05$

A positive relation was found between changes in professional help and changes in the number of difficulties performing ADL. Table 7.10 shows that the majority of the RA patients did not have any changes in professional help. It is, however, notable that none of the RA patients did have an increase in professional help re- 
lated to a decrease in difficulties performing $\mathrm{ADL}$ and vice versa. Due to the fact that only a few patients did actualy receive professional help (see section 5.4.4), it can be concluded that not many patients called upon the help of a professional during the research period, despite changes in the number of difficulties performing $A D L$.

Table 7.10: Changes in the amount of professional help and changes in difficulties with $A D L$ for the RA patients $(N=45)(t 3-t l)$.

\begin{tabular}{lrrrr}
\hline $\begin{array}{l}\text { Changes in: } \\
\text { Professional help }\end{array}$ & $\begin{array}{r}\text { ADL } \\
\text { decrease }\end{array}$ & equal & increase & lotal \\
\hline decrease & 1 & 5 & 0 & 6 \\
equal & 6 & 21 & 8 & 35 \\
increase & 0 & 1 & 3 & 4 \\
& & & & \\
total & 7 & 27 & 11 & 45 \\
\hline
\end{tabular}

Several relations were found between the control variables and obtaining and using aids and appliances (table 7.9). It is, however, possible that significant relations were found because one or two patients did have changes in the number of difficulties obtaining and using aids and appliances. It is difficult to draw conclusions because the majority of the RA patients (39) did not show changes in the number of difficulties obtaining aids and and appliances.

RA patients rarely mentioned any difficulties with relational functioning during the first interview, and only few patients did have changes in the number of difficulties with relational functioning (two patients a decrease, six patients an increase) it is, therefore, difficult to draw any conclusions.

In the case of professional help, it can be seen that patients with a decrease in professional help showed a decrease in time spent resting and vice versa. However, the majority of patients did not show any changes concerning the amount of professional help (table 7.11).

Table 7.11: Changes professional help and changes in the number of hours rest for the RA patient diary group $(N=22)(t 3-t l)$.

\begin{tabular}{lrrr}
\hline Changes in: & \multicolumn{3}{c}{ Number of hours rest } \\
Professional help & decrease & equal/increase & total \\
\hline decrease & 2 & 0 & 2 \\
equal & 7 & 10 & 17 \\
increase & 0 & 3 & 3 \\
& & & \\
total & 9 & 13 & 22 \\
\hline
\end{tabular}

An increase in seeking social support behavior is accompanied by a decrease in loneliness. RA patients who show less seeking social support behavior did show an increase in their feelings of loneliness (table 7.9). 


\subsection{Multivariate Relations Between Health Deviation, Control, and Outcome Variables}

Finally, three stepwise multiple regression analyses were performed, with ADL, relational functioning and loneliness as the dependent variables. Not all health deviation and control variables were included in the analyses because of the small sample size (Tabachnick and Fidell, 1989).

The first multiple regression analysis concerned the RA patient group ( $N=45)$. This meant that of the health deviation variables only functional capacity was included in the analysis. Pf-complaints and the duration of morning stiffness were not part of the analysis because pf-complaints and the duration of morning stiffness are only available for the RA patient diary group $(\mathrm{N}=22)$. No relations were found between the duration of RA and the outcome variables (table 6.1), therefore, the duration of RA was not part of the analysis. Four control variables were included: relational meaning of RA, "awailing, avoiding", dependent care facillities, and size of personal network. The choice for these variables was based on the relations found between these variables and the outcome variables (table 7.3). Of the meaning of RA subscales, the relational meaning was chosen because of the high interrelation between the bodily and relational meaning of RA (.68). Professional help, for example, was not included because the amount of professional help can be viewed as a consequence of having problems with daily functioning instead of being intervening, moderating, or determining. Table 7.12 gives an overview of the stepwise multiple regression analyses.

Table 7.12: Multiple regression analysis outcome variables (bera's) $(N=45)$.

\begin{tabular}{lccr}
\hline & ADL & Relational functioning & Loneliness \\
\hline Functional capacity & $.54^{*}$ & & \\
Relational meaning of RA & $.28 \#$ & $.51^{*}$ & $.58^{*}$ \\
Awaiting, avoiding & & $.28 \#$ & $.31^{*}$ \\
Dependent care facilities & & & $-.47^{*}$ \\
Personal network: & & & \\
size & & .32 & .67 \\
$\mathrm{R}^{2}$ & .53 & .28 & .65 \\
adjusted $\mathrm{R}^{2}$ & .51 & & \\
\hline
\end{tabular}

$* \mathrm{p}<.01 ;$; $\mathrm{p}<.05$

Difficulties performing ADL are determined by functional capacity and the relational meaning of RA. More difficulties performing $A D L$ exist in the higher ARA functional classes and if the patient attributes more relational meanings to RA. Problems with relational functioning are related to the relational meaning of RA and awaiting, and avoiding behavior. Patients who attribute more relational meanings to RA and patients who show more awaiting, and avoiding behavior, do have more difficulties with relational functioning.

Feelings of loneliness are influenced by the relational meaning of RA, awaiting, and avoiding behavior, and dependent care facilities. More relational mean- 
ings attributed to RA, more awaiting, and avoiding behavior, and less dependent care facilities mean that RA patients have more feelings of loneliness.

The size of the personal network did not have a direct influence on the outcome variables. This might be explained by the fact that a negative correlation exists between network size and relational meaning of RA $(-.46, p<.01)$. In addition there is a positive relation between functional capacity and the meanings attributed to $\operatorname{RA}(.50, \mathrm{p}<.01)$.

Figure 7.2: Relations between outcome variables, health deviation and conirol variables.

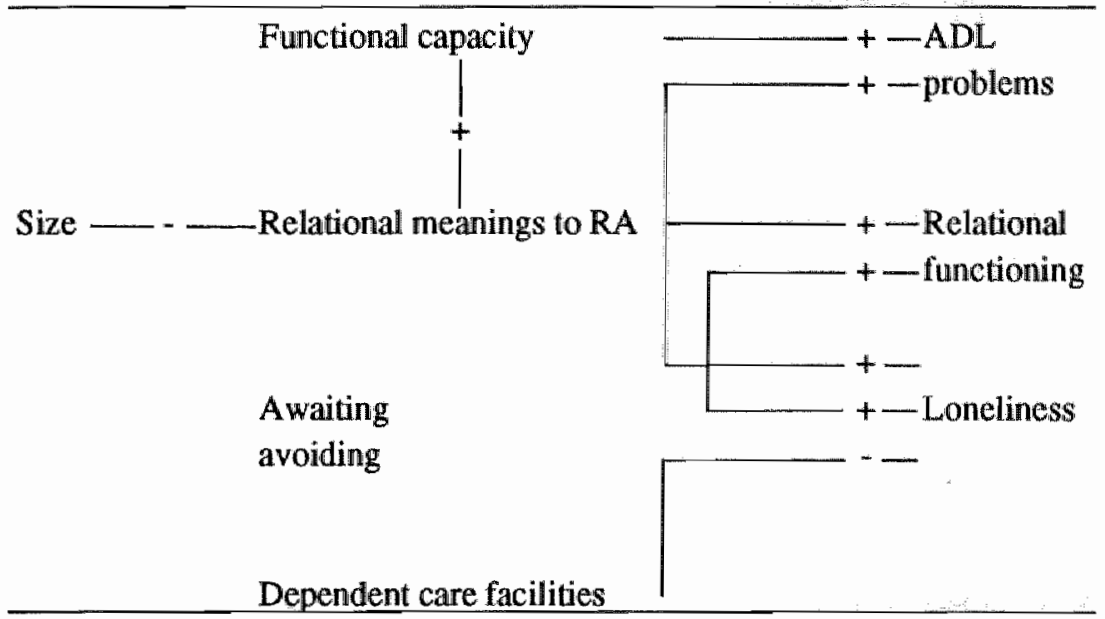

Figure 7.2 gives an overview of the relations found between health deviation, control variables and outcome variables.

In general, it can be concluded that functional capacity influences the number of difficulties with ADL. The relational meaning of RA does have an impact on $A D L$, relational functioning, as well as feelings of loneliness. Awaiting, and avoiding influences relational functioning and feelings of loneliness. Finally, dependent care facilities negatively determines feelings of loneliness.

Finally, two multiple regression analyses were performed concerning the RA patient diary group $(\mathrm{N}=22)$. Again $A D L$, relational functioning and loneliness were the dependent variables. Independent variables were pf-complaints (table 6.1), the duration of morning stiffness (table 6.1) of the health deviation variables, and relational meaning of RA, and dependent care facilities of the control variables (table 7.3). Density was not part of the analysis because of the high intercorrelation with dependent care facilities $(6.63, \mathrm{p}<.01)$.

As can be seen in table 7.13, the number of difficulties performing ADL were determined by pf-complaints. Patients experiencing more pain and fatigue, did have more difficulties performing ADL.

The number of difficulties with relational functioning are related to the relational meanings attributed to RA. Patients who have more difficulties with relational functioning do also attribute more relational meanings to RA. 
Feelings of loneliness are determined by pf-complaints and the relational meanings attributed to RA. Patients who experience more pain and fatigue and patients who attribute more relational meanings to $\mathrm{RA}$, do have more feelings of loneliness.

Table 7.13: Multiple regression analysis outcome variables (bèta's)(N=22)

\begin{tabular}{|c|c|c|c|}
\hline & ADL & Relational functioning & Loneliness \\
\hline Pf-complaints & $.47 \#$ & & $.44 t$ \\
\hline Relational meaning of RA & & $.60^{*}$ & .444 \\
\hline Dependent care facilities & & & \\
\hline $\mathrm{R}^{2}$ & .22 & .37 & .66 \\
\hline adjusted $\mathrm{R}^{2}$ & .17 & .33 & .61 \\
\hline
\end{tabular}

Table 7.14 shows that no relations were found between the dependent variables and stiffness. All dependent variables are related to a number of relational meanings attributed to RA. Finally, a relation was found between dependent care facilities and loneliness. Patients with more dependent care facilities did experience less feelings of loneliness.

Table 7.14: Multiple regression analyses outcome variables (beta' $s)(N=22)$.

\begin{tabular}{lccc}
\hline & ADL & Relational functioning & Loneliness \\
\hline Stiffness & & & \\
Relational meaning of RA & $.47 \#$ & $.60^{*}$ & $.61^{*}$ \\
Dependent care facilities & & & $-.36 \#$ \\
$\mathrm{R}^{2}$ & .22 & .36 & .61 \\
adjusted $\mathrm{R}^{2}$ & .17 & .32 & .56 \\
\hline
\end{tabular}

Figure 7.3 gives an overview of the relations found. 
Figure 7.3: Relations between outcome variables, health deviation and control variables.

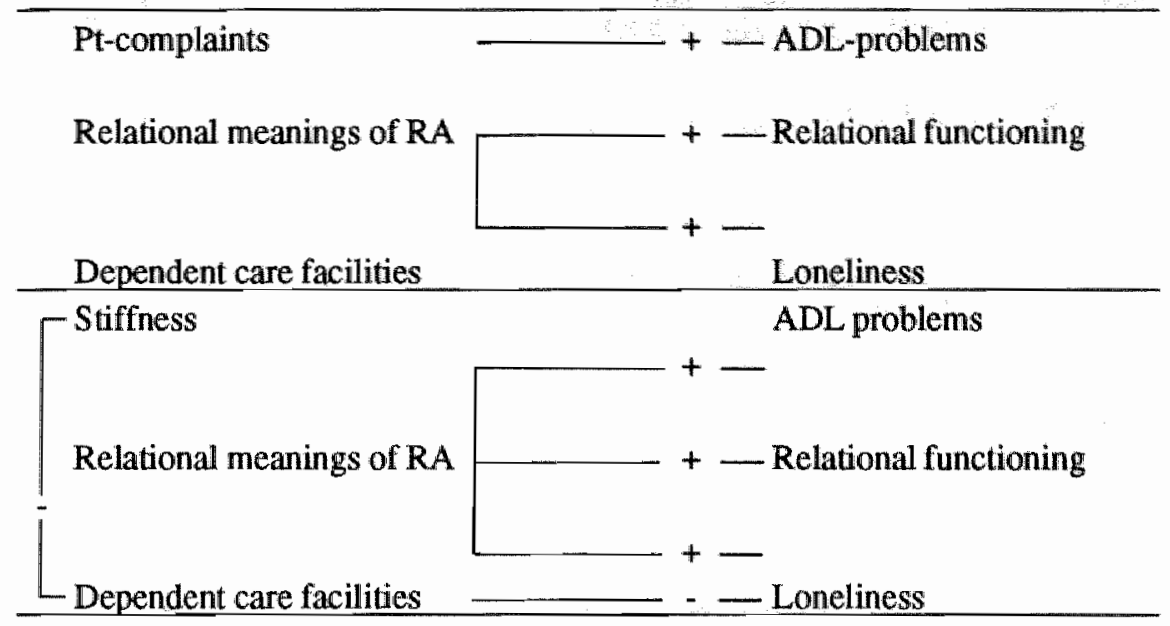

\subsection{Summary and Conclusions}

Three questions were to be answered in this chapter: the impact of the control variables on the health deviation variables, the outcome variables, and the relation between the health deviation and outcome variables.

The impact of control variables on health deviation variables was not very large. Few relations were found between the coping behavior variables, personal network variables and the health deviation variables. None of the control variables were related to the duration of RA.

Functional Capacity.

Patients who attributed more negative bodily and relational meanings to RA did have worse functional capacity. Being confronted with more restrictions in daily activities, due to a decreasing functional capacity, possibly means that RA patients attribute more meanings to their disease.

The amount of professional help given to the RA patients increased with an increase in ARA functional class. This result was expected because an increase in functional class often means that patients will have more difficulties with ADL and therefore, will need more professional help.

Pf-complaints.

Patients with more pf-complaints also attribute more meanings to RA, bodily as well as relational. This means that RA patients who have more complaints about pain and fatigue will have more negative feeling towards their disease. 
Duration of Morning Stiffness.

Patients with a longer duration of moming stiffness have less dependent care facilities and have personal networks which have less density than patients with shorter duration of morning stiffness. To reduce morning stiffness, patients are advised to exercise and to take a hot bath or shower. It is possible that patients with less dependent care facilities are less supported with these activities and, therefore, have a longer duration of moming stiffness.

Three relations were found between the changes in control variables and changes in heal th deviation variables, namely:

- more bodily meanings are attributed to RA if patients have a longer duration of morning stiffness;

- male RA patients reported a decrease in the amount of pf-complaints, opposite to female RA patients, and

- patients receive more professional help if the have worse functional capacity, and vice versa.

Different relations were found between control variables and outcome variables.

ADL.

The number of difficulties with ADL increased when RA patients attributed more (bodily and relational) meanings to their disease.

RA patients with more awaiting, avoiding behavior did report less difficulties performing ADL. It is possible that patients with more problems concerning ADL are forced to no longer turn away from these existing problems.

Female RA patients have more problems performing $\mathrm{ADL}$ than male RA patients, which may be related to traditional role-differentiations.

A negative relation between difficulties performing ADL and dependent care facilities was expected. Patients with less dependent care facilities have more problems performing ADL. It is possible that spouses, housemates or daughters (in law) take over certain ADL activities on a more regular basis, in which case patients do not experience problems with those activities.

More difficulties performing ADL did lead to more professional help.

In relation to the personal network it can be concluded that a smaller size, less relatives, and if patients receive more instrumental support than they give, they have more problems with $A D L$.

Obtaining and Using Aids and Appliances.

A positive relation was found between professional help and obtaining and using aids and appliances. This relation was expected because the procedures to obtain aids and appliances are often complicated and longlasting. The help of a professional is often needed.

A negative relation was found between the density of the personal network and obtaining and using aids and appliances. This means that RA patients of whom the persons in the network do not all know each other, experience less problems obtaining and using aids and appliances.

Relational Functioning.

RA patients who attribute more relational meanings to RA have more difficulties with relational functioning. Most problems with relational functioning, concerned 
the acceptance of the disease by the patient or the spouse. These patients also attribute more relational meanings to $\mathrm{RA}$.

Two relations were found between coping behavior and relational functioning. Patients with less action directed behavior and patients with more awaiting and/or avoiding behavior have more problems with relational functioning. More 'information seeking' behavior leads to less problems with relational functioning, while "turning away" from problems lead to more relational problems. It was concluded in section 7.2.3, that it is possible that patients experiencing more difficulties with relational functioning do spend more time and attention on these difficulties and less 'information seeking' time and energy on the disease itself.

Rest.

Only one relation was found between the control variables and rest. Female RA patients do spend less hours resting than male RA patients do. Given the traditional role differentiation, it is likely that female RA patients spend more time, for instance, performing household activities, than the male RA patients, despite their disease.

Loneliness.

More feelings of loneliness were associated with more relational meanings attributed to RA. RA patients with more than the mean loneliness score (2.6), attributed approximately twice as much relational meanings to RA than patients with less than the mean loneliness score.

Although a positive relation was found between loneliness and awaiting, avoiding behavior, the difference between patients with more and less than the mean loneliness score was small.

Female RA patients have more feelings of loneliness than male RA patients.

RA patients with less dependent care facilities, with smaller personal networks, with fewer relatives in the network, and RA patients with a lower density of the network do have more feelings of loneliness.

Although, several relations were found between changes in control variables and changes in outcome variables, only a few RA patients did show changes in control, as well as, outcome variables. Therefore, it is hard to draw conclusions from the relations found.

Finally, multiple regression analyses were performed to analyse the impact of the health deviation and control variables on the outcome variables.

It was found that RA patients do have more difficulties performing ADL if they have a poorer functional capacity and if they attribute more relational meanings to RA. Difficulties performing ADL were also influenced by pf-complaints. This means that more complaints of pain and fatigue indicates that patients have more difficulties performing ADL. Indirect relations were found between the relational meaning of RA and functional capacity and between relational meaning of RA and size of the personal network.

Patients did have more difficulties with relational functioning when they attribute more relational meanings to their disease and if they show more awaiting and avoiding behavior.

More feelings of loneliness are experienced if patients attribute more meanings to RA, have more awaiting and avoiding behavior, and if patients have less 
dependent care facilities. An indirect relation was found between having less dependent care facilities and a longer duration of morning stiffness. 


\section{SUMMARY, DISCUSSION, AND CONCLUSIONS}

\subsection{Problem Statement and Research Questions}

RA patients meet several problems in daily functioning. Health deviations are, generally, viewed as the major causes of these problems. Social position, attitudes, and care facilities, however, might also have an impact on problems with daily functioning. This thesis reports on a longitudinal cohort study in which the problems and the development of problems of the elderly RA patients living at home, with activities of daily functioning are studied. In addition, the influence of health deviation, social position, attitudes and care facilities, on the problems with daily functioning, are investigated.

RA is a chronic systemic disease, which appears most often in the joints. Pain, fatigue, stiffness, and decreased functional abilities are the major complaints of the RA patients. RA is more frequent in females than in males, and has an increased incidence and prevalence in older age groups. Medical treatment is focused on reducing inflammation and prevention of deformity. As the disease process continues, the emphasis of the treatment changes to the maintenance of muscle function and the provision of aids and appliances, as well as, physiotherapy and occupational therapy. Patients are often restricted in daily functioning which implies that patients become more dependent on the help of non-professionals and professionals.

Areas of daily functioning in which the patients are confronted with problems are, identified as, ADL, obtaining and using aids and appliances, relational functioning, rest and activity pattern, and loneliness.

Problems concerning dressing, bathing and walking stairs are the most frequently mentioned ADL problems. Eating, drinking, walking in the house, getting in and out of a bed or chair, and toiletting are less frequently mentioned. If problems with daily functioning exist, patients are advised to use aids and appliances, especially in the later stages of the disease process. Procedures to obtain aids and appliances are, however, complicated and longlasting. The help of professionals is often needed.

A third area of problems with daily functioning as indentified is relational functioning. Problems in this area concern the acceptance of the consequences of RA and its medical treatment, problems with the self, and problems with relationships.

Feelings of loneliness might be developed because when functional abilities decrease, patients are less able to meet other people, or have to spend more time on household and ADL activities, meaning that less time and energy can be spent on meeting others. 
A final area of daily functioning in which RA patients can run into problems is rest and activity. Patients are often advised to rest more, to avoid heavy (household) work, and to frequently alternate rest and activity.

As mentioned earlier health deviation is viewed as a major cause of problems with daily functioning in elderly RA patients. Decreased functional ability, pain, fatigue, the duration of moming stiffness, and the duration of RA may restrict RA patients in their activities.

In addition to health deviation factors, social position, attitudes, and care facilities are supposed to have impact on problems with daily functioning, on health deviation, and on the relation between health deviation and problems with daily functioning. Social position, and attitude factors identified in the literature, were health perception, that is, the meaning of RA to the RA patient, coping behavior, gender, and dependent care facilities. Care facility factors identified were: professional help and personal network.

The research took place in Breda, a city in the southern part of the Netherlands. The study was prepared in cooperation with the Community Nursing Association of Breda, who, prior to this study, participated in a study about the consensus between RA patients and community nurses on the community nursing care for these patients (Mostert, 1987). Only one rheumatologist is working in this area. In cooperation with the rheumatologist, working in a local hospital in Breda, 100 RA patients were approached to take part in the study. Finally, 65 RA patients, who met the inclusion criteria, participated in the study. Either through the RA patients, local Community Nursing Associations, or local organisations of elderly, fifty references were found, who were willing to participate. During the research period, ten RA patients and five references withdrew from the study. Finally, the response in the RA patient group was 55, and 45 in the reference group.

Two matching procedures took place. At the start of the study, references were matched to the RA patient group using distribution matching. After the data gathering period, RA patients were matched to the references using precision matching. Matching criteria were: age, gender, and neighborhood. Analyses were, then, conducted with $45 \mathrm{RA}$ patients and 45 references. All respondents were interviewed and asked to keep a diary about their rest and activity patterns on three separate occassions. Intervals between measurements were approximately eight months. In the case where all RA patients and references underwent three interviews, not all the respondents retumed three diaries. Twenty-nine RA patients and 25 references returned three diaries. Precision matching resulted in 22 matched pairs of RA patients and references with three interviews and three diaries.

\subsection{Outline of the Book}

Chapter 1 contains: a short introduction to the subject is given, which leads to the formulation of the problem and goals of the present study.

Chapter 2 contains: a brief outline on RA and its medical treatment and continues with a review of the literature of the problems of RA patients with daily functioning, and the factors influencing these problems. 
Chapter 3 contains: the research questions and research model and how they were formulated. This chapter ends with the discussion of some design issues.

Chapter 4 contains: the sampling of the research population, a discussion and a review of the research methods used.

Chapter 5 contains: the descriptive results, transversal and longitudinal, of the separate variables of the research model.

Chapter 6 contains: a description of the relation between health deviation and outcome variables, transversal and longitudinal.

Chapter 7 contains: a description of the relation between social position, attitudes and care facilities and health deviation and outcome variables. Finally, multivariate analyses are described regarding the influence of health deviation, social position, attitudes, and care facilities regarding the outcome variables.

The final chapter (chapter 8) contains the summary and conclusions of this study as well as methodological remarks, theonetical remarks, implications for professional practice, and recommendations for further research.

In the next sections, the results of this study will be summarized and discussed. Methodological, theoretical and practical remarks will be made.

\subsection{Conclusions}

The central hypothesis of this study was that chronic illness and its treatment have consequences for everyday life of the patient and her immediate environment. In addition, social position, attitudes and care facilities were believed to influence problems with daily functioning, health deviation, and the relation between problems with daily functioning and health deviation. Before discussing the impact of health deviation variables and control variables on the outcome variables, the problems of the elderly RA patients with daily functioning, compared to the reference group, will be discussed.

\subsubsection{Problems of Elderly RA Patients with Daily Functioning}

The majority of difficulties met by the RA patients concerned ADL. The number of difficulties increased significantly during the research period, problems also increased when compared to the reference group, who rarely mentioned any difficulties performing ADL. The most frequently mentioned problem was dressing. Other often mentioned difficulties were: bathing, eating, and getting in and out of a bed. These results are comparible to the results found by Rasker (1984), the Kruisvereniging Twente (1989), and Mostert (1987).

RA patients mentioned several problems concerning relational functioning. The majority of problems concerned acceptance of RA by the patient herself, her spouse, and sometimes her children. The reference group did not mention any problems regarding relational functioning. In general, although, the number of difficulties with relational functioning was at a very low level, few problems were mentioned during the first interview, but increased in the second and third interview. It is possible that information bias might have played a role. 
Difficulties concerning obtaining and using aids and appliances were mentioned only by a few patients. During the first interview all patients already had, several aids and appliances. Therefore, it is possible only few patients entered the procedures in order to obtain aids and appliances during the research period, did already enter the procedures, or did not have difficulties with the procedures.

A second aspect of daily functioning was the rest and activity pattern. It was found that RA patients do approximately spend four hours more resting (mean: 14.7 hours) than references (mean: 11.4 hours), and were approximately three hours less active (RA palients mean: 9.0 hours; references mean: 12.0 hours). Profile analyses on time spent for rest, activity, leisure and selfcare revealed that in all four categories RA patients" activity profiles differed from the reference profiles. RA patients spent more time resting (mean: 14.6; references: 11.7) and less time being active (mean: 8.9 hours; references 11.8), doing selfcare activities (mean: 5.3; references: 5.7), and having leisure time ( mean: 8.1; references 8.8). In the case of leisure, it was further found that RA patients spend more time at home (mean: 5.8; references 4.6), and had more passive leisure activities (mean: 4.2; references: 2.6 ) than references. This result indicates that RA patients do alter their rest and activity patterns. However, it remains unclear as to what extent the prescriptions on rest and activity given by the rheumatologist or other health care professionals, contribute to this alteration. It was found in the literature that presciptions given are often vague and confusing (Smith et al., 1987). It is also possible that RA patients alter their rest and activity pattern because of the consequences of the disease and its subsequent treatment, independent of the advice given.

A final area of daily functioning was identified as loneliness. The feelings of loneliness in the total RA patient group did not differ significantly from the reference group, or from results found by Van Tilburg (1988), and De Witte et al. (1989). During the research period, however, the feelings of loneliness decreased significantly in both groups. A possible explanation for this is that respondents were informed about the purpose of the study, they knew they were selected as patients. Possibly, respondents, unconsiously, slightly exaggerated their feelings of loneliness at the start of the study, and at the end of the study understated their feelings of loneliness.

\subsection{Transversal Analyses}

\subsubsection{Transversal Bivariate Relations}

The central relation studied was the relation between health deviation and daily functioning of elderly RA patients. Due to the high individual stability of the variables between the different measurement moments (annex VII), and because only few changes were found for the control, health deviation, and outcome variables between the first and third interview (chapter 5) the results presented refer to mean scores derived from the scores of the first and third interview.

Functional capacity, complaints of pain and fatigue, duration of morning stiffness, and the duration of RA were supposed to influence difficulties performing 
ADL, obtaining and using aids and appliances, relational functioning, rest, and feelings of loneliness. From the bivariate analyses it appeared that all health deviation variables, except the duration of RA, did influence the number of difficulties performing $A D L$, the number of problems with relational functioning, and feelings of loneliness, but not obtaining and using aids and appliances and rest.

The number of difficulties performing ADL were:

- lowest in ARA functional classes I and II and highest in ARA functional class IV;

- lowest for patients with less complaints of pain and fatigue, and

- lowest for patients experiencing a shorter duration of morning stiffness.

Smith Pigg et al. (1985) stated that pain, fatigue, stiffness, decreased endurance, and diminished strength affect the range of motion and function by limiting movement. A decreased ability to move leads to difficulties performing ADL. Several studies investigated the relation between health deviation and difficulties with ADL, with results comparable to the results found in this study (section 2.1.1).

The number of difficulties with relational functioning were:

- highest in ARA functional class III and IV;

- lowest for patients with less complaints of pain and fatigue.

In the literature, three categories of problems with relational functioning are mentioned: problems with the self, problems involving the consequences of RA and its medical treatment and problems with relationships. Problems with relational functioning, as used in this study, concerned acceptance problems. It appears that patients in the higher functional classes and patients complaining more about pain and fatigue, have more problems with the acceptance of the disease.

Finally, feelings of loneliness were:

- lowest in ARA functional classes I and II and highest in ARA functional class IV;

- lowest for patients with less complaints of pain and fatigue.

The experienced lack of social contacts is a major component of loneliness (De Jongh-Gierveld, 1985). Being more restricted in the ability to move and experiencing more pain and fatigue can disrupt social interactions, consequently, feelings of loneliness can develop.

Patients in functional classes III and IV, experienced a higher level of loneliness. This result is congruent with the results found by Mostert (1987).

In addition to health deviation and outcome variables, control variables were added to the research model. The control variables (social position and attitudes, and care facilities) were supposed to have an impact on health deviation, and outcome variables.

Three relations were found between the meaning of RA to the RA patient, health deviation and outcome variables. Patients attribute more bodily meanings to RA if they have:

- worse functionall capacity;

- more pain and fatigue complaints, and

- if they have more difficulties performing ADL.

Five relations were found concerning the relational meaning of RA, health deviation and problems with daily functioning. Patients attribute more relational meanings to RA if they have: 
- worse functional capacity:

- more pf-complaints:

- more difficulties performing ADL;

- more difficulties with rellational functioning;

- and if they have more feelings of loneliness.

It is probable that, if RA patients experience more problems with daily functioning, they will translate these problems, partly by attributing more meanings to RA.

Only a few relations were found between coping behavior, health deviation and outcome variables.

First; RA patients with more action directed behavior did have less problems with relational functioning. Action directed behavior is primarily concerned with changing the threatening situation. It is possible that, patients who have more action directed behavior were able to find a way to cope with the everyday stresses and uncertainty of RA and, therefore, have less problems with the acceptance of the disease. Viney and Westbrook (1984) found in relation to uncertainty, patients who see themselves as using action strategies were more likely to keep their uncertainty to a minimum. They also found that when patients' uncertainty is minimal, they are then able to have a preference for action strategies.

Second, patients with more awaiting, avoiding behavior did have less difficulties performing $\mathrm{ADL}$, but more difficulties with relational functioning and more feelings of loneliness.

More dependent care facilities were found in patients with:

- a shorter duration of morning stiffness;

- less difficulties performing ADL, and

- less feelings of loneliness.

Having a spouse, a housemate, and/or daughters (in law), means that the RA patient will be helped with certain activities of daily functioning. This explains why these activities are not experienced as problematic.

Female RA patients had worse functional abilities, more difficulties performing ADL, and more feelings of loneliness than their male counterparts. Male RA patients spent more hours resting than female RA patients. The difference in hours spent resting could indicate that female RA patients continue doing household activities, despite their disease. Traditional mole differentiation might play a role in this respect. If female RA patients continue doing household activities, it is possible that they strain themselves, in which case, the findings that they have a poorer functional capacity and experience increased difficulties performing ADL, becomes more comprehensible.

Additional professional help was received by RA patients with poorer functional capacity, more difficulties performing ADL and greater difficulties obtaining aids and appliances.

Finally, several negative relations were found between the personal network variables and the health deviation and outcome variables.

1 Having a smaller network size and less relatives in the network meant that patients had:

- mote difficulties performing ADL, and

- experienced greater feelings of loneliness. 
It is possible that patients have a smaller network because they ane less able to meet other people, causing feelings of loneliness. If patients have a smaller network, they also have less chance of receiving support.

2 Patients with a longer duration of morning stiffness, more difficulties obtaining aids and appliances and greater feelings of loneliness had a lower density of the personal network.

3 Finally, patients with a negative balance in instrumental support, had a higher degree of difficulty performing ADL.

RA patients who give more instrumental support than they receive from people in the personal network, had greater difficulty performing $A D L$.

\subsubsection{Transversal Multivariate Results}

Based on multiple regression analyses, it appears that several relations, as stated in the research model, can be confirmed. Functional capacity, pain and fatigue, and the relational meaning of RA are positively related to difficulties performing ADL (figure 8.1). This means that more difficulties performing ADL exist when patients:

- have poorer functional capacity;

- complain of greater pain and fatigue, and

- attribute more relational meanings to RA.

Figure 8.1: Results of multiple regression analysis: ADL problems

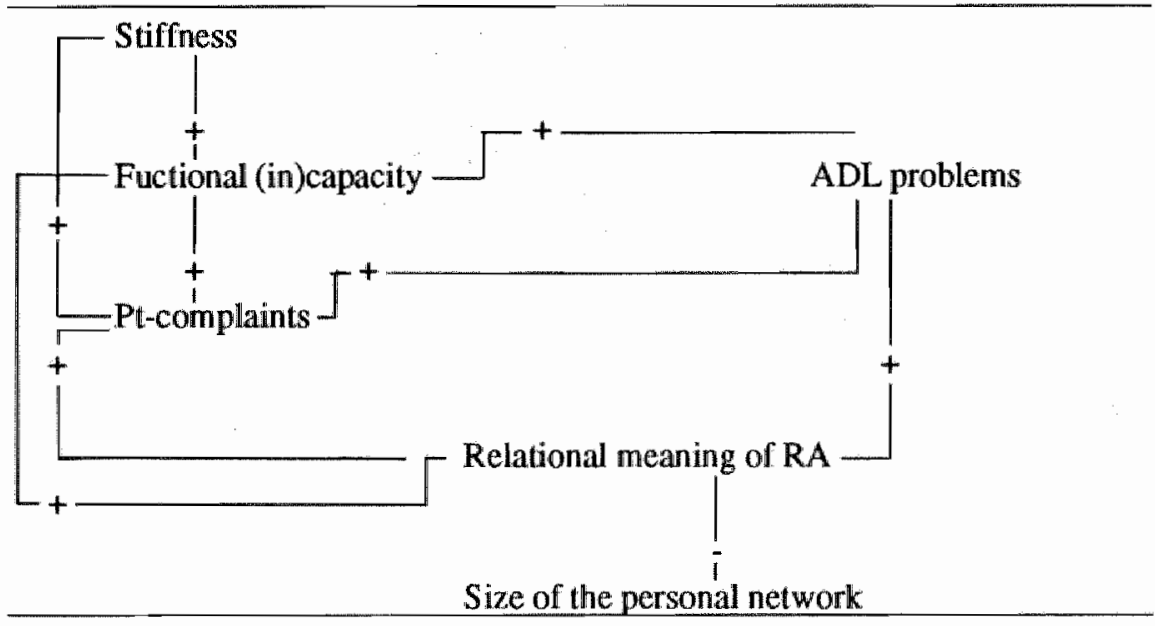

Size of the personal network was strongly related to the relational meaning of RA, therefore, an indirect relation exists between size of the personal network and difficulties performing ADL. Patients with a smaller size of the personal network, experience more difficulties performing ADL. Through the attribution of relational meanings to RA, several interrelations exist between the independent variables. A positive relation exists between functional capacity and pf-complaints, between pf-complaints and stiffness, and between functional capacity, pf- 
complaints and the relational meaning of RA. It can be concluded that health deviations (not being able to move certain joint groups and pain and fatigue complaints) cause difficulties performing $\mathrm{ADL}$, but RA patients who attribute more relational meanings to RA and (indirectly) patients with a small personal network, will also have more difficulties performing ADL.

More problems with relational functioning are related to (figure 8.2):

- attributing more relational meanings to $R A$, and

- showing more awaiting, avoiding coping behavior.

Figure 8.2: Results of multiple regression analyses: relational functioning.

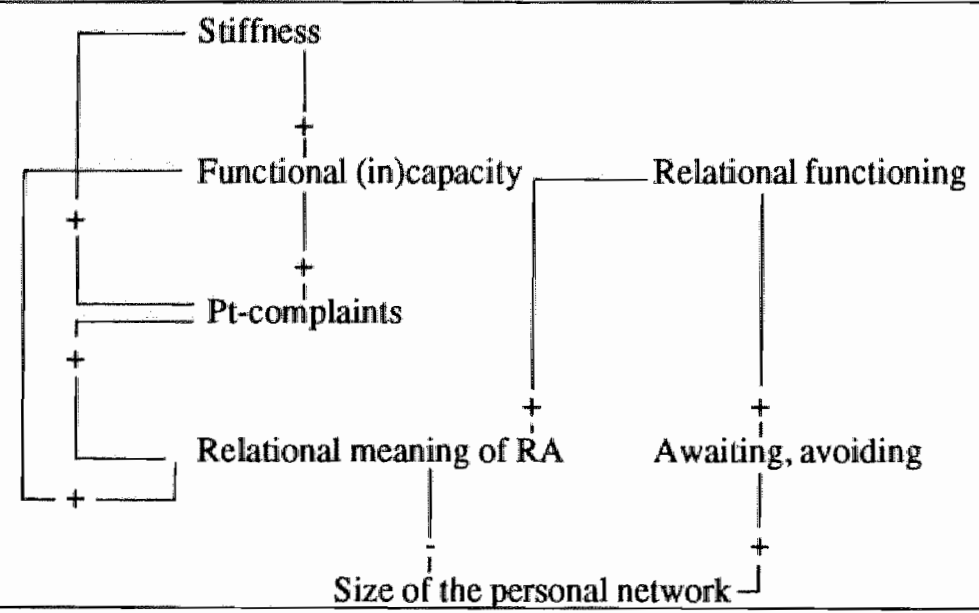

Both the relational meaning to RA and awaiting, avoiding coping behavior are negalively related to the size of the personal network. As previously mentioned, the number of problems with relational functioning were, in general, at a very low level. The majority of problems mentioned, concerned acceptance problems by the patients themselves, their spouses, and sometimes by their children. Thus, patients who have more problems with the acceptance of the disease, attribute more relational meanings to $\mathrm{RA}$, show more coping behavior directed to reduce the experience of physical and emotional stress, and have smaller personal networks. Health deviation variables, functional capacity and pf-complaints did have an indirect effect on the problems with relational functioning, through the relational meaning of RA.

Feelings of loneliness are related to (figure 8.3):

- pain and fatigue complaints;

- the relational meaning of RA;

- awaiting, avoiding coping behavior;

- and dependent care facilities.

RA patients who complain more about pain and fatigue, attribute more relational meaning to RA, have more awaiting, avoiding coping behavior, and less dependent care facilities do experience more feelings of loneliness. 
Indirect relations exist between:

- size of the personal network which is related to the relational meaning of RA and awaiting, avoiding, and loneliness, and

- functional capacity which is related to the relational meaning of $\mathbb{R A}$, and lomeliness.

Figure 8.3: Results of multiple regression analyses: loneliness

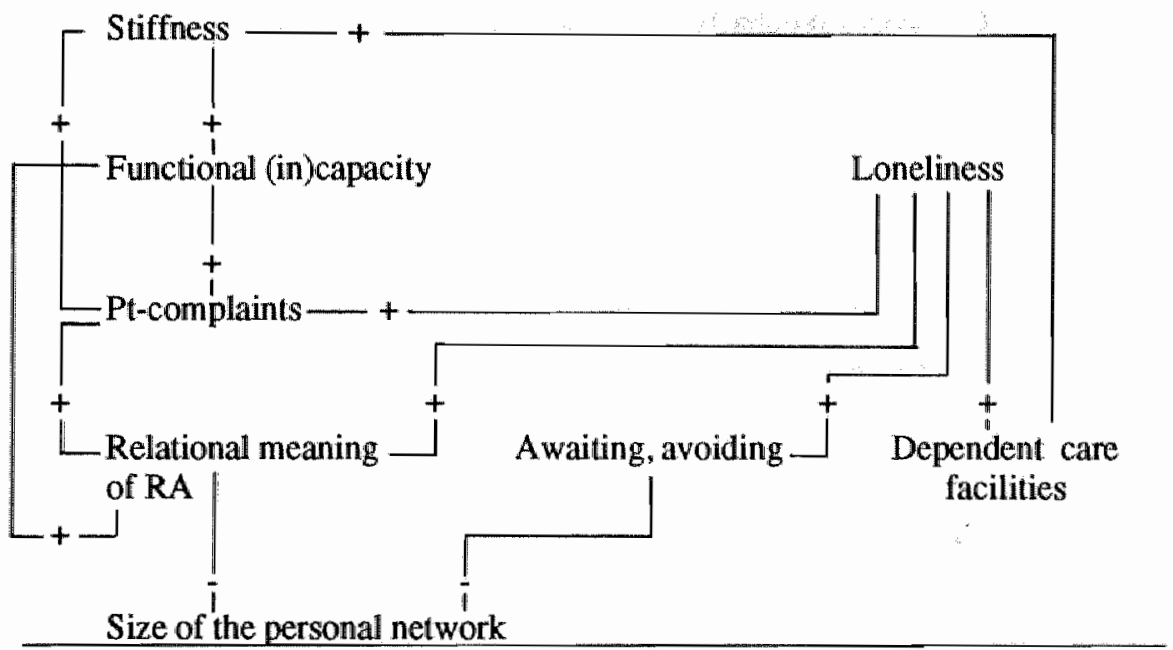

In general, it can be concluded that difficulties with daily functioning of elderly RA patients (ADL, relational functioning, and loneliness) can, in part, be explained through health deviation (functional capacity, pf-complaints, and duration of morning stiffness) and social position and attitudes (relational meaning of RA, awaiting, avoiding, and dependent care facilities).

Three relations are notable:

1 The relational meaning of RA is related to all outcome variables;

2 Indireclly related to all outcome variables is size of the personal network;

3 Dependent care facilities is related to loneliness, and to the duration of morning stiffness.

\subsubsection{Longitudinal Analyses}

Longitudinal analyses were performed to find out if changes in health deviation or in social position, attitudes and care facilities were accompanied by changes in the outcome variables. In general, it has to be noted, that the majority of RA patients did not show changes concerning outcome, health deviation or control variables. It is, therefore, difficult to draw conclusions. 
Relevant relations were (figure 8.4 ):

- Changes in functional capacity influenced the number of difficulties performing $\mathrm{ADL}$.

A decrease in functional abilities was accompanied by an increase in difficulties performing ADL. An increase in functional abilities was accompanied by a slight decrease in difficulties with ADL.

- Changes in functional capacity are related to changes in the amount of professional help.

When patients did have a decrease in functional abilities they received more professional help.

- An increase in the duration of morning stiffness was accompanied by an increase in the number of difficulties with $\mathrm{ADL}$.

\section{Figure 8.4:" Longitudinal analyses.}

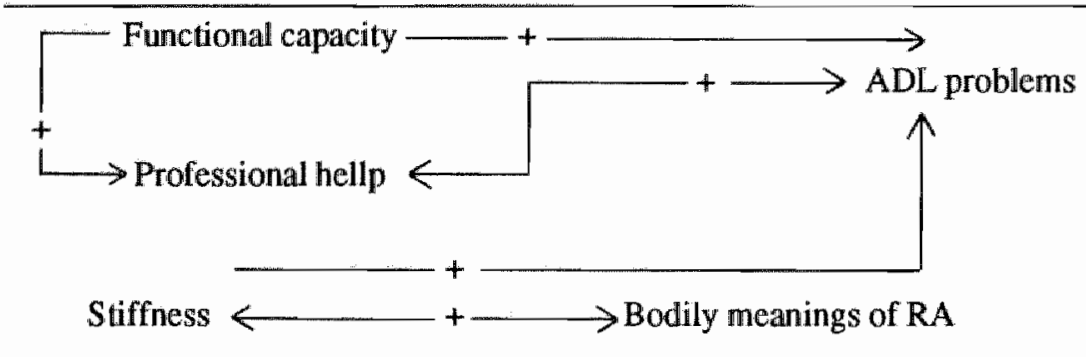

Gender $\longrightarrow+\longrightarrow$ Pt-complaints

\section{Seeking social support $\longleftarrow$}

- RA patients with an increase in the duration of moming stiffness attributed more bodily meanings to RA.

- Male RA patients reported a decrease in the amount of pain and fatigue experienced, in contrast to female RA patients who showed a decrease in pfcomplaints.

- A positive relation was found between changes in professional help and changes in the number of difficulties with ADL.

Although, only few patients did call upon the help of professionals during the research period, it was notable that none of the RA patients did have an increase in professional help related to a decrease in difficulties performing ADL.

- An increase in seeking social support was accompanied by a decrease in feelings of loneliness.

Health deviation is viewed as a predictor of outcome variables. In general, it can be concluded that the relations found between functional capacity, duration of morning stiffness and ADL problems and the relation between functional capacity and professional help are causal relations. Further, in connection to the relation between functional capacity and ADL problems, it can be concluded that RA patients with a decrease in functional capacity did show an increase in the number of difficulties performing ADL. Patients with an increase in functional capacity did, however, not always show a decrease in difficulties with ADL. 


\subsection{Methodological Comments}

This cohort study had a longitudinal character. Main advantages of this type of study are:

- the ability to shed light upon trends or changes over time (Pollit and Hungler, 1983);

- the temporal sequencing for establishing causality (Polit and Hungler, 1983);

- that relationships can be studied at various stages of the disease process, and

- that stability of relations can be examined.

In order to find trends and changes over time, the design of this study included three measurement moments. Originally, measurements were planned at six month intervals. It was, however, difficult to find references willing to participate at the start of the study. Therefore, the measurements were scheduled to be taken at approximately 8 month intervals. Not many changes were found in relation to the outcome, health deviation and control variables. Two factors might have contributed to this. First, variance in variables at the start of the study. Second, relative stability in the disease process. For example, in relation to the duration of RA and functional capacity, no relations were found in the first two measurements, although a negative relation was found at the third measurement. This might indicate that patients with a shorter duration of RA did show changes in functional capacity, while patients with a longer duration of RA were relatively stable in functional class.

Another problem, which has to be mentioned in relation to trends and changes over time, is that, because only few patients changed on the variables in the research model, it is possible that a small number could cause significant relations. Another problem appeared to be that sometimes relations were found in longitudinal analyses which were not found in transversal analyses. For example, a relation exists between changes in the relational meaning of RA and changes in the duration of morning stiffness. However, no relation was found between the relational meaning of RA and stiffness in the transversal analyses.

A second advantage of this type of reseach was identified as allowing the investigation of the direction of causality. The research model, as used in this study, contains several relations which are supposed to have "causality". Health deviation variables are, generally, viewed as predictors of the outcome variables. That is problems in daily functioning. Although these relations are found in this study, social position, attitudes and care facilities are found to influence the outcome variables, health deviation variables and the relation between health deviation and outcome variables. Social position, attitudes, and care facilities sometimes have a determining, moderating or intervening effect on the relation between health deviation and the outcome variables, which makes it more difficult to interpret causality.

A third advantage was investigating relationships at various stages of the disease process. To investigate the relationships at various stages of the disease process, was difficult because of the small sample size.

A final advantage was that stability of the relations can be examined. Measurement of the same variables at different moments in time might be preferred to the measurement at one particular point in time. Instruments, as used in this study, appeared to be relatively stable. Two factors might have influenced the sta- 
bility of the relations found. First, changes over time. Particularly in the areas of health deviation and problems with ADL, obtaining aids and appliances, and relational functioning. These were the areas that were expected to change during the research period. As mentioned earlier the majority of RA patients did not show any change concerning these variables. To find changes, the intervals between the measurement moments would have to be longer. Second, information bias. In case of the relational functioning subscale, it was found that patients hardly mentioned any problems during the first interview. The number of problems mentioned markedly increases during the second interview. Being more acquaintend with the interviewer and interviewing, probably played a role in the outcome.

Several other remarks can be made in relation to the methodology used.

Patients and references were familiar with the objective of the study. Blinding of the study could, for obvious reasons, not be accomplished. It is possible that in the first measurement, RA patients uncounsciously, exaggerate their difficulties with daily functioning, while in the third measurement they understate their problems with dailly functioning (Cook and Campbell, 1979). These phenomenon may have played a role in the finding: Feelings of loneliness decreased significantly during the research period.

The average interview time was 2.5 hours, particularly for patients suffering from a chronic disease this was long and this may have influenced concentration and, therefore, precision of the answers given. In practice, working with precoded answers, which were handed to the respondents, and alternation between openended and closed-ended questions did make it easier to complete the questionnaires.

Finally methodological remarks concerning the non-response. In section 4.4 it was mentioned that 32 of the 97 RA patients did not take part in the study. A non-response analyses was performed, which indicated that, in particular, older females did not participate in the study. It is possible that the severity of the disease played a role in their decision not to participate. In that case, it should be noted that underrepresentation of older females and patients with more severe RA is possible.

A factor which might have reduced the response rate for the RA patients, as well as, the references was the fact that respondents were not only asked to be interviewed three times but also to keep a diary of their activities over one period on three separate occassions. Less than half the respondents did actually return these diaries, despite measures to increase the response rate. Due to the fact that only 22 RA patients and references returned three diaries, the results of the analyses conceming the diaries could be biased. 


\subsection{Elaboration of the Theoretical Model}

The central relation studied in this thesis was the relation between health deviation and the daily functioning of elderly RA patients. Control factors were supposed to influence health deviation, daily functioning as well as the relation between health deviation and daily functioning. In this section, findings will be discussed in relation to the research model, as stated in chapter 3. A differentiation will be made between the ADL-like outcomes and the relational functioning-like outcomes

The causal influence of health deviation on problems with daily functioning is widely accepted. In this study, several relations were found between functional capacity, pain and fatigue complaints, the duration of morning stiffness, and ADL, relational functioning and loneliness. RA patients with poorer functional capacity, more pain and fatigue complaints, and a longer duration of moming stiffness, did have more difficulties in daily functioning. The relations found were, however, influenced by social position, attitudes, and care facilities.

Figure 8.5: Relations between ADL-like outcomes, health deviation, social position, attitudes, and care facilities.

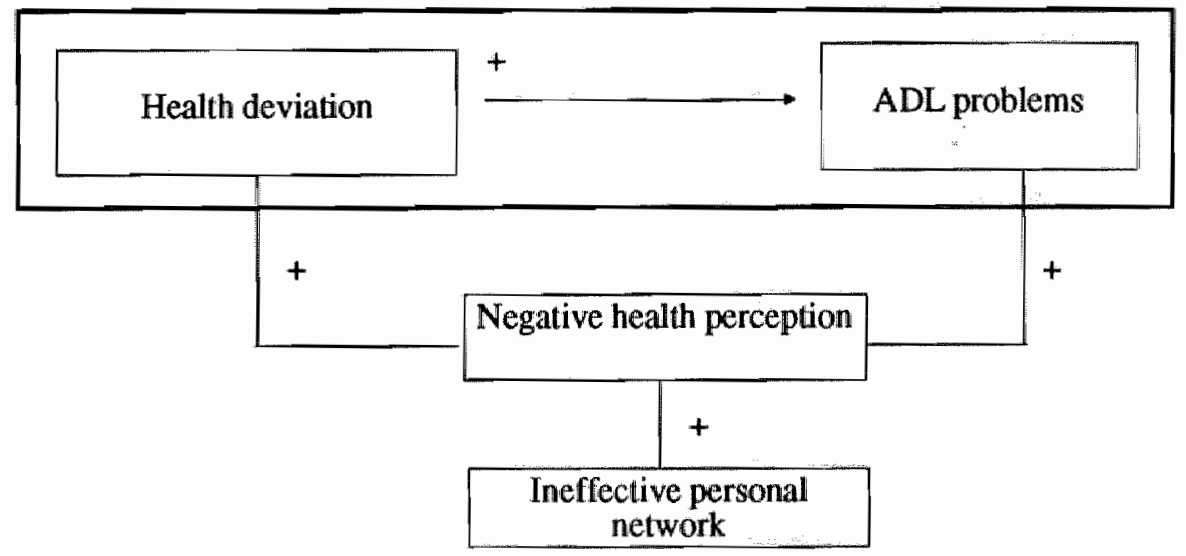

Figure 8.5 presents the relations as found between health deviation, ADL-like outcomes, social position, attitudes and care facilities. It can be seen that a direct positive relation exists between health deviation and ADL-like outcomes.

In section 2.4 .1 , it was argued that the health perception of elderly RA patients, that is, the meaning of the disease to the patients, could influence health deviation as well as the problems with daily functioning. Based on the analyses, health perception is related to both health deviation and ADL-like outcomes. Attributing more meanings to RA, means that patients have poorer functional capacity, more pf-complaints and more difficulties performing ADL. An additional relation was found in the longitudinal analyses, namely, that changes in the duration of morning stiffness were accompanied by changes in the number of meanings attributed to RA. 
More probably, health perception constitutes an additional effect which might mean that health perception is a modifier in the relation between health deviation and ADL-like outcomes.

Health perception was also related to the size of the personal network. It is possible that RA patients with more persons in the network, do have more possibilities of sharing the meaning given to RA, with other people. By sharing the meanings given to $\mathrm{RA}$, a certain reduction in these meanings, or consensus about the meaning of the disease can be reached. The personal network might, therefore, be an important background variable.

It can be concluded that:

- health deviation is related to ADL-like outcomes of RA,

- health perception influences both health deviation and ADL-like outcomes, and might be a modifier in the relation between health deviation and ADL-like outcomes,

- the personal network is directly related to health perception and indirectly related to the health deviation and ADL-like outcomes.

Health deviation also had a direct relation to relational functioning-like outcomes. Patients with more health deviations, experienced increased difficulties with relational functioning and did experience more feelings of loneliness (figure 8.6).

Figure 8.6: Relational functioning-like outcomes, health deviation, social position , attitudes and care facilities.

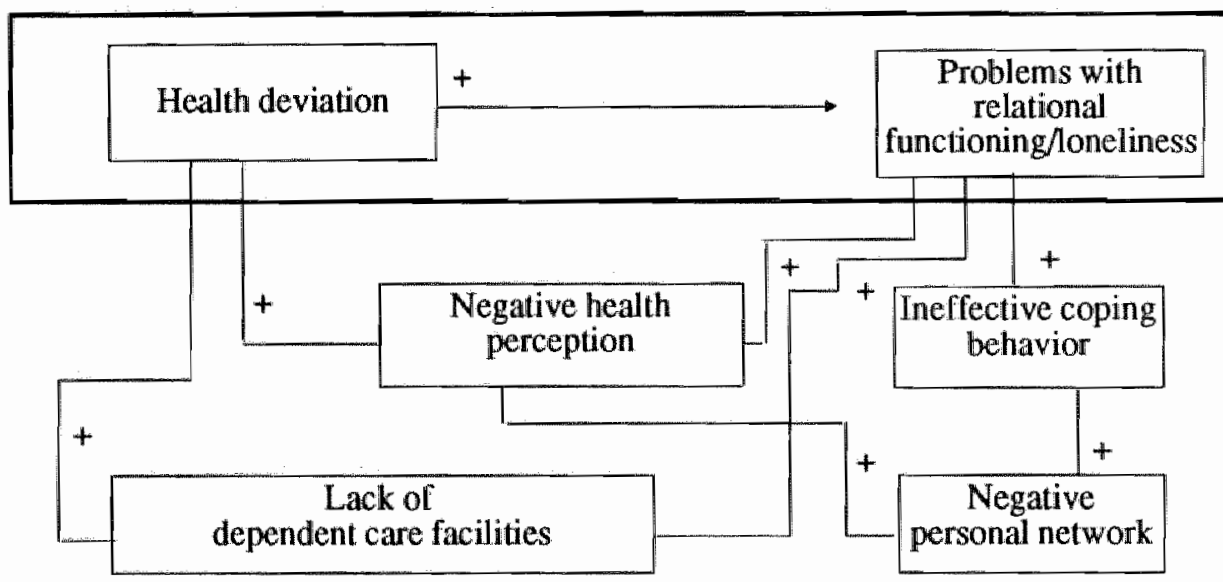

As can be seen in figure 8.6, the relation between health deviation and relational functioning-like outcomes, is influenced by social position, attitudes, and care facilities.

The relations between health perception, health deviation, and relational functioning-like outcomes is similar to the relation found between health perception, health deviation, and ADL-like outcomes. Patients who attribute more meanings to their disease, have poorer functional capacity, more pf-complaints, a 
longer duration of moming stiffness, more difficulties with relational functioning and more feelings of loneliness. Their health perception can be viewed as having a modifying effect on the relation between health deviation and relational functioning-like outcomes.

Their coping behavior is related to the relational functioning-like outcomes, but not to health deviation. A relation was found between awaiting and avoiding behavior and relational-like outcomes. This means that patients who show more behavior directed to reducing the experience of physical and emotional stress have more difficulties with relational functioning and experience more feelings of loneliness.

Both health perception and coping behavior, are negatively related to the personal network. Being able to share the meaning of RA with others might reduce the importance of certain consequences of RA and its medical treament, and may, therefore, reduce the number of meanings attributed to RA. In the case of the relation between coping behavior and personal network, it is possible that RA patients with more people in the network are, to a larger extent, forced to face the consequences of RA and its medical treatment. Having a smaller network could mean that these patients have more opportunities to turn away from these consequences.

Through health perception and coping behavior, the personal network has an indirect effect on relational functioning-like outcomes. Possibly, the personal network is an important background variable, not influencing health deviation or relational functioning-like outcomes, but strengthening this relation.

Finally, a relation was found between dependent care facilities, health deviation and relational functioning-like outcomes. Having a spouse, a housemate, or daughters (in law) means less health deviations and less difficulties with relational functioning-like outcomes. Having more people in the immediate environment enhances the possibility that patients receive more support regarding the activities of daily living or receive more advice on how to reduce morning stiffness or receive advice regarding rest in the case of pain or fatigue. In this way patients are less bothered by health deviations and have less difficulties with relational functioning-like outcomes of RA. Although, a relation was found between dependent care facilities and health deviation, and between dependent care facilities and relational functioning-like outcomes, a intervening, modifying or determining effect of dependent care facilities on the relation between health deviation and relational functioning-like outcomes was not found.

It can be concluded that:

- health perception is related to both health deviation and relational functioninglike outcomes, and might have a modifying effect in the relation between healt th deviation and relational functioning-like outcomes;

- coping behavior increases difficulties with relational functioning-like outcomes, but has no effect on health deviation;

- the personal network is an important factor, and should have a place in any theoretical model in dependency research;

- dependent care facilities reduces health deviation and difficulties with relational functioning-like outcomes. 


\subsection{Practical Considerations}

Looking at the results found in this study several implications for future research and for professional practice can be put forward.

\subsubsection{Implications for Practice}

In relation to professional care given to elderly RA patients the following suggestions can be put forward:

Eiderly RA patients experience several problems with regard to daily functioning. These problems are not only related to health deviations, but also to health perception, coping behavior, dependent care facilities and the personal network.

It was found in this study that elderly RA patients do not receive much professional help. In most instances, the people in the personal network, provide for the help needed. However, the majority of the patients do have regular contact with their rheumatologist.

1 It might, therefore, be recommendlable that meumatologists in their contact with RA patients would not only pay attention to the medical aspects, but also to the problems associated with daily functioning and thus, factors associated with these problems.

2 Another reccomandation is that rheumatologists pay more attention to the possibilities of home aid and community nursing, who

3 on their turn should provide more information to the RA patients and their care providers about the organisations who can provide care for this group.

In relation to gender, it was found that female RA patients do have less hours of rest than their male counterparts, do a have poorer functional capacity, and experience more difficulties with ADL activities. Traditional role differentiation might play a role in this. It is perhaps expected from female RA patients to continue their household activities. This could mean that they strain themselves, despite their disease, which could have an effect on their functional abilities and problems with ADL.

4 It is, therefore, important that health care providers give special attention to the problems of elderly female RA patients in relation to their rest and activity pattem.

In daily practice, professionals usually, ask their patients if they have dependent care facilities. In this study, it was found that not only dependent care facilities, but also the personal network is important in relation to health deviation and daily functioning of the elderly RA patient.

5 Professionals should, therefore, not only ask if the patient has dependent care facilities, but they should also gather information about the personal network of the patient.

6 In general, it can be stated that the care for RA patients asks for a multidisciplinairy approach. In this respect the suggestion made in the 'Memorandum on Chronic Illness Policy" (WVC, 1991) to rethink the position of the community nurse specialised in the care for patients with a rheumatic disorder can be sup- 
ported. Special attention should then be given to the provision and organisation of the professional and non-professional care for elderly RA patients.

\subsubsection{Implications for Future Research}

The results of this study are mainly descriptive in nature. Several relations, as found in this study, could be investigated separately in order to get a more precise view on the inter-relationships between the variables (i.e., the relation between health perception, health deviation and the problems with daily functioning). As mentioned earlier, meanings might be attributed to RA because of the outcomes of the disease process, and might for instance, influence the help asked by the RA patients from the personal network, as well as, from professionals. Secondly, in this study, coping behavior was studied as a phenomenon, having influence on the health deviation and outcome variables. It is, however, possible that, a patient uses different kinds of coping behavior in relation to different health deviation or outcome variables.

Dependent care facilities, as well as the personal network appeared to be important in relation to the difficulties experienced with daily functioning. More research should be done in relation to these variables and the problems experienced by elderly RA patients, concerning daily functioning. Besides this, the relation between these variables and professional help, should be further explored. For example, at what moment in their patient career do elderly RA patients call upon the help of a professional and which factors influence this decision in terms of the support received in the immediate environment.

As mentioned in section 8.5 , a negative relation was found between the duration of RA and functional capacity. Patients with a longer duration of RA were relatively stable in functional class while patients with a shorter duration of RA did experience changes in functional capacity. It might, therefore, be recommended to choose a RA patient sample which is homegeneous in relation to the duration of RA.

In this research, the activity pattern was investigated through the number of hours patients spent on their daily activities. In futher research, it might be possible to obtain more insight into the alternation between activities in order to find out to what extent the advice of the rheumatologist is integrated into every day life. Diaries are a possible method to use, although measures to increase the response rate have to be taken. The diary method is also time-consuming and expensive, therefore, other methods might be preferred. 


\section{SAMENVATTING, DISCUSSIE EN CONCLUSIES}

\section{Probleem Beschrijving en Onderzoeksvragen}

RA patienten ondervinden diverse problemen in het dagelijks functioneren. In het algemeen worden afwijkingen van de gezondheid gezien als de oorzaak van deze problemen. Echter, ook sociale positie, attitudes en zorg-faciliteiten kunnen invloed hebben op problemen met het dagelijks functioneren. In dit proefschrift wordt een onderzoek beschreven naar de problemen in het dagelijks functioneren en de ontwikkeling in deze problemen van thuiswonende ouderen met RA. Daarnaast is de invloed van bovengenoemde factoren is onderzocht.

RA is een chronische aandoening, die zich met name manifesteert in de gewrichten. De hoofdklachten zijn pijn, moeheid, stijfheid en verminderde functionele capaciteit. RA komt meer bij vrouwen voor dan bij mannen en heeft een verhoogde incidentie en prevalentie in oudere leeftijdscategorieën. De medische behandeling is gericht op het verminderen van ontstekingsprocessen en preventie van deformatie(s). In latere stadia van het ziekteproces richt de behandeling zich op behoud van de spierfunctie, het gebruik van hulpmiddelen en aanpassingen, alsmede op het aanbod van fysiotherapie en ergotherapie. De patiënten zijn in het algemeen beperkt in hun dagelijks functioneren, wat betekent dat zij afhankelijker worden van de hulp van mensen uit de omgeving of professionele hulp.

Onderdelen van het dagelijks fuctioneren waarbij patiënten problemen ondervinden werden, in de literatuur, geïdentificeerd als: $A D L$, verkrijgen en gebruiken van hulpmiddelen en aanpassingen, relationeel functioneren, het rust en activiteiten patroon en eenzaamheid (uitkomst-variabelen).

Problemen met aankleden, baden en trappen lopen zijn de meest genoemde ADL problemen. Minder frequent genoemde problemen betreffen: eten en drinken, lopen in huis, thet opstaan of gaan zitten in een stoel of gaan liggen in een bed en naar het toilet gaan. Wanneer een patiènt problemen ondervindt met het dagelijks functioneren, zeker in de latere stadia van het ziekteproces, wordt geadviseerd hulpmiddelen te gebruiken of aanpassingen aan te vragen. Procedures voor het aanvragen van hulpmiddelen en aanpassingen zijn echter langdurig en ingewikkeld. De hulp van de theumatoloog of wijkverpleegkundige is vaak noodzakelijk.

Relationeel functioneren hoort tot het terrein van het dagelijks functioneren. Problemen met betrekking tot relationeel functioneren hebben vaak te maken met de acceptatie van de consequenties van $R A$ en de medische behandeling, problemen aangaande de eigen persoon en problemen met relaties.

Gevoelens van eenzaamheid kunnen ontstaan vanwege verminderde functionele capaciteit, hierdoor kunnen patiënten minder mogelijkheden hebben anderen te ontmoeten. Vanwege de verminderde functionele capaciteit hebben zij 
meer tijd nodig voor huishoudelijke en ADL activiteiten, wat betekent dat minder tijd en energie besteed kan worden aan het ontmoeten van anderen.

Een laatste terrein waarop patiënt met problemen te maken kunnen krijgen is het rust en activiteiten patroon. Patiënten worden geadviseerd meer rust te nemen, zwaar (huishoudelijk) werk te vermijden, en rust en activiteit frequenter af te wisselen.

Zoals eerder gezegd worden afwijkingen van de gezondheid gezien als de hoofdoorzaak van problemen met het dagelijks functioneren van oudene RA patiënten. Verminderde functionele mogelijkheden, pijn, moeheid, stijfheid en de duur van de RA kunnen patiënten beperken in hun activiteiten.

Naast afwijkingen van de gezondheid, wordt verondersteld dat sociale positie, attitudes, en zorg-faciliteiten (controle variabelen) invloed hebben op het dagelijks functioneren, op afwijkingen van de gezondheid en op de relatie tussen afwijkingen van de gezondheid en problemen met het dagelijks functioneren. Sociale positie en attitude factoren die in de literatuur werden geidentificeerd, waren: gezondheidsopvattingen, dat wil zeggen de betekenis van RA voor de RA patiënt, coping gedrag, geslacht en mogelijkheden voor mantelzorg. Zorg-faciliteiten werden geìdentificeerd als: professionele hulp en persoonlijk netwerk.

Het onderzoek heeft plaatsgevonden in Breda, een stad in het zuiden van Nederland. Er is samengewerkt met de Kruisvereniging Breda, die eerder participeerde in een onderzoek naar de (on)vervulde behoeften aan hulp bij RA patiënten in wijkverpleegkundige zorg (Mostert, 1987). In de regio Breda is éen rheumatoloog werkzaam. In samenwerking met deze rheumatoloog, werkzaam in een van de locale ziekenhuizen te Breda, werden $100 \mathrm{RA}$ patienten benaderd voor deelname aan het onderzoek. Uiteindelijk stemden 65 van deze patiënten, die voldeden aan de inclusie criteria, toe. Hetzij via de RA patiènten, via locale kruisverenigingen, of locale ouderen organisaties werden 50 referenten bereid gevonden deel te nemen aan het onderzoek. Gedurende het onderzoek trokken tien RA patiënten en vijf referenten zich terug. De uiteindelijke respons in de RA patiënten groep kwam hierdoor op 55 en 45 in de referentengroep.

Twee matching procedures vonden plaats. Door middel van distributie matching werden, bij de aanvang van het onderzoek, referenten gekoppeld aan RA patiënten. Na de data verzameling werden de RA patiènten gekoppeld aan de referenten door middel van precisie matching. De matching criteria waren in beide gevallen leeftijd, geslacht en woonomgeving. In de analyses werden uiteindelijk 45 RA patiënten en 45 referenten betrokken. Alle respondenten werden drie maal geinterviewd en gevraagd aansluitend aan het interview een dagboek bij te houden over hun rust en activiteiten patroon gedurenden 1 week. De periodes tussen de interviews bedroegen ongeveer acht maanden. Alle respondenten werden drie keer geînterviewd, maar niet alle respondenten retoumeerden drie dagboeken. Van 29 RA patiènlen en 25 referenten werden drie dagboeken ontvangen. Precisie matching resulteerde in 22 gematchte paren van RA patiènten en referenten met drie dagboeken en drie interviews. 


\section{Opzet van het Boek}

Hoofdstuk 1 bevat: een korte introductie van het onderwerp, leidend tot de formulering van het probleem en de doelstellingen van deze studie.

Hoofdstuk 2 bevat: een korte inleiding over RA en de medische behandeling en vervolgt dan met een beschrijving van de literatuur over de problemen van ouderen met RA in het dagelijks functioneren en de factoren die deze problemen beinvloeden.

Hoofdstuk 3 bevat: de onderzoeksvragen en het onderzoeksmodel. Dit hoofdstuk eindigt met een discussie over enkele onderwerpen aangaande het design van deze studie.

Hoofdstuk 4 bevat: een beschrijving van de onderzoekspopulatie en de gebruikte onderzoeksmethoden.

Hoofdstuk 5 bevat: de descriptieve resultaten, transversaal en longitudinaal, van de verschillende variabelen van het onderzoeksmodel.

Hoofdstuk 6 bevat: een beschrijving van de relatie tussen afwijkingen van de gezondheid en problemen met het dagelijks functioneren.

De relatie tussen sociale positie, attitudes, zorg-faciliteiten en afwijkingen van de gezondheid en problemen met het dagelijks functioneren is onderwerp van hoofdstuk 7. Ook in hoofdstuk 7 worden multivariate analyses beschreven met betrekking tot de relatie tussen sociale positie, attitudes, zorg-faciliteiten, afwijkingen van de gezondheid en problemen met het dagelijks functioneren.

Het laatste hoofdstuk (hoofdstuk 8) bevat een samenvatting en de conclusies van dit onderzoek, alsmede methodologisch commentaar, theoretische opmerkingen, aanbevelingen voor de professionele praktijk en aanbevelingen voor verder onderzoek.

In de volgende paragrafen zullen de resultaten van dit onderzoek worden samengevat en bediscussiëerd. Methodologisch en theoretisch commentaar wordt gegeven en aanbevelingen worden gedaan.

\section{Conclusies}

De centrale hypothese van dit onderzoek was dat een chronische ziekte en haar medische behandeling consequenties heeft voor het dagelijks leven van de patiènt en haar omgeving. Daarnaast werden sociale positie, attitudes en zorg-faciliteiten gezien als factoren die invloed hebben op problemen met het dagelijks functioneren, afwijkingen van de gezondheid en de relatie tussen problemen met het dagelijks functioneren en afwijkingen van de gezondheid. Voorafgaand aan de discussie over de invloed van afwijkingen van de gezondheid en controle variabelen op de uitkomst variabelen, zullen de problemen van oudere RA patiënten met het dagelijks functioneren, vergeleken met de referentiegroep bediscussiëerd worden. 


\section{Problemen van Oudere RA Patiënten met het Dagelijks Func- tioneren}

De meerderheid van problemen die RA patiènten ondervinden betreffen ADL (gemiddeld 3.3). Er was een significante toename van het aantal problemen gedurende de onderzoeksperiode. Ook vergeleken met de referentie groep nam het aantal problemen toe. De referentie groep noemde nauwelijks problemen met betrekking tot ADL (gemiddeld 0.1). Het meest genoemde ADL probleem betrof aankleden (gemiddeld: 30 ), andere vaak genoemde problemen waren baden (gemiddeld: 24), eten (gemiddeld: 23), en in/uit bed stappen (gemiddeld: 20). Deze resultaten zijn vergelijkbaar met resultaten gevonden door Rasker (1984), de knuisvereniging Twente (1989) en Mostert (1987).

RA patiënten benoemden diverse problemen met betrekking tot relationeel functioneren (gemiddeld 0.6). De meerderheid van deze problemen had te maken met de acceptatie van de ziekte door de patiënt zelf, door de partner en soms door de kinderen. De referentiegroep noemde geen enkel probleem met betrekking tot relationeel functioneren. Opgemerkt dient te worden dat patiènten slechts weinig problemen met relationeel functioneren aangaven. Bijna geen problemen werden genoemd in het eerste interview, in tegenstelling tot het tweede en derde interview waarin meer problemen genoemd werden. Het is mogelijk dat informatie bias hierbij een rol gespeeld heeft.

Problemen met betrekking tot het aanvragen en gebruiken van hulpmiddelen en aanpassingen werden door slechts enkele patiënten genoemd (gemiddeld: 0.3 ). Gedurende het eerste interview bleek dat alle patiënten al verscheidene hulpmiddelen en aanpassingen in huis hadden. Het is daarom mogelijk dat slechts enkele patiënten de procedures voor het verkrijgen van hulpmiddelen en aanpassingen startte gedurende het onderzoek, of zij zaten reeds in deze procedure, danwel ondervonden geen problemen met de procedures.

Een tweede aspect van het dagelijk functioneren was het rust en activiteiten patroon. RA patiënten rusten ongeveer 4 uur meer per dag (gemiddeld: 14.7 uur) dan referenten (gemiddeld: 11.4 uur), en waren gemiddeld 3 uur minder actief (RA patiẽnten gemiddeld: 9.0 uur; referenten: 12 uur). Profiel analyses over de tijd besteed aan rust, activiteit, vrije tijd en zelfzorg gaven te zien dat de activiteiten patronen van de RA patiënten in alle 4 categorièen afweken van de profielen van de referenten. RA patiënten spendeerden meer tijd aan rust (gemiddeld: 14.6 uur; referenten: 11.7 uur), waren minder actief (gemiddeld: 8.9 uur; referenten: 11.8 uur), besteden minder tijd aan zelfzorg activiteiten (gemiddeld: 5.3 uur; referenten: 5.7 uur), en minder tijd aan vrije tijd (gemiddeld 8.1 uur; referenten: 8.8 uur). In geval van vrijetijds besteding werd gevonden dat RA patiënten meer lijd besteden aan activiteiten in huis (gemiddeld: 5.8 uur; referenten: 4.6 uur), en aan passieve vrije tijd activiteiten (gemiddeld 4.2 uur; referenten: 2.6 uur). Dit resultaat impliceert dat RA patiënten hun rust en activiteiten patroon aanpassen. Het blijft echter onduidelijk in welke mate de adviezen van de theumatoloog en eventuele andere gezondheidswerkers bijdragen aan deze aanpassingen. In de literatuur werd gevonden dat de voorschriften op het gebied van rust en activiteit vaak vaag en verwarrend zijn (Smith e.a., 1987). Het is ook mogelijk dat RA patiënten hun rust en activiteiten patroon aanpassen vanwege de consequenties van de ziekte en de medische behandeling, onafhankelijk van de gegeven adviezen. 
Een laatste onderdeel van het dagelijks functioneren betrof eenzaamheid. De gevoelens wan eenzaamheid in de RA patiënten populatie week niet af van die in de referentengroep (RA patiènten gemiddeld: 2.5 ; referenten: 2.1 ), of van de resultaten gevonden door Van Tilburg (1988) en De Witte e.a. (1989). Echter, gedurende de onderzoeksperiode werd een significante daling van de gevoelens van eenzaamheid geconstateerd. Een mogelijke verklaring hiervoor is dat de respondenten op de hoogte waren van het doel van het onderzoek, de patiënten werden daarbij aangesproken op hun patiènt-zijn. Mogelijk hebben respondenten, onbewust, hun gevoellens van eenzaamheid gedurende het eerste interview enigszins overdreven, terwijl zij in het derde interview een onderrapportage gaven.

\section{Transversale Analyses}

\section{Transversale Bivariate Analyses}

De centrale relatie bestudeerd in dit onderzoek was die tussen afwijkingen van de gezondheid en het dagelijks functioneren van oudere RA patiënten. Vanwege de hoge individuele stabiliteit van de variabelen tussen de verschillende meetmomenten (annex VII), en vanwege het feit dat slechts kleine veranderingen werden gevonden voor de controle variabelen, afwijkingen van de gezondheid en uitkomstvariabelen (hoofdstuk 5), refereren de hier gevonden resultaten aan gemiddelde scores van het eerste en derde meetmoment. Functionele capaciteit, klachten ten aanzien van pijn en moeheid (pm-klachten), duur van de ochtendstijfheid en duur van RA werden verondersteld de problemen met ADL, het verkrijgen van hulpmiddelen en aanpassingen, relationeel functioneren, rust en gevoelens van eenzaamheid te beïnvloeden. Uit de bivariate analyses bleek dat alle 'afwijkingen van de gezondheid'-variabelen, behalve de duur van de RA, invloed hadden op de hoeveellieid problemen met ADL, relalioneel functioneren en de gevoelens van eenzaamheid, maar niet op het aanvragen en gebruiken van hulpmiddelen en aanpassingen en rust.

Problemen met ADL waren:

- het laagst in ARA functionele klassen I en II en het hoogst in functionele klasse IV;

- het laagst bij patiẻnten met minder klachten op het gebied van pijn en moeheid, en

- het laagst voor patiènten met een kortere duur van de ochtendstijfheid.

Smith Pigg e.a. (1985) stelden dat pijn, moeheid, stijfheid, verminderd uithoudingsvermogen, en verminderde kracht de range of motion (ROM) en functie beïnvloeden door beperking van bewegingsmogelijkheden. Een verminderde mogelijkheid tot bewegen leidt tot problemen bij het uitwoeren van ADL. Diverse studies onderzochten de relatie tussen afwijkingen van de gezondheid en problemen met ADL, de resultaten van deze studies zijn vergelijkbaar met de resultaten die in dit onderzoek werden gevonden (par. 2.1.1.). 
Problemen met relationeel functioneren waren:

- hoger in ARA functionele klassen III en IV;

- lager voor patiënten met minder klachten over pijn en moeheid.

In de literatuur worden drie calegorièen van problemen met relationeel functioneren genoemd: problemen met de persoon, problemen met betrekking tot de consequenties van RA en de medische behandeling en problemen met relaties. Problemen met betrekking tot relationeel functioneren zoals gebruikt in dit onderzoek betroffen met name acceptatieproblemen. Hel bleek dat patiènten in de hogere ARA functionele klassen en patiënten met meer pijn- en moeheidsklachten meer problemen hadden met de acceptatie van de ziekte.

Als laatste, gevoelens van eenzaamheid waren:

- minder in ARA functionele klassen I en II en het hoogst in ARA functionele klasse IV;

- minder bij patiënten met minder klachten op het gebied van pijn en moeheid.

Het ervaren gebrek aan sociale contacten is een belangrijke component van eenzaamheid (De Jongh-Gierveld, 1985). Meer beperkt zijn in de mogelijkheden tot bewegen en meer pijn en moeheid kunnen sociale interacties verstoren, waardoor gevoelens van eenzaamheid kunnen ontstaan.

Patiënten in ARA functionele klassen III en IV ondervonden de meeste gevoelens van eenzaamheid. Dit resultaat stemt overeen met resultaten gevonden door Mostert (1987).

In aanvulling op afwijkingen van de gezondheid en uitkomst variabelen werden controle variabelen aan het onderzoeksmodel toegevoegd. De controle variabelen (sociale positie, attitudes en zorg-faciliteiten) werden verondersteld afwijkingen van de gezondheid en uitkomst variabelen te beïnvloeden.

Drie relaties werden gevonden tussen de betekenis van RA voor de patiënt, afwijkingen van de gezondheid en uitkomst variabelen. Patiënten kenden meer lichamelijke betekenissen aan RA toe, wanneer zij:

- een slechtere functionele capaciteit hadden;

- meer pijn en moeheid ondervonden, en

- meer problemen hadden met ADL.

Vijf relaties werden gevonden met betrekking tot de relationele betekenis van RA, afwijkingen van de gezondheid en problemen met dagelijks functioneren. Patiènten kenden meer relationele betekenissen aan hun ziekte toe, wanneer zij:

- een slechtere functionele capaciteit hadden;

- meer pijn en moeheid ondervonden;

- meer problemen hadden met ADL;

- meer problemen hadden met relationeel functioneren, en

- meer gevoelens van eenzaamheid hadden.

Het lijkt waarschijnlijk dat patiënten die meer problemen ondervinden met het dagelijks functioneren, deze problemen gedeeltelijk vertalen door meer betekenissen aan de ziekte toe te kenmen.

Slechts enkele relaties werden gevonden tussen coping gedrag, afwijkingen van de gezondheid en de uitkomstvariabelen.

Allereerst, RA patiènten die meer actiegericht gedrag vertoonden hadden minder problemen met relationeel functioneren. Actiegericht gedrag is voornamelijk gericht op het aambrengen van veranderingen in een bedreigende situatie. Het is mogelijk dat patiènten die meer actiegericht gedrag vertonen hiermee een 
wijze gevonden hebben om te gaan met de stress van alledag en met de onzekerheid die gepaard gaat met RA en dat zij daarom minder problemen hebben met de acceptatie van de ziekte. Viney en Westbrook (1984) vonden in relatie tot onzekerheid dat patienten die zichzelf zien als gebruikers van actiestrategiëen hun onzekerheid beter op een voor hen aanvaardbaar niveau konden houden. Tevens vonden zij dat patiènten die een minimaal niveau van onzekerheid hadden een grotere voorkeur hadden yoor actiestrategièen.

Op de tweede plaats: patiënten met meer afwachtend, vermijdgedrag hadden minder problemen met $\mathrm{ADL}$, maar meer problemen met relationeel functioneren en meer gevoelens van eenzaamheid.

Meer mogelijkheden voor mantelzorg werden gevonden bij patiënten met:

- een kortere duur wan de ochtend stijfheid;

- minder problemen met ADL, en

- minder gevoelens van cenzaamheid.

Het hebben van een partner, iemand die in huis woont, of (schoon)dochters betekent dat de RA patiënt waarschijnlijk geholpen wordt met bepaalde dagelijkse activiteiten. Dit verklaart waarom deze activiteiten niet als problematisch ervaren worden.

Vrouwelijke RA patiënten hadden een slechtere functionele capaciteit, meer problemen met $\mathrm{ADL}$, en meer gevoelens wan eenzaamheid dan hun mannelijke tegenhangers. Mannelijke RA patiënten rusten meer dan vrouwelijke RA patiënten. Het verschil in uren besteed aan rust impliceert dat vrouwelijke RA patiënten hun huishoudelijke activiteiten voortzetten, ondanks hun ziekte. Traditionele rolpatronen zouden in dit opzicht een rol kunnen spelen. Wanneer vrouwelijke RA patiênten hun huishoudelijke activiteiten continueren is het mogelijk dat zij zichzelf overbelasten. In dat geval is het begrijpelijk dat zij een slechtere functionele capaciteit en meer problemen met ADL hebben.

Patiënten met een slechtere functionele capaciteit krijgen meer professionele hulp. Dit geldt ook voor patiënten met meer problemen met ADL en meer problemen met het verkrijgen en gebruiken van hulpmiddelen en aanpassingen.

Als laatste werden diverse negatieve relaties gevonden tussen het persoonlijk netwerk, afwijkingen van de gezondheid en de uitkomst wariabelen.

1 Een kleinere omvang van het netwerk en minder verwanten in thet netwerk betekende dat deze patienten:

- meer problemen hadden met ADL, en

- meer gevoelens van eenzaamheid ondervonden.

Het is mogelijk dat RA patiënten een kleiner persoonlijk netwerk hebben omdat zij minder in staat zijn andere mensen te ontmoeten, waardoor meer gevoelens van eenzaamheid ontstaan.

2 Patiènten met een langere duur van de ochtendstijfheid en meer problemen met het verkrijgen en gebruiken van hulpmiddelen en aanpassingen hadden een lagere dichtheid van het netwerk.

3 Als laatste, patiënten met een negatieve balans in instrumentele hulp hebben meer problemen met $\mathrm{ADL}$.

RA patienten die meer instrumentele hulp gaven dan ontvingen dan personen in het netwerk hadden meer problemen met de uitvoering van ADL-handelingen. 


\section{Transversale Multivariate Resultaten}

Uit multiple regressie analyses blijkt dat diverse relaties binnen het onderzoeksmodel bevestigd kunnen worden. Functionele capaciteit, pijn- en moeheidsklachten en de relationele betekenis van de ziekte zijn positief gerelateerd aan de problemen met ADL (figuur 1). Dit betekent dat meer problemen met ADL bestaan wanneer patiënten:

- een slechtere functionele capaciteit hebben;

- meer klachten over pijn en moeheid;

- meer relationele betekenissen aan RA toekennen.

Figuur 1: Resultaten van multiple regressie analyse: $A D L$-problemen

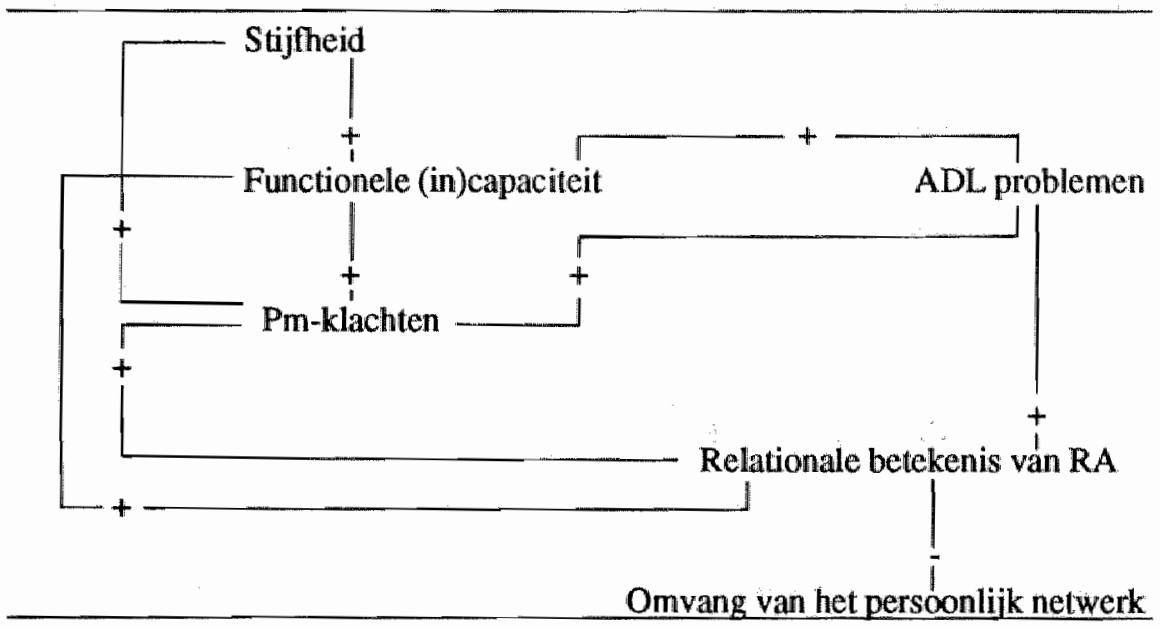

Omvang van het sociale netwerk was sterk gerelateerd aan de relationele betekenis van de ziekte, een indirecte relatie bestaat derhalve tussen de omvang van het netwerk en de problemen met ADL. Verscheidene interrelaties bestaan tussen de onafhankelijke variabelen. Een positieve relatie bestaat tussen functionele capaciteil en pm-klachten, tussen pm-klachten en stijfheid, en tussen functionele capaciteit, pm-klachten en de relationele betekenis van RA. Geconcludeerd kan worden dat afwijkingen van de gezondheid (verminderde beweeglijkheid van bepaalde gewrichtsgroepen, pijn- en moeheidsklachten) problemen met ADL veroorzaken. Maar RA patiênten die meer relationele betekenissen toekennen aan RA en (indirect) patiënten met een kleiner persoonlijk nefwerk hebben ook meer problemen met ADL.

Meerdere problemen met relationeel functioneren hangen samen met (figuur 2):

- attributie van meer relationele betekenissen aan RA, en

- meer afwachtend en vermijdend gedrag. 


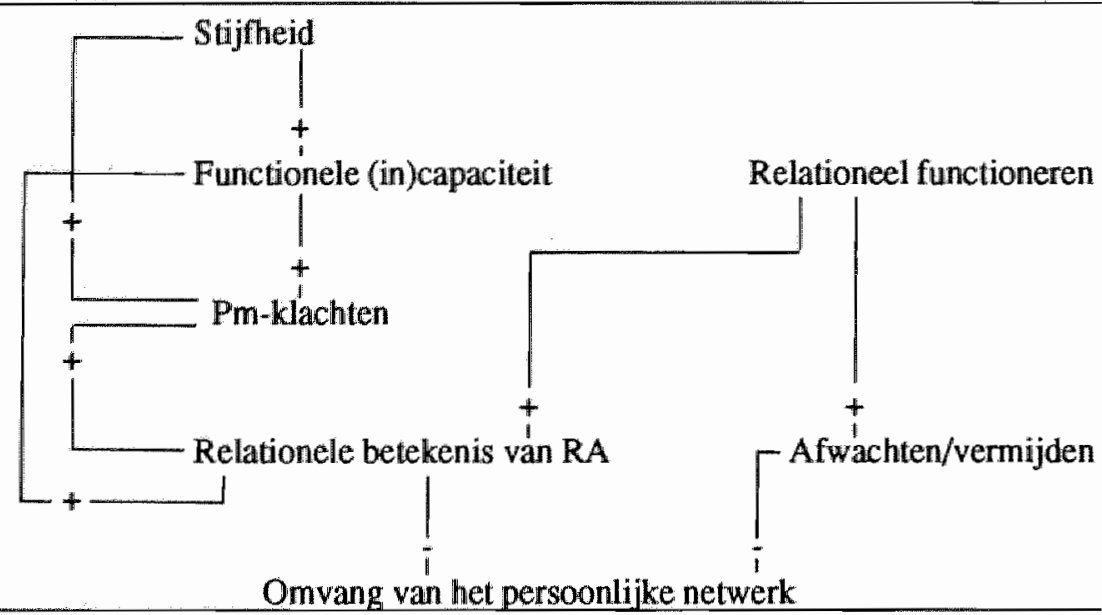

Zowel de relationele betekenis van RA als afwachten en vermijden zijn negatief gerelateerd aan de omvang van het persoonlijk netwerk. Zoals reeds vermeld was het aantal problemen op het gebied van het relationeel functioneren laag. De genoemde problemen betroffen voornamelijk acceptatie problemen door de patiënt zelf, haar partner en in een enkel geval haar kinderen. Samengevat: patiënten die meer problemen hebben met de acceplatie van de ziekte, kennen meer betekenissen toe aan RA, vertonen meer coping gedrag gericht op het verminderen van het gevoel van fysieke of emotionele stress, en hebben kleinere persoonlijke netwerken. Afwijkingen van de gezondheid hebben een indirect effect op de problemen met relationeel functioneren, via de relationele betekenis van RA.

Gevoelens van eenzaamheid zijn gerelateerd aan (figuur 3):

- pijn- en moeheidsklachten;

- de relationele betekenis van RA;

- afwachten/vermijdings gedrag, en

- mogelijkheden tot mantelzorg.

RA patiènten die meer pijn en moeheidsklachten hebben, meer relationele betekenissen aan de ziekte hechten, meer afwachten en vermijdings gedrag vertonen, en minder mogelijkheden hebben tot mantelzorg ondervinden meer gevoelens van eenzaamheid.

Indirecte relaties bestaan tussen:

- omvang van het persoonlijke netwerk, dat gerelateerd is aan de relationele betekenis van RA en afwachten en ver-mijdings gedrag, en eenzaamheid;

- functionele capaciteit, welke gerelateerd is aan de relationele betekenis van de ziekte, en eenzaamheid. 


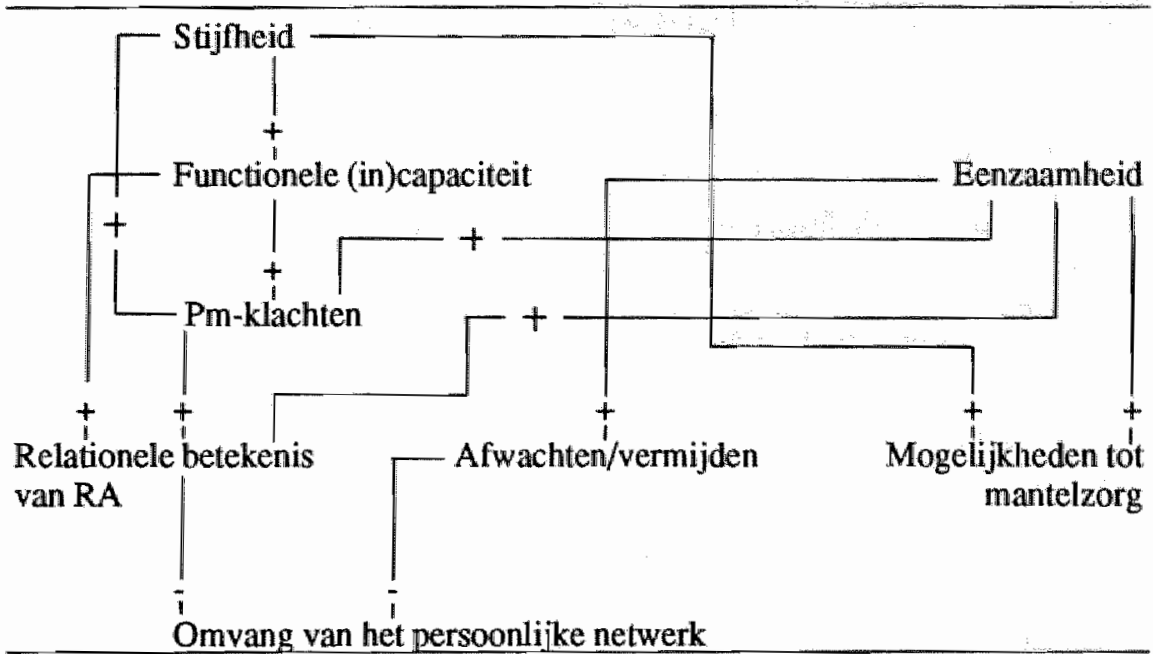

In het algemeen kan geconcludeerd worden dat problemen met het dagelijks functioneren bij oudere RA patiënten ( $A D L$, relationeel functioneren en eenzaamheid) gedeeltelijk verklaard kunnen worden door afwijkingen van de gezondheid (functionele capaciteit, pm-klachten, en duur van de ochtendstijfheid) en door sociale positie en attitudes (relationele betekenis van de RA, afwachten/vermijden coping gedrag en mogelijkheden tot mantelzorg).

Drie relaties zijn hierbij opvallend:

- de relationele betekenis van de RA is gerelateerd aan alle uitkomstvariabelen;

- indirect gerelateerd aan alle uitkomstvariabelen is de omvang van het persoonlijke netwerk;

- de mogelijkheden tot mantelzorg zijn gerelateerd aan eenzaamheid en aan de duur van de ochtendstijfheid.

\section{Longitudinale Analyse}

Longitudinale analyses werden uitgevoerd om de relatie te bestuderen tussen veranderingen in afwijkingen van de gezondheid, sociale positie, attitudes en zorgfaciliteiten en veranderingen in de uitkomst variabelen. In het algemeen kan gezegd worden dat de meerderheid van de RA patiënten geen veranderingen vertoonden aangaande de uitkomst variabelen, afwijkingen van de gezondheid en controle variabelen. Het is daarom moeilijk conclusies te trekken uit de gevonden resultaten.

Relevante resultaten waren (figuur 4):

- Veranderingen in functionele capaciteit beïnvloeden het aantal problemen met ADL. 
Een vermindering van functionele capaciteit ging gepaard met een toename van het aantal $A D L$ problemen. Een toename van functionele capaciteit ging gepaard met een kleine verlaging van $A D L$ problemen.

- Veranderingen in functionele capaciteit waren gerelateerd aan veranderingen in de hoeveelheid professionele zorg.

Wanneer patiênten een verminderde functionele capaciteit hadden kregen zij meer professionele hulp.

- Een toename in de duur van de ochtendstijfheid ging samen met cen toename van het aantal problemen met ADL.

\section{Figuur 4: Longitudinale analyses}

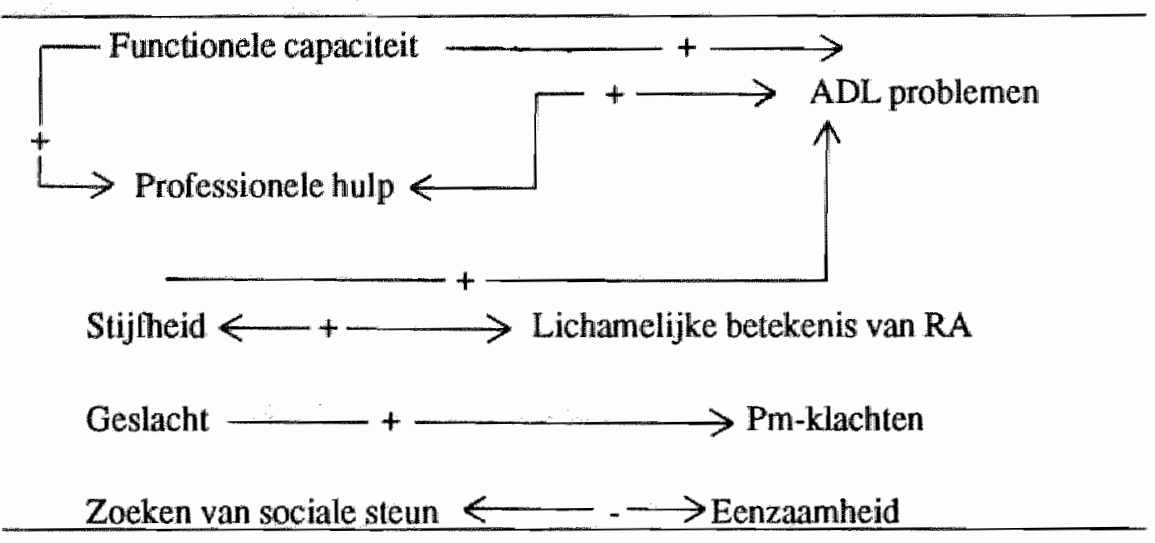

- RA patiënten met een toename in de duur van de ochtendstijfheid kenden meer lichamelijke betekenissen toe aan RA.

- Mannelijke RA patiënten rapporteerden een toename in de hoeveelheid pmklachten, in tegenstelling tot de vrouwelijke patiènten die een vermindering rapporteerden.

- Een positieve relatie werd gevonden tussen de veranderingen in professionele hulp en veranderingen in thet aantal problemen met ADL.

Alhoewel slechts enkele patienten beroep deden op professionele hulp gedurende het onderzoek, was het opvallend dat bij geen van de patiënten een toename van professionele hulp gerelateerd was aan een afname van de hoeveelheid problemen met ADL.

- Een toename in het zoeken van sociale steun ging samen met een afname in gevoelens van eenzaamheid.

Afwijkingen van de gezondheid worden gezien als een voorspeller van de uitkomst variabelen. In het algemeen kan geconcludeerd worden dat de relaties gevonden tussen functionele capaciteit, duur van de ochtendstijfheid en ADL problemen en de relatie tussen functionele capaciteit en professionele hulp geïnterpreteerd kunnen worden als causale relaties. Verder kan in relatie tot functionele capaciteit en ADL problemen gezegd worden dat RA patiënten met een verslechtering van functionele capaciteit een toename kenden van de problemen met ADL, terwijl patiënten met een verbeterde functionele capacileit een geringe afname kenden in de hoeveelheid problemen met ADL. 


\section{Methodologisch Commentaar}

Deze cohort studie had een longitudinaal karakter. Belangrijke voordelen van dit type onderzoek zijn:

- de mogelijkheid om tendensen of veranderingen in de tijd te belichten (Polit \& Hungler, 1983);

- opeenvolgende meetmomenten voor het vaststellen van causaliteit (Pollit \& Hungler, 1983);

- dat relaties bestudeerd kunnen worden in de verschillende stadia van het ziekteproces, en

- dat de stabiliteit van relaties onderzocht kan worden.

Om tendensen en veranderingen in de tijd te kunnen vaststellen werd gebruik gemaakt van drie meetmomenten. In aanvang waren de intervallen tussen de meetmomenten vastgesteld op zes maanden. Bij aanvang van de data verzameling bleek het echter moeilijk om referenten te vinden die bereid waren deel te nemen aan het onderzoek. De intervallen tussen de meetmomenten werden daarom 8 maanden.

Slechts weinig veranderingen werden gevonden in de uitkomst variabelen, afwijkingen van de gezondheid en controle variabelen. Twee factoren kunnen hierop van invloed zijn geweest. In de eerste plaats de variantie in de variabelen bij het begin van de studie. Ten tweede de relatieve stabiliteit van het ziekteproces bij de RA patiënten. Bijvoorbeeld in relatie tot de duur van RA en functionele capaciteit werden geen relaties gevonden in de eerste twee metingen. Een negatieve relatie werd gevonden in de derde meting. Dit zou kunnen betekenen dat patiènten met een kortere duur van RA veranderingen vertoonden in functionele capaciteit, terwijl patiënten die al langer RA hadden relatief stabiel waren in functionele capaciteit.

Een probleem dat genoemd moet worden in relatie tot tendensen en veranderingen in de tijd is dat, omdat weinig patiënten veranderingen vertoonden, het mogelijk is dat een klein aantal patiënten significante relaties kunnen bewerkstelligen. Een ander probleem bleek dat soms relaties werden gevonden in de longitudinale analyses die niet werden gevonden in de transversale analyses. $\mathrm{Er}$ bestond bijvoorbeeld een relatie tussen veranderingen in de relationele betekenis van RA en veranderingen in de duur van de ochtendstijfheid, geen relatie werd echter gevonden tussen de relationele betekenis van RA en de duur van de ochtendstijfheid in de transversale analyses.

Een tweede voordeel van dit type onderzoek is de mogelijkheid om de richting van causaliteit te onderzoeken. Het onderzoeksmodel zoals gebruikt in deze studie bevatte diverse relaties die verondersteld werden causaliteit te bezitten. Afwijkingen van de gezondheid worden in het algemeen gezien als voorspellers van problemen met het dagelijks functioneren. Deze relaties werden gevonden. Daarnaast werd verondersteld dat sociale positie, attitudes en zorg-faciliteiten de relatie tussen afwijkingen van de gezondheid en uitkomst variabelen beinvloeden. Sociale positie, attitudes en zorg-faciliteiten hadden soms een bepalend, bemiddelend of intervenièerend effect op de relatie tussen afwijkingen van de gezondheid en de uitkorist variabelen, hetgeen het in bepaalde gevallen moeilijk maakt causaliteit te interpreteren. 
Een derde woordeel was het onderzoeken van de relaties in diverse stadia van het ziekteproces. Het onderzoken van de relaties in de diverse stadia van het ziekteproces was moeilijk vanwege het geringe aantal RA patiënten betrokken in het onderzoek.

Een laatste voordeel was het onderzoeken van de stabiliteit in de relaties. Het meten van dezelfde variabelen op meerdere tijdstippen in de tijd kan geprefereerd worden boven het meten op een moment. Instrumenten zoals gebruikt in deze studie bleken relatief stabiel in de tijd. Twee factoren zouden die stabiliteit kunnen beirvloeden. Ten eerste veranderingen in de tijd. Met name functionele capaciteit, problemen met ADL, aanvragen en gebruiken van hulpmiddelen en aanpassingen, en relationeel functioneren werden geacht te veranderen gedurende het onderzoek. Zoals reeds gezegd, vertoonden echter slechts enkele RA patiènten dergelijke veranderingen gedurende het onderzoek. Om die veranderingen vast te kunnen stellen zouden de intervallen tussen de meetmomenten groter moeten zijn. Ten tweede, informatie bias. In het geval van de subschaal relationeel funcioneren werd gevonden dat patiènten nauwelijks problemen noemden in het eerste interview. Het aantal genoemde problemen bleek duidelijk gestegen bij de tweede afname van het interview. Het meer bekend zijn met de interviewer of met het geïnterviewd worden heeft hierin mogelijk een rol gespeeld.

Verscheidene andere opmerkingen kunnen gemaakt worden in relatie tot de gebruikte methodologie.

Patienten en referenten waren op de hoogte van het doel van het onderzoek. Blindering van het onderzoek kon, om duidelijke redenen, niet bereikt worden. Het is mogelijk dat patiènten, onbewust, in eerste instantie hun problemen met het dagelijks functioneren overschat hebben, terwijl zij in de derde meting een onderschatting van de problemen geven (Cook \& Campbell, 1979). Deze fenomenen kunnen een rol gespeeld hebben bij de bevinding dat de gevoelens van eenzaamheid gedurende het onderzoek significant afinamen.

De gemiddelde duur van een interview was 2.5 uur. Vooral voor patiènten met een chronische aandoening was dit erg lang en heeft mogelijk het concentratievermogen beïnvloed. Daarom werd gewerkt met geprecodeerde antwoorden en werden open en gesloten vragen met elkaar afgewisseld, wat het eenvoudiger maakte het interview af te ronden.

Een laatste opmerking over de methodologie betreft de non-respons. In paragraal 4.4 werd gezegd dat 32 van de 97 RA patiënten niet aan het onderzoek hebben deelgenomen. Een non-respons analyse werd uitgevoerd. Deze bracht aan het licht dat met name oudere vrouwelijke RA patiënten niet aan het onderzoek hebben deelgenemen. Het is mogelijk dat de ernst van de aandoening een rol heeft gespeeld in het besluit niet deel te nemen. In dat geval moet geconstateerd worden dat oudere vrouwen en patiënten met een ernstiger vorm van RA niet aan het onderzoek hebben deelgenomen.

Een factor die mede de respons beinvloed zou kunnen hebben is dat patiënten en referenten niet alleen drie keer geinterviewd werden maar ook drie keer werden gevraagd gedurende een week een activiteiten dagboek bij te houden. Minder dan de helft van de patiènten hebben uiteindelijk deze dagboeken geretourneerd, ondanks maatregelen om de respons te verhogen. Omdat slechts 22 RA patiênten en referenten drie dagboeken retourneerden kan het zijn dat de resultaten van de dagboeken vertekend zijn. 


\section{Uitwerking van het Onderzoeksmodel}

De centrale relatie die in dit onderzoek werd bestudeerd is de relatie tussen afwijkingen van de gezondheid en het dagelijks functioneren wan oudere RA patienten. Controle factoren werden verondersteld invloed te hebben op afwijkingen van de gezondheid, dagelijks functioneren, en de relatie tussen afwijkingen van de gezondheid en dagelijks functioneren. In deze paragraaf worden de bevindeningen besproken in relatie tot het onderzoeksmodel (hoofdstuk 3). Een onderscheid zal gemaakt worden tussen ADL-achitige uitkomsten en relationeel functioneren-achtige uitkomsten.

De causale invloed van afwijkingen van de gezondheid op het dagelijk functioneren wordt algemeen geacepteerd. In deze studie werden diverse relaties gevonden tussen functionele capaciteit, pijn en moeheidsklachten, duur van de ochtendstijfheid en ADL, relationeel functioneren en eenzaamheid. RA patiènten met verminderde functionele capaciteit, meer pijn en moeheids-klachten, en langere duur van de ochtendstijfheid hadden meer problemen met dagelijks functioneren. De gevonden relaties werden echter beïnvloed door sociale positie, attitudes en zorg-faciliteiten.

Figuur 5 presenteert de relaties zoals gevonden tussen afwijkingen van de gezondheid, sociale positie, attitudes en zorg-faciliteiten. Zoals te zien bestaat een directe positieve relatie tussen afwijkingen van de gezondheid en ADL-achtige uitkomsten.

Figuur 5: Relaties tussen ADL-achtige uitkomsten, afwijkingen van de gezondheid, sociale positie, attitudes en zorg-faciliteiten.

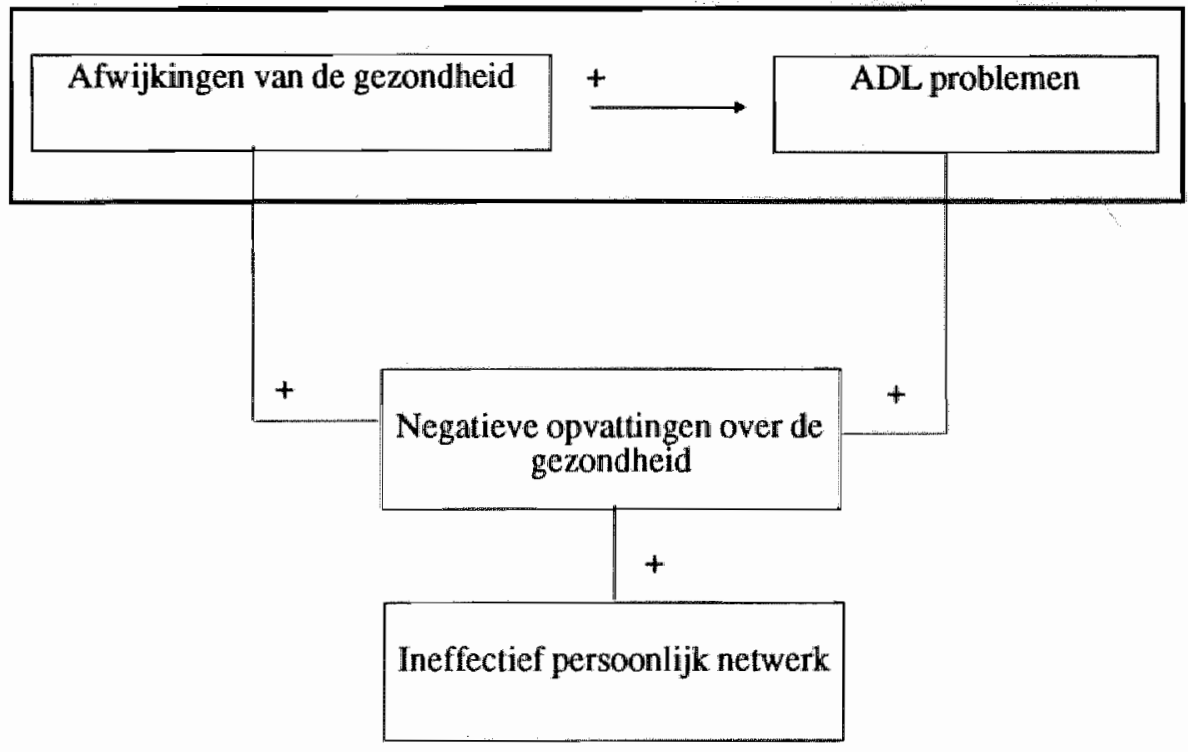


In paragraaf 2.4.1 werd gesteld dat de opvattingen over de gezondheid van oudere RA patiénten, dat is de betekenis van de ziekte voor de patiënt, afwijkingen van de gezondheid en problemen met dageilijks functioneren kunnen beïnvloeden. Uit de analyses blijkt dat opvattingen over de gezondheid gerelateerd zijn aan zowel afwijkingen van de gezondheid als aan problemen met dagelijks functioneren. Het toekennen van meer betekenissen aan RA betekent dat patiënten een verminderde functionele capaciteit hebben, meer pm-klachten en meer problemen met $A D L$. Een verdere relatie werd gevonden in de longitudinale analyses, namelijk dat veranderingen in de duur van de ochtendstijfheid gepaard gingen met veranderingen in het aantal betekenissen toegekend aan RA.

Meer waarschijnlijk is het dat opvattingen over de gezondheid een begeleidend verschijnsel zijn, wat betekent dat opvattingen over de gezondheid een modificator zijn in de relatie tussen afwijkingen van de gezondheid en ADLachtige uitkomsten.

Opvattingen over de gezondheid zijn ook gerelateerd aan de omwang van het persoonlijke netwerk. Het is mogelijk dat RA patiënten met meer personen in het netwerk meer mogelijkheden hebben de betekenissen gegeven aan RA te delen met de mening die anderen over RA hebben. Door dit toetsen van opvattingen over RA kan een zekere vermindering van deze meningen of consensus over de opvattingen bereikt worden. Het persoonlijk netwerk is daarom een belangrijke variabele.

Geconcludeerd kan worden dat:

- afwijkingen van de gezondheid gerelateerd zijn aan ADL-achtige uitkomsten van RA;

- opvaltingen over de gezondheid zowel afwijkingen van de gezondheid als ADL-achtige uitkomsten beïnvloeden, ze treden waarschijnlijk op als een modificator in de relatie tussen afwijkingen van de gezondheid en ADL-achtige uitkomsten;

- het persoonlijk netwerk direct gerelateerd is aan gezondheidsopvattingen en indirect aan afwijkingen van de ge-zondheid en ADL-achtige uitkomsten.

Opvattingen over de gezondheid waren ook direct gerelateerd aan relationeel functioneren-achtige uitkomsten. Patiënten die meer betekenissen toekennen aan RA bleken ook meer problemen met relationeel functioneren te hebben en meer gevoelens van eenzaamheid (figuur 6). 


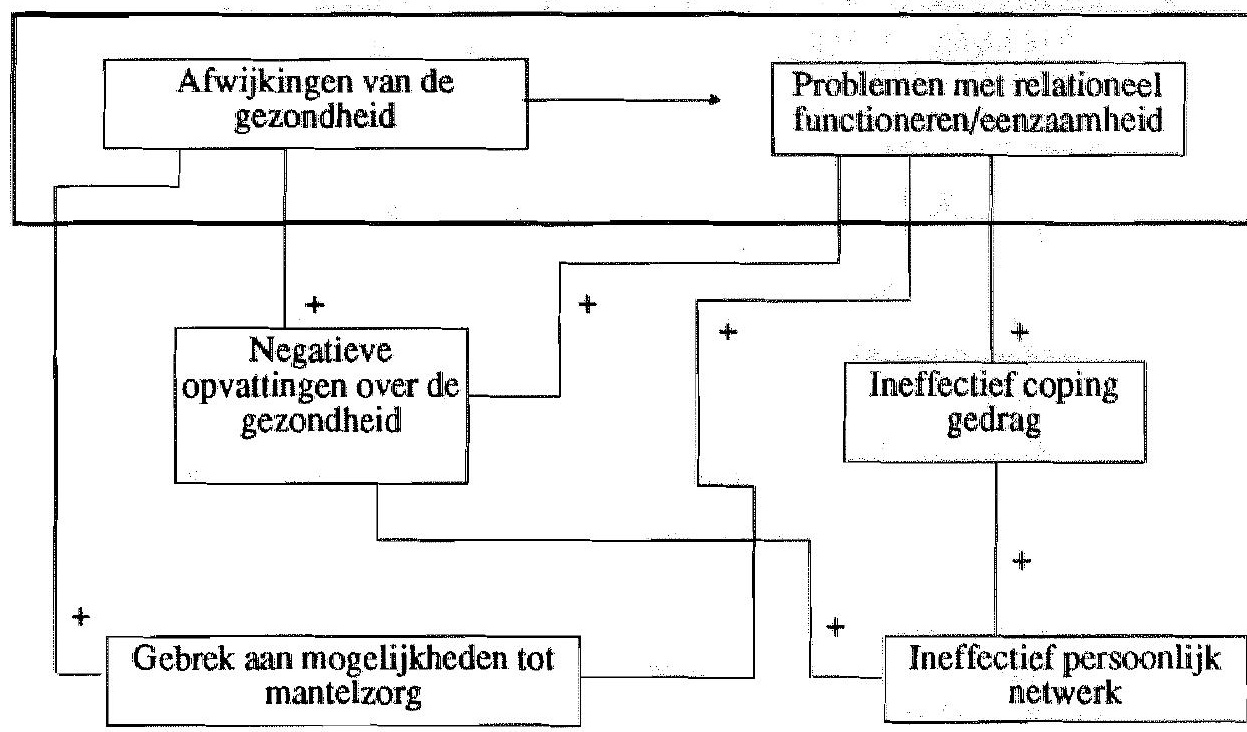

Zoals te zien in figuur 6 wordt de relatie tussen afwijkingen van de gezondheid en relationeel functioneren-achtige uitkomsten beïnvloed door sociale positie, attitude en zorg-faciliteiten. De relaties tussen opvattingen over de gezondheid, afwijkingen van de gezondheiden en relationeel functioneren-achtige uitkomsten is vergelijkbaar met de relatie tussen opvattingen over de gezondheid, afwijkingen van de gezondheid en ADL-achtige uitkomsten. Patiënten die meer betekenissen aan hun ziekte toekennen hebben een slechtere functionele capaciteit, meer pmklachten, langere duur van de ochtendstijfheid, meer problemen met relationeel functioneren en meer gevoelens van eenzaamheid. Opvattingen over de gezondheid kunnen gezien worden als een modificator in de relatie tussen afwijkingen van de gezondheid en relationeel functioneren-achtige uitkomsten.

Coping gedrag is gerelateerd aan relationeel functioneren-achtige uitkomsten, maar niet aan afwijkingen van de gezondheid. Een relatie werd gevonden tussen afwachten en vermijdings gedrag en relationeel functioneren-achtige uitkomsten. Dit betekent dat patienten die meer gedrag vertonen dat gericht is op het reduceren van psychische of emotionele stress ervaringen, meer problemen hadden met relationeel functioneren en meer gevoelens van eenzaamheid hadden.

Zowel opvattingen over de gezondheid als coping gedrag waren negatief gerelateerd aan het persoonlijk netwerk. De mogelijkheid tot het delen van de betekenis van de ziekte met anderen zou het belang van RA en de medische behandeling kunnen reduceren, en daarmee het aantal betekenissen dat toegekend wordt aan RA. In het geval van de relatie tussen coping gedrag en persoonlijk netwerk is het mogelijk patiènten met meer personen in het netwerk, in hogere mate de consequenties van RA en de medische behandeling onder ogen moeten zien. Een kleiner netwerk geeft meer mogelijkheden om deze consequenties te vermijden. 
Via opvattingen over de gezondheid en coping gedrag heeft het persoonlijk netwerk invloed op relationeel functioneren-achtige uitkonsten. Mogelijkerwijs is het persoonlijk netwerk cen belangrijke achtergrond variabele, die niet de afwijkingen wan de gezondheid of de relationeel functioneren-achtige uitkomsten beinvloeden, maar de relatie tussen beide versterkt.

Als laatste werd een relatie gevonden tussen de mogelijkheden tot mantelzorg, afwijkingen wan de gezondheid en relationeel functioneren-achtige uitkomsten. Het hebben van een partner, iemand die in huis woont, of (schoon)dochters betekent minder afwijkingen van de gezondheid en minder problemen met relationeel functioneren-achtige uitkomsten. Meer personen in de directe omgeving vergroot de mogelijkheid dat patiènten meer hulp krijgen bij het dagelijks functioneren, meer advies krijgen om ochtendstijfheid tegen te gaan of meer advies krijgen in het geval van pijn of moeheid. Op deze wijze worden patiènten waarschijnlijk minder gehinderd door afwijkingen van de gezondheid en hebben zij minder problemen met relationeel functioneren-achtige uitkomsten van RA. Hoewel een relatie gevonden werd tussen de mogelijkheden tot mantelzorg en afwijkingen wan de gezondheid en tussen mogelijkheden tot mantelzorg en relationeel functioneren-achtige vitkomsten, werd een interveniëerende, modificerende of bepalende invloed van mogelijkheden tot mantelzorg op de relatie tussen afwijkingen van de gezondheid en relationeel functioneren-achtige uitkomsten niet gevonden.

Geconcludeerd kan worden dat:

- opvattingen over de gezondheid gerelateerd zijn aan zowel afwijkingen van de gezondheid als aan relationeel functioneren-achtige uitkomsten, en zij wellicht een modificerend effect hebben op de relatie tussen afwijkingen van de gezondheid en relationeel-functioneren-achtige uitkomsten;

- coping gedrag het aantal problemen met relationeel functioneren-achtige uitkomsten verhoogt, maar geen effect heeft op afwijkingen van de gezondheid,

- het persoonlijk netwerk een belangrijke variabele is, die in ieder theoretisch model voor afhankelijkheids-onderzoek thuishoort;

- mogelijkheden tot mantelzorg, afwijkingen van de gezondheid en problemen met relationeel functioneren-achtige uitkomsten reduceren.

\section{Aanbevelingen}

Gezien de resultaten van dit onderzoek kunnen diverse aanbevelingen voor verder onderzoek en voor de gezondheidszorgpraktijk gegeven worden.

\section{Suggesties voor de Praktijk}

In relatie tot de professionele zorg voor oudere RA patiënten kunnen de volgende suggesties gedaan worden.

Oudere RA patiënten hebben diverse problemen met dagelijks functioneren. Deze problemen hangen niet alleen samen met afwijkingen van de gezondheid 
maar ook met opvattingen over de gezondheid, coping gedrag, mogelijkheden tot mantelzorg en thet persoonlijk netwerk.

Uit deze studie bleek dat oudere RA patienten weinig professionele zorg ontvangen. In de meerderheid van de gevallen zorgden de personen wit het netwerk voor de benodigde hulp. De meerderheid van de patiènten heeft echter regelmatig contact met de theumatoloog.

1 Het zou daarom aan te bevelen zijn dat de rheumatoloog in het contact met de RA patiënt niet alleen aandacht besteed aan de medische aspecten van RA, maar ook aan de problemen met het dagelijks functioneren en de daarmee samenhangende factoren.

2 Een verdere mogelijke zou zijn dat theumatologen meer aandacht besteden aan de mogelijkheden van gezinszorg en wijkverpleging, die

3 op hun beurt meer informatie zouden moeten verstrekken aan de RA patiënten en hun zorgverleners over de mogelijkheden van hun oganisaties op het gebied van hulp voor deze groep.

In relatie tot geslacht werd gevonden dat vrouwelijke RA patiènten minder uren rusten dan hun mannelijke tegenhangers, een slechtere functionele capaciteit hebben en meer problemen met ADL. Traditionele rolindelingen kunnen hierop van invloed zijn. Het is mogelijk dat van vrouwelijke RA patiënten verwacht wordt hun huishoudelijke taken te continueren. Dit zou kunnen betekenen dat zij zichzelf overbelasten, ondanks hun ziekte, wat invloed zou kunnen hebben op functionele capaciteit en problemen met ADL.

4 Het is daarom belangrijk dat zorgverleners speciaal de aandacht vestigen op het rust en activiteiten patroon van oudere vrouwelijke RA patiënten.

In de dagelijkse praktijk vragen zorgverleners of patiënten mogelijkheden hebben tot mantelzorg. In dit onderzoek werd gevonden dat niet alleen de mogelijkheden tot mantelzorg, maar ook het persoonlijk netwerk belangrijk is in relatie tot afwijkingen van de gezondheid en het dagelijks functioneren.

5 Professionele zorgverleners zouden daarom niet alleen moeten vragen naar de mogelijkheden tot mantelzorg maar ook infomatie moeten verzamelen over het persoonlijke netwerk.

6 In het algemeen vraagt de zorg voor RA patiënten om een multidisciplinaire aanpak. In dit kader zou de suggestie gedaan in de 'Nota Chronisch Ziekenbeleid' (WVC, 1991) om de positie van de districtsverpleegkundige reuma te her-overwegen, ondersteund moeten worden. Specialle aandacht zou dan gegeven moeten worden aan het aanbieden en de organisatie van de professionele en niet-professionele zorg voor oudere RA patiënten.

\section{Aanbevelingen voor verder Onderzoek}

De resultaten van dit onderzoek zijn voornamelijk descriptief. Relaties zoals gevonden in dit onderzoek zouden apart onderzocht kunnen worden om een meer precieze kijk te krijgen op de interrelaties tussen de variabellen. Bij voorbeeld, de relatie tussen opvattingen over de gezondheid, afwijkingen van de gezondheid en problemen met het dagelijks functioneren. Zoals eerder vermeld zou het kunnen zijn dat betekenissen gehecht worden aan RA vanwege de uitkomsten van het 
ziekteproces: Deze zouden de hulp die gevraagd wordt van (niet)-professionele zorgverleners kunnen beïnvloeden.

Ten tweede, coping gedrag werd in dit onderzoek bestudeerd als een fenomeen dat invloed heeft op afwijkingen van de gezondheid en uitkomst variabelen. Het is echter mogelijk de patiënt verschillende vormen van coping gedrag gebruikt in relatie tot de verschillende afwijkingen van de gezondheid en uitkomsten van thet ziekteproces.

Mogelijkheden tot mantelzorg, en het persoonlijk netwerk werden belangrijk bevonden in relatie tot problemen met dagelijks functioneren. Verder onderzoek zou gedaan moeten worden naar mogelijkheden tot mantelzorg, het persoonlijk netwerk en de problemen van oudere RA patiènten met dagelijks functioneren. Daamaast zou gekeken moeten worden naar deze variabelen in relatie tot professionele hulp. Bijvoorbeeld, op welk moment in de patiëntencarierre roepen oudere RA patienten de hulp in van professionals en welke factoren in de directe omgeving beinvloeden deze beslissing.

Zoals naar voren gebracht in paragraaf 8.5 werd een negatieve relatie gevonden tussen de duur van de ziekte en functionele capaciteit. Patiënten met een langere duur van de ziekte waren relatief stabiel in functionele klasse, terwijl patienten met een kortere duur meer veranderingen in funtionele capaciteit vertoonden. Het zou daarom aan te bevelen zijn de ondezoeksgroep te homogeniseren in relatie tot de duur van de ziekte.

In dit onderzoek werd het activiteiten patroon onderzocht door middel van het aantal uren dat patiênten besteden aan dagelijkse activiteiten. In vervolg onderzoek zou wellicht meer inzicht verkregen kunnen worden in de afwisseling in rust en activiteit om uit te zoeken in hoeverre de adviezen van de rheumatoloog op dit terrein worden geintegreerd in het dagelijks functioneren. Dagboeken zijn een mogelijke methode, hoewel maatregelen om de respons te verhogen genomen moeten worden. Daarbuiten is de dagboek methode tijdrovend en kostbaar, in welk geval andere methodes geprefereerd zouden kunnen worden. 


\section{REFERENCES}

Abrham H.S., The psychology of chronic illness, Journal of Chronic Diseases, 25, 659-664, 1972.

Akhtar A.J., Broe G.A., Combre A., McLean W.M.R., Andrews G.R., Caird F.J., Disability and dependence in the elderly at home, Age and Aging, 2, 102. $111,1973$.

Allen G.I., Breslow L., Weissman A., Nisselson H., Interviewing versus diary keeping in eliciting information in a morbidity survey, American Journal of Public Health, 919-927, 1954.

American Nurses' Association and Arthritis Health Professions Association Nursing Task Force, Outcome Standards for Rheumatology Nursing Practice, Kansas City Mo, American Nurses' Association, 1983.

American Rheumatism Association Glossary Committee, Dictionary of Rhewmatic Diseases: Signs and Symptoms, New York, Contact Associates International Lid., 1982.

Arluke A., Judging drugs: Patients' conceptions of therapeutic efficacy in the treatment of arthritis, Human Organisation, 39, 84-88, 1980.

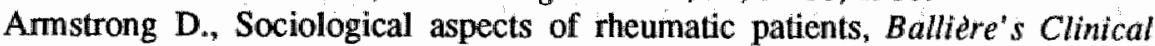
Rheumatology, 1,455-466, 1987.

Barney J.L., Neukom J.E., Use of arthritis care by the elderly, The Gerontologist. $19,548-554,1979$.

Bird, H.A., Le Gallez, P., Hill J., Combined care of the rheumatic patients, Springer Verlag, Berlin, 1985.

Blalock S.J., McEvoy-deVellis B., deVellis R.F., H.Sauter S. van, Self-evaluation processes and adjustment to rheumatoid arthritis, Arthritis and Rheumatism, 31, 1245-1251, 1980.

Bos G.A.M. van den, Zorgen van en voor chronisch zieken, Bohn, Scheltema \& Holkema, Amsterdam, Proefschrift Universiteit van Amsterdam, 1989.

Bradley L.A., Young L.D., Anderson K.O., Tunner R.A., Agudelo C.A., McDaniel L.K., Pisko E.J., Semble E.L., Morgan T.M., Effecls of psychological therapy on pain behavior of rheumatoid arthritis patients, Arthritis and Rheumatism, 30, 1105-1114, 1987.

Branch L.G., Katz S., Kniepmann K., Papsidero J.A., A prospective study of functional status among community elders, American Journal of Public Health, 74, 266-268, 1984.

Burckhardt C.S., The impact of arthritis on quality of life, Nursing Research, 34, $11-16,1980$.

Cantor M.H., Neighbours and friends; an overlooked recourse of the informal support system, Research on Aging, 1, 434-436, 1976.

Convery F.R., Minteer M.A., Amiel D., Connet K.L., Polyarticular disability; a functional assessment, Archieves of Physical Medicine and Rehabilitation, 58, 434-438, 1977. 
Cook Th:D., Cambell D.T., Quasi-experimentation, Rand McNally, Chicago, 1979.

Craigh H.M. Edwards J.E., Adaptation in chronic illness; an electic model for nurses. Jowrnal of Advanced Nursing, 8, 397-404, 1983.

Dickinson G.R., Kraince German $T$., Adult arthritis, the assessment, American Journal of Nursing, 83, 262-265, 1983.

Duthie J.J., Brown P.E., Truelove L.H., Baragar F.D., Lawrie, A.J., Course and prognosis in theumatoid arthritis, Annals of Rheumatic Diseases, 23, 193 $204,1964$.

Ehrlich G.E., Rehabilitation management of rheumatic conditions, Williams \& Williams, Baltimore, 1980.

Escobar P.L. Managment of chronic pain, Nurse Practitioner, 10, 24-25, 29-30, 32,1985 .

Everitt B.S., The analysis of contigency tables, Chapman and Hall, London, 1977.

Felton B.J., Revenson T.A., Hinrichsen G.A., Stress and coping in the explanation of psychological adjustment among chronically ill adults, Social Sclence and Medicine, 18, 889-898, 1984.

Follick M.J., Ahern D.K., Laser-Wolston W., Evaluation of daily activity diary for chronic pain patients, Pain, 19, 373-378, 1984.

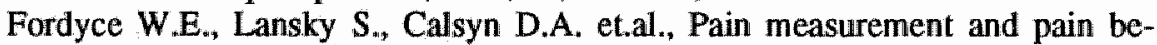
havior, Pain, 18, 53-59, 1984.

Frederiks C.M.A., Zorgbehoefte van en zorgverlening aan ouderen. Proefschrift Rijksuniversiteit Limburg, 1990.

Fries J.F., Towards an understanding of patient outcome measurement, Arthritis and Rheumatism, 26, 697-704, 1983b.

Fries J.F., Spitz P., Kraines R.G., Holman H.R., Measurement of patient outcome in arthritis, Arthritis and Rheumatism, 23, 137-145, 1980.

Fries J.F., Spitz P.W., Young D.Y., The dimensions of health outcomes, the health assessment questionnaire, disability and pain scales, The Journal of Rheumatism, 9, 789-793, 1982.

Gallez P. Le, Outpatient nursing 3, theumatology health education, Nursing Mirror, $160,37-39,1985$.

Gorter K.A. Thuishulp gewogen, een onderzoek naar de behoefte van lichamelijk gehandicapte mensen aan hulp thuis, Nederlands Institunt voor Maatschappelijk Werk Onderzoek, Den Haag, 1990.

Grennan D.M., Rheumatology, Ballière Tindall, London, 1984.

Haralambos $\mathrm{M}_{*}$, Heald R., Sociology, themes and perspectives, University Tutorial Press Lid., Slough, 1980.

Higgins C.A., McClean R.J., Conrath D.W., The accuracy and biases of diary communication data, Social Networks, 7, 173-187, 1985.

Hollander J.L., Editorial, Whether weather affects arthritis, The Journal of Rheumatology, 12, 655-656, 1985.

Instituut voor Toegepaste Sociologie, Beroepenklapper Instituur woor Toegepaste Sociologie, Nijmegen, 1975.

Jankowski R.F., Robinson E., Paterson S., Carson D.W., Patients expectations of health care, fullfilled and unfullfilled, The Practitioner, 224, 352-353, 1980. 
Jette A.M., Functional status index; reliability of a chronic disease evaluation instrument, Archives of Physical Medicine and Rehabilitation, 61, 395-401, 1980.

Jette A.M., Branch L.G., Framingham disability study II, physical disability among the aging, American Journal of Public Health, 71, 1211-1216, 1981.

Jongh-Gierveld J. de, Kamphuis $\mathrm{F}_{\text {.x }}$ The development of a Rash-type loneliness scale, Applied Psychological Measurement, 9, 289-299, 1985.

Kaplan S., Kozin F., A controlled study of group counseling in rheumatoid arthritis, The Journal of Rheumatology, 8, 91-99, 1981.

Katz S., Ford A.B., Moskowitz R.W., Jackson B.A., Jaffe M.W., Studies of illness in the aged, the index of ADL, a standardized measure of biological and psychological function, JAMA, 185, 914-919, 1963.

Katz S., Hedrich S.C., Henderson N.S., The measurement of long-term care needs and impact, Health and Medicine Care Services Review, 2, 2-20, 1979.

Kempen G.I.J.M., Thuiszorg voor ouderen, een onderzoek naar individuele determinanten van het gebruik van wijkverpleging en/of gezinszorg op verzorgend en huishoudelijk gebied. Proefschrift Rijks Universiteit Groningen, Styx Publications, Groningen, 1990.

Kerlinger F.N., Foundations of behavioral research, Holt, Rinehart and Winston Inc., New York, 1964.

Kerns R.D., Finn P., Haythornthwaite E., Self-monitored pain intensity; psychometric properties and clinical utility, Journal of Behavioral Medicine. 11, $71-82,1988$.

Kirwan J.R., Silman A.J., Epidemiological, sociological and environmental aspects of rheumatoid arthritis and osteoarthritis, Clinical Rheumatology, 1 , $467-490,1987$.

Knipscheer, C.P.M., Oude mensen en hun sociale omgeving, een studie van het primaire sociaal netwerk, Vuga Boekerij, Den Haag, 1980.

Knox J.D.E., Rheumatic diseases; a general practitioners' view, Balliere's Clinical Rheumatology, 1, 601-622, 1987.

Koemer M.E., Dickinson G.R., Adult arthritis, a look at some of it's forms, American Journal of Nursing, 83, 255-262, 1983.

Kooiker S.E., Het gebruik van eerstelijnszorg 1974-2005, trends en ramingen. Nederlands Instituut voor onderzoek Van de Eerste Lijn, 1990

Korst J.K. van der, Gewrichtsziekten, Bohn, Scheltema \& Holkema, Utrecht, 1980.

Knisvereniging Twente \& Nationale Kruisvereniging, Reuma onderzoek Twente. de zorg vanuit het kruiswerk aan patienten met reumatoide arthritis, eindverslag, Kruis- vereniging Twente \& Nationale Kruisvereniging, 1988.

Large R.G., Self concepts and illness behavior in chronic pain; a repertory grid study of a pain management program,

Lazarus R.S., The stress and coping paradigm. In: Eisdorfer C., Kleinman A., Maxim P. (eds), Theoretical basis for psychopathology. Spectrum, New York, 1980.

Lee P., Jasani M.K., Dick W.C., Buchanan W.W., Evaluation of a functional index in rheumatoid arthritis, Scandinavian Journal of Rheumatology, 2, 71$77,1973$. 
Levinson S.S., Bearfield J.L., Ausbrook D.K., Muriel H., Shireman L., Pacell C., Stanton H., Masterson J., The Chicago Rheumatic Fever Program, a 20 plus year history, Journal of Chronic Diseases, 35, 199-206, 1982.

Liang M.H., Gall V., Partridge A., Eaton $\mathrm{H}_{\text {., }}$ Management of functional disability in home-bound patients, J. Fam. Pract., 17, 429-435, 1983.

Liang M.H., Jette A.M., Measuring functional ability in chronic arthritis, a critical review, Arthritis and Rheumatism, 24, 80-86, 1981.

Liang M.H., Partridge A.J., Larson M:G., Gall V., Taylor J.E., Master R., Fellin $M_{\text {., }}$ Taylor J., Evaluation of comprehensive rehabilitation services for elderly homebound patients with arthritis and orthopedic disability, Arthritis and Rheumatism, 27, 258-266, 1984.

Linos A., Wortington J.W., O'Fallon W.M., Kurland L.T., The epidemiology of rheumatoid arthritis in Rochester, Minnisota; a study of incidence, prevalence and mortality, American Journal of Epidemiology, 11, 87-98, 1980.

Lorig K.R., Arthritis self-managment, a pilot patient education program, Rehabilitation Nursing, 7, 16-20, 1982.

Lorig K.R., Cox T., Cuevas Y., Graines G.R., Britton M.C., Converging and diverging beliefs about arthritis, caucasian patients, spanish speaking patients and physicians, The Journal of Rheumatism, 11, 76-79, 1984.

Lüschen G., Cockeran W.C., Kunz G., Social stratification, health welfare and health culture, a contribution to class-specific integration of the welfare state. In: Lüschen G., Cockeran W.C., Kunz G., Health and illness in America and Germany, comparative sociology of health conduct and public policy, Roldenburg Verlag, Munchen, 1989.

Makisara G.L., Makisara P., Progression of fuctional capacity and work capacity in rheumatoid arthritis, Clinical Rheumatology, 1, 117-125, 1982.

Mannheimer J.S., Non-medical and non-invasive pain control techniques in the management of rheumatic diseases and related musculoskeletal disorders, Journal of Rheumatology, 14, 26-31, 1987.

Marden P.G., Burnight R.G., Social consequences of physical impairment in an aging population, Gerontologist, 9, 39-46, 1969.

McGaffery M., Nursing the patient in pain. Harper \& Row Publishers, London, 1983.

Mechanic D., Illness behavior, social adaptation and the management of illness, Journal of Nervous and Mental Diseases, 165, 79-85, 1977.

Meenan R.F., Anderson J.J., Kazis L.E., Egger M.J., Altz-Smith M., Samualson Jr. C.O., Wilkins F.F., Solkey M.A., Haynes S.P., Blocka K.L., Weinstein A., Guttadauria M., Kaplan S.B., Kippel J., Outcome assessment in clinical trails; evidence for the sensitivity of a health status measure, Arthritis and Rheumatism, 27, 1344-1352, 1984.

Meenan R.F., Gertman P.M., Mason J.H., Measuring health status in arthritis; The Arthritis Impact Measurement Scale, Arthritis and Rheumatism, 23, 146-152, 1980.

Mishel M., Braden C.J., Finding meaning, antecedents of uncertainty in illness, Nursing Research, 37, 98-103, 127, 1988.

Mitchell J.C., Social networks in urban situations, analyses of personal relationships in central african towns, Manchester University Press, Manchester, 1969. 
Mooney N.E., Coping with chronic pain in rheumatoid arthritis, patient behaviors and nursing interventions, Rehabilitation Nursing, 8, 20-25, 1983.

Moskowitz R.W., Haug M.R. (eds), Arthritis and the elderly. Springer Publishing Company, New York, 1986.

Mostert H.A., De (on)vervulde behoeften aan hulp bij reumatoide arthritis patienten in wijkverpleegkundige zorg. een explorerende studie. Afstudeerscriptie, Maastricht, 1987.

Moulton P.J., Chronic illness, grief, and family, Journal of Commumity Health Nursing, 1,75-88, 1984.

Muhlenkamp A.F., Joyner J.A., Arthritis patients' self- reported affective states and their caregivers' perceptions ..., nurses caring for arhtretic patients, Nursing Research, 35, 24-27, 1986.

Muhlenkamp A.F., Sayles J.A., Self-esteem, social support and positive health practice, Nursing Research, 35, 334-338, 1986.

Mullen P.D., Laville E.A., Biddle A.K., Lorig K., Efficacy of psycho-educational interventions on pain, depression, and disability in people with arthritis; a meta-analysis. Journal of Rheumatology, 14, 33-39, 1987.

Nicassio P.M., Wallstone K.A., Callahan L.T., Herbert M., Pincus T., The measurement of helplessness in rheumatoid arthritis, the development of the Arthritis Helplessness Index, Journal of R heumatology, 12, 462-467, 1985.

Nuki G., Brooks R., Buchanan W.W., The economics of arthritis, Bulletin on the Rheumatic Diseases, 23, 726-733, 1972.

Orem D.E., Nursing, concepts of practice, McGraw-Hill Book Company, New York, 1985.

Parker J., McRea C., Smarr K., Beck N., Frank R., Anderson S., Walker S., Coping strategies in rheumatoid arthri tis, The Journal of Rheumatology, 15 , 1376-1381, 1988.

Patrick D.L., Morgan M., Charlton J.R.H., Psychosocial support and change in the health status of physically disabled people, Social Science and Medicine, 22, 1347-1354, 1986.

Pearlin L.T., Schooler K., The structure of coping, Journal of Health and Social Behavior, 19, 2-21, 1987.

Philipsen H., Afwezigheid wegens ziekte, een onderzoek naar oorzaken van verschillen in ziekteverzuim tussen 83 middelgrote bedrijven. Nederlands Instituut voor Praeventieve Geneeskunde TNO, Wolters Noordhoff, 1969.

Pincus T., Summey J.A., Soraci Jr. S.A., Wallston K.A., Hummon N.P., Assessment of patient satisfaction in activities of daily living, using a modified Stanford Health Assessment Questionnaire, Arthritis and Rheumatism, 26, 1346-1353, 1983.

Polit D., Hungler B., Nursing research, principles and methods, J.B. Lippincot Company, Philadelphia, 1983.

Pollock S.E., Human responses to chronic illness, physiologic and psychosocial adaptation, Nursing Research, 35, 90-95, 1986.

Potts M., Weinberger M., Brandt K.D., Views of patients and providers regarding the importance of various aspects of an arthritis treatment program, The Journal of Rheumatology, 11, 721-75, 1984.

Rachman S., Lopatka C., Accurate and inaccurate predictions of pain, Behavioral Research and Therapy, 26, 291-296, 1988. 
Ragan $\mathrm{C}_{\text {., }}$ Farrington $\mathrm{E}$, The clinical features of rheumatoid arthritis, JAMA, 181, $663,1962$.

Rasker J.., Reuma hebben, wat het betekent reumatoide arthritis patient te zijn, Lederle BV Holland, Etten Leur, 1984.

Rasker J.J., Peters H.J.G., Boon K.L., Influence of weather on stiffness and force in patients with rheumatoid arthritis, Scandinavian Journal of Rheumatology, 15, 27-36, 1986.

Rhind $\mathrm{V}_{\text {., }}$ Unsworth A., Haslock I., Assessment of stiffness in rheumatology, the use of rating scales, British Journal of Rheumatology, 26, 126-130, 1987.

Robinson I. Managing symptoms in chronic disease, some dimensions of patients' experience, International Disabilility Studies, 10, 112-118, 1988.

Rochmann K.J., Haggerty R.J., The diary as a research instrument in the study of health and illness behavior, experiences with a random sample of young families, Medical Care, 10, 143-163, 1972.

Rogers M.P., Liang M.H., Partridge A.J., Psychological care of adults with rheumatoid arthritis, Annals of Internal Medicine, 96, 344-348, 1982.

Russel R.A., Concepts of adjustment to disability, an overview, Rehabilition Literatwre, 42, 330-338, 1981.

Safilios-Rothschild $\mathrm{C}$., The sociology and social psychology of disability and rehabilitation, Random House, New York, 1970.

Schiltmans M.M.C., Evers G.C.M., Zelfzorgvermogen en sociale ondersteuning bij reumapatiënten, een onderzoek op basis van Orem's zelfzorg-tekort theorie, Verplee gkunde, 4, 195-200, 1988/89.

Schreurs P.J.G., Tellegen B., Willige G. van de, Gezondheid, Stress en coping: de ontwikkeling van de Utrechtse Coping-schaal, Gedrag, Tijdschrift voor Psychologie, 12, 101-116, 1984.

Schreurs P.J.G., Persoonskenmerken en essentiële hypertensie, Proefschrift RL, Maastricht.

Schreurs PJ.G., Willige G. van de, Gedragstherapie bij essentiële hypertensie, Tijdschrift v. klinische psychologie, Belgiè, 1985, vol 1.

Sherrer Y.S., Bloch D.A., Mitchell D.M., Young D.Y., Fries J.F., The development of disability in rheumatoid arthritis, Arthritis and Rheumatism, 29, 494-500, 1986.

Sibley J.T., Weather and arthritis symptoms, The Journal of Rheumatlogy, 12 , 707-710, 1985.

Silvers I.L., Hovell M.F., Weisman M.H., Mueller M.R., Assessing physician/patient perceptions in rheumatoid arthritis, Arthritis and Rheumatism, $28,300-307,1985$.

Smith T.W., Peck J.R., Cognitive distortion in rheumatoid arthritis; relation to depression and disability, Journal of Consulting and Clinical Psychology, 56, 412-416, 1988.

Smith R.D., Polly H.F., Rest therapy for rheumatoid arthritis, Mayo Clinic Proceedings, 53, 141-145, 1978.

Smith Pigg J., Webb Driscoll P., Caniff R., Rheumatology nursing, a problem oriented approach, J. Wiley \& Sons, New York, 1985.

Steinbrocker O., Treager C.H., Batterman R.C., Therapeutic criteria in rheumatoid arthritis, JAMA, 140, 659-662, 1949. 
Swaan A. de, De mens is de mens een zorg, opstellen 1971-1981, Meulenhof, Amsterdam, 1982.

Swanborn, P.G., Methoden van sociaal wetenschappelijk onderzoek, inleiding in ontwerpstrategieen, Boom, Meppel, 1981.

Tabachnick B.G., Fidell L.S., Using multivariate statistics, Harper \& Row Publishers, New York, 1989.

Taylor A.G., Skelton J.A., Butcher J., Duration of pain condition and physical pathology as determinants of nurses' assessment of patients in pain, Nursing Research, 38, 4-8, 1984.

Tilburg Th, van, Verkregen en gewenste ondersteuning in het licht van eenzaamheidservaringen, Proefschrift, Amsterdam, 1988

Turner R.J., Noh S., Physical disability and depression; a longitudinal analysis, Journal of Health and Social Behavior, 29, 23-37, 1988.

Vignos P.J., Thompson H.M., Katz S., Comprehensive care and psychosocial factors in rehabilitation in chronic rheumatoid arthritis, a controlled study, Journal of Chronic Diseases, 25, 457-467, 1971.

Viney L.L., Westbrook M.T., Coping with chronic illness, strategy preferences changes in preferences and associated emotional reactions, Journal of Chronic Diseases, 37, 489-502, 1984.

Weekers A.M.C.L., Jonkers L.V., Mostert H.A., Pruyn J.F.A., Reuma, de aandoening en gevolgen, de wijkverpleegkundige zorgverlening en het beleid, IVA (Instituut voor Sociaal-Wetenschappelijk Onderzoek) \& Provinciale Kruisvereniging Zuid-Holland, Tilburg, 1989.

Weiner C.L., The burden of reumatoid arthritis, tolerating the uncertainty, Social Science and Medicine, 9, 97-104, 1975.

Williams G.H., Disablement and the social context of daily activity, International Disability Studies, 9, 97-102, 1987.

Williams G.H., Wood P.H.N., Coming to terms with chronic illness, the negotiation of autonomy in theumatoid arthritis, International Disability Studies, $10,128-133,1988$.

Witte L.P. de, Tilli D.J.P., Ticheler A.J.G., Winants B.A.C., Horst F.G. van der, Linden Sj. van der, Leven met een reumatische aandoening, een onderzoek naar de ervaren kwaliteit van het leven bij 372 mensen met een reumatische aandoening, Instituut voor Revalidatievraagstukken, Hoensbroek, 1989.

WVC, Nota Reumabeleid, Tweede Kamer, Vergaderjaar 1988-1989, 21 010, nrs. $1-2,1989 \mathrm{~d}$.

WVC, Nota Chronisch zieken beleid, Tweede Kamer, Vergaderjaar 1990-1991, 22 025, nr 1, 1991

Yelin E.H., Henke CJ., Kramer J.S., Nevitt M.C., Schearn M., Epstein W.V., A comparison of the treatment of rheumatoid arthritis in health maintenance organisations and fee-for-service practices, New England Journal of Medicine, 312, 962-967, 1985. 


\section{ANNEX I}

Factorloadings on three factors, after varimaxrotation, and Cronbach's alpha's of the Scale Difficulties Performing Activities for the RA patient group ( $N=45)$.

\begin{tabular}{|c|c|c|c|c|}
\hline & Factor 1 & Factor 2 & Factor 3 & Cronbach's alpha \\
\hline \multicolumn{5}{|l|}{$\mathrm{ADL}$} \\
\hline Bathing & .72 & -.02 & .06 & \\
\hline Dressing & .72 & -.08 & -.05 & \\
\hline Washing & .71 & .04 & .07 & \\
\hline Eating & .67 & .15 & .07 & \\
\hline In/out chair & .67 & -.07 & .17 & \\
\hline In/out bed & .64 & .16 & -.05 & \\
\hline Toilet & .52 & .29 & .11 & .80 \\
\hline \multicolumn{5}{|l|}{ Aids and appliances } \\
\hline Walking & -.02 & .84 & -.08 & \\
\hline Housing & -.02 & .83 & -.04 & \\
\hline Small appliances & .10 & .80 & -.02 & \\
\hline ADL appliances & .16 & .68 & .01 & .80 \\
\hline \multicolumn{5}{|l|}{ Relational functioning } \\
\hline Acceptance partner & .04 & .01 & .86 & \\
\hline Acceptance children & .06 & -.01 & .83 & \\
\hline Sexuality & .13 & .02 & .59 & \\
\hline Acceptance self & .21 & -.06 & .57 & \\
\hline Contacts & -.08 & -.04 & .33 & .66 \\
\hline Eigenvalues & 3.64 & 2.68 & 1.69 & \\
\hline \% explained variance & 22.8 & 16.7 & 12.3 & \\
\hline
\end{tabular}




\section{ANNEX II}

Factorloadings on two factors, after varimaxrotation, of the Scale Meaning of RA to the RA patient group $(N=45)$.

\begin{tabular}{lrr}
\hline & Factor 1 & Factor 2 \\
\hline Loneliness & .68 & .04 \\
Loss of social contacts & .65 & .08 \\
Loss of control on life & .63 & .13 \\
Feelings of fear/depression & .62 & .24 \\
Grief/stress in the family & .58 & .17 \\
Lack of understanding of partner/family & .55 & .18 \\
Decreased sense of self-worth & .53 & .19 \\
Hopes for the future shattered & .52 & .25 \\
Uncertainty about disease progression & .44 & .30 \\
Financial problems & .31 & .03 \\
& & \\
Complaints about bodily functioning & .20 & .82 \\
Pain & .27 & .71 \\
Dependency & .00 & .69 \\
Restrictions in freedom of movement & .25 & .64 \\
No longer able to perform certain activities & .08 & .64 \\
Fatigue & .24 & .44 \\
\hline Eigenvalues & 4.88 & 1.63 \\
Cummulative \% explained variance & 30.5 & 40.8 \\
\hline
\end{tabular}




\section{ANNEX III}

Factorloadings on three factors, after varimaxrotation, of the 'Utrechtse Coping Lijst ${ }^{*}$, for the Utrecht population $(N=1226)$.

\begin{tabular}{lrrr}
\hline & $\mathrm{F} 1$ & $\mathrm{~F} 2$ & $\mathrm{~F} 3$ \\
\hline Using a direct approach in order to solve the problem & .75 & -.08 & .15 \\
Considering different solutions to the problem & .72 & -.02 & .16 \\
Finding out all about the problem & .68 & -.03 & .12 \\
Making several alternative plans for handling a problem & .68 & -.03 & .15 \\
Considering problems as a challange & .56 & -.15 & .01 \\
Making a direct intervention when problems occur & .55 & -.03 & .16 \\
*Realising every cloud has a silver lining & .53 & .24 & -.02 \\
Trying to avoid difficult situations as much as possible & -.20 & .65 & -.06 \\
Giving-in in order to avoid difficult situations & -.14 & .62 & -.11 \\
Worrying about the past & -.07 & .57 & -.15 \\
Looking for distraction & .20 & .54 & .10 \\
Resigning oneself to the situation & -.16 & .52 & -.16 \\
Taking a gloomy view of the situation & -.09 & .51 & .23 \\
*Feeling unable to do anything & -.12 & .49 & .09 \\
*Directing one's thoughts towards other matters & .18 & .48 & -.01 \\
*Trying to dispell one's worries temporarely by taking a break & .16 & .48 & .04 \\
*Telling oneself that other people also have their problems & .38 & .46 & .03 \\
from time to time & & & \\
*Being totally preoccupied with the problems & -.02 & .44 & .23 \\
*Trying to make onesell feel better one way or the other & .34 & .42 & .12 \\
Showing that there are things, which are bothering you & .04 & .02 & .78 \\
Seeking sympathy and comfort from somebody & .04 & .17 & .74 \\
Show one's feelings & .17 & -.00 & .70 \\
Asking someone to help & .08 & -.01 & .59 \\
Sharing one's worries with someone & .11 & .03 & .53 \\
Showing one's annoyance & .10 & .10 & .41 \\
*Showing one's anger with those responsible for the problem & .23 & .05 & .26 \\
\hline Eigenvalues & 4.40 & 3.39 & .2 .06 \\
Cummulative \% explained variance & 16.9 & 30.0 & 38.0 \\
\hline ins & & &
\end{tabular}

* items were left out of the scale after the factor-analysis 


\section{ANNEX IV}

Non-completion analyses for the RA patients $(N=20, N=45)$ on the variables of the research model in the first interview period.

RA patients completed: No $(\mathrm{N}=20) \quad$ Yes $(\mathrm{N}=45)$

Outcome variables

Difficulties performing activities

ADL

3.7

Aids and appliances

.5

3.2

Relational functioning

$.6 \quad .3$

Loneliness

2.9

2.9

Health deviation variables

Functional capacity/ARA classes

I

II

67

III

$5 \quad 19$

IV

4

Duration of RA

11.1

14.4

Control variables

Gender male

11

fermale

9

Dependent care facilities:

None

Spouse and/or housemate and/or daughter(s)

Spouse and housemate and daughter(s)

Professional help

ADL

Aids and appliances

Relational functioning

Coping behavior:

action directed

seeking social support

awaiting/avoiding

Meaning of RA: bodily 


\section{ANNEX V}

MANOVA and t-test analyses of the variables of the research model for the RA patients $(N=45)$, the reference group $(N=45)$, the $R A$ patient diary group $(N=22)$, and the reference diary group $(N=22)$ in three interviews.

\begin{tabular}{|c|c|c|c|c|}
\hline & & $\begin{array}{l}\text { Effects: } \\
\text { Group }\end{array}$ & time & Interaction \\
\hline \multicolumn{5}{|c|}{ Outcome variables } \\
\hline \multicolumn{5}{|c|}{ Difficulties performing activities } \\
\hline \multirow{2}{*}{$\begin{array}{l}\text { Activities of daily } \\
\text { living }\end{array}$} & RA & - & - & \\
\hline & RA-R & $F(2,88)=121.4^{*}$ & $F(2,88)=6.8 \#$ & \\
\hline \multirow[t]{2}{*}{ Aids and appliances } & RA & - & - & \\
\hline & RA-R & $\mathrm{F}(2,88)=22.7^{*}$ & - & - \\
\hline \multirow{2}{*}{$\begin{array}{l}\text { Relational func- } \\
\text { tioning }\end{array}$} & RA & - & $F(1,44)=6.9 *$ & \\
\hline & RA-R & $\mathrm{F}(2,88)=36.0^{*}$ & $\mathrm{~F}(2,88)=6.8^{*}$ & $F(2,88)=6.8^{*}$ \\
\hline \multicolumn{5}{|c|}{ Rest and activity pattern } \\
\hline \multirow[t]{3}{*}{ Rest" } & RA & - & - & \\
\hline & RA-R & $\mathrm{F}(2,42)=57.3^{*}$ & Pillai's=.2\# & - \\
\hline & & & $\mathrm{F}=3.9, \mathrm{df}=2$ & \\
\hline \multirow[t]{3}{*}{ Activity" } & RA & - & $F(1,20)=5.8 \#$ & \\
\hline & RA-R & $F(2,41)=51.3^{*}$ & Pillia $s=.2 \#$ & - \\
\hline & & & $\mathrm{F}=3.7, \mathrm{df}=2$ & \\
\hline \multirow[t]{2}{*}{ Loneliness } & RA & - & $F(1,44)=5.0 \#$ & \\
\hline & RA-R & - & $F\left(1,88=11.6^{*}\right.$. & \\
\hline \multicolumn{5}{|c|}{ Healch deviation variables } \\
\hline \multirow[t]{2}{*}{ Functional capacity } & RA & - & $F(1,44)=4.7 \#$ & \\
\hline & RA-R & $F(2,88)=144.5^{*}$ & - & - \\
\hline \multirow[t]{2}{*}{ Pain' } & RA & - & - & \\
\hline & RA-R & $F(2,40)=24.4^{*}$ & - & - \\
\hline \multirow[t]{2}{*}{ Fatigue' } & RA & - & - & \\
\hline & RA-R & $\mathbb{F}(2,38)=16.5^{*}$ & - & - \\
\hline \multirow[t]{2}{*}{ Stiffness" } & RA & - & - & \\
\hline & RA-R & $F(2,36)=71.0^{*}$ & * & - \\
\hline
\end{tabular}


Control variables

Meaning of RA:

Bodily

RA

$F(1,44)=6.8 \#$

Relational

RA

$F(1,44)=9.5^{*}$

Coping behavior:

Action directed

RA

RA-R

Seeking social

support

RA

RA-R

Awaiting/avoiding $\mathrm{RA}$

\begin{tabular}{ll} 
& RA-R \\
\hline Professional help & RA
\end{tabular}

RA-R $\quad F(2,88)=12.2$ *

Dependent care $\mathrm{RA}$

facilities

RA-R

Personal network:

\begin{tabular}{|c|c|c|}
\hline Size & RA-R & - \\
\hline Density & RA-R & - \\
\hline Relatives & RA-R & - \\
\hline Non-relatives & RA-R & - \\
\hline \multicolumn{3}{|c|}{ Balance in support: } \\
\hline instrumental & RA-R & $\mathrm{t}=-4.3^{*}$ \\
\hline cmotional & RA-R & - \\
\hline
\end{tabular}

Control variables 


\section{ANNEX VI}

Daily activities of the $R A$ patient diary group $(N=22)$ and the reference diary group $(N=22)$ as reported in three diaries.

\begin{tabular}{lrrrrrr}
\hline & \multicolumn{3}{c}{ RA patients } & \multicolumn{5}{c}{ References } \\
& I & II & III & I & II & III \\
\hline No activity named & .9 & 0 & 0 & 1.8 & 0 & 0 \\
rest & & & & & & \\
& 8.9 & 10.5 & 10.4 & 7.4 & 8.9 & 8.8 \\
eating & & & & & & \\
& 2.0 & 2.0 & 1.9 & 2.0 & 2.2 & 2.3 \\
selfcare & & & & & & \\
& 1.3 & 1.4 & 1.6 & .8 & 1.0 & 1.0 \\
household activities & & & & & & \\
& 1.9 & 2.0 & 1.7 & 2.7 & 2.7 & 2.6 \\
Indoors: & & & & & & \\
passive leisure & & & & & & \\
active leisure & 4.0 & 3.9 & 4.2 & 2.2 & 2.6 & 2.7 \\
social activities & 1.0 & 1.2 & 1.1 & 1.1 & 1.1 & 1.2 \\
& .6 & .8 & .7 & .9 & 1.1 & .9
\end{tabular}

Outdoors:

\begin{tabular}{lrrrrrr} 
necessary activities & .6 & .7 & .7 & .8 & .6 & .9 \\
passive leisure & .3 & .3 & .3 & .1 & .4 & .2 \\
active leisure & .3 & .5 & .5 & 1.6 & 1.6 & 1.2 \\
social activities & .9 & .7 & .8 & 1.5 & 1.7 & 2.1 \\
\hline
\end{tabular}




\section{ANNEX VII}

Stability of the seperate variables on three measurement moments (Pearson product moment correlations).

\begin{tabular}{lccc}
\hline & $\mathrm{t} 1-\mathrm{t2}$ & $\mathrm{t} 2-\mathrm{t3}$ & $\mathrm{t1}-\mathrm{13}$ \\
\hline ADL & $.45^{*}$ & $.47^{*}$ & $.47^{*}$ \\
Aids and appliances &. .01 & -.13 & -.02 \\
Relational functioning & $.35^{*}$ & $.38^{*}$ & -.04 \\
Rest & $.52^{*}$ & $.82^{*}$ & $.57^{*}$ \\
Loneliness & $.76^{*}$ & $.79^{*}$ & $.73^{*}$ \\
\hline Function al capacity & $.79^{*}$ & $.64^{*}$ & $.55^{*}$ \\
Pain & $.72^{*}$ & $.55^{*}$ & $.38^{*}$ \\
Fatigue & $.79^{*}$ & $.52^{*}$ & .37 \\
Stiffness & $.59^{*}$ & .35 & $.55^{*}$ \\
Professional help & .66 & $.31 \#$ & \\
Bodily meaning of RA & & & $.65^{*}$ \\
Relational meaning of RA & & & $.69^{*}$ \\
Action directed & & & $.49^{*}$ \\
Seeking social support & & & $.52^{*}$ \\
Awaiting/avoiding & & & $.32 \#$ \\
$*$ p<.01; \# p<.05 & & &
\end{tabular}


Pearson correlations between the health deviation and outcome variables for the RA patients $(N=45)$ and $R A$ patient diary group $(N=22)$ in three interviews.

\begin{tabular}{|c|c|c|c|c|c|c|}
\hline & & $\mathrm{ADL}$ & $\mathrm{A} \& \mathrm{~A}$ & REL & $\operatorname{Rest}^{2}$ & Lonelliness \\
\hline \multirow{3}{*}{$\begin{array}{l}\text { Functional } \\
\text { capacity }\end{array}$} & I & $.58 *$ & .09 & $.25 \#$ & .09 & $.38 *$ \\
\hline & II & $.58 *$ & -.07 & .22 & .13 & $.30 \#$ \\
\hline & III & $.70^{*}$ & $.26 \#$ & $.35^{*}$ & .12 & $.26 \#$ \\
\hline \multirow{3}{*}{$\begin{array}{l}\text { Duration of } \\
\text { RA }\end{array}$} & I & -.01 & -.11 & .05 & .03 & .01 \\
\hline & II & .01 & .13 & .01 & -.32 & -.00 \\
\hline & III & -.16 & -.18 & $-.26 \#$ & $-.48 *$ & .13 \\
\hline \multirow[t]{3}{*}{ Pain $^{2}$} & I & $.37 \#$ & $.40 \#$ & .36 & .12 & $.75^{*}$ \\
\hline & II & $.52^{*}$ & -.16 & $.55^{*}$ & .18 & $.43 \#$ \\
\hline & III & .28 & .18 & .14 & .05 & .31 \\
\hline \multirow[t]{3}{*}{ Fatigue $^{2}$} & I & $.57^{*}$ & .29 & $.41 \#$ & .20 & $.85 *$ \\
\hline & II & $.65^{*}$ & -.15 & $.63^{*}$ & .16 & $.45 \#$ \\
\hline & III & $.40 \#$ & .23 & .19 & .02 & $.37 \#$ \\
\hline \multirow[t]{3}{*}{ Stiffness $^{2}$} & I & .29 & -.19 & .12 & -.02 & .15 \\
\hline & II & -.31 & -.25 & -.07 & -.12 & .05 \\
\hline & III & $.45 \#$ & .24 & .34 & -.06 & $.40 \#$ \\
\hline
\end{tabular}




\section{ANNEX IX}

Pearson correlations between the control and health deviation variables for the $R A$ patients $(N=45)$ and $R A$ patient diary group $(N=22)$ in three interviews.

\begin{tabular}{|c|c|c|c|c|c|c|}
\hline & & $\begin{array}{l}\text { Functioual } \\
\text { capacity }\end{array}$ & $\begin{array}{l}\text { Duration } \\
\text { of RA }\end{array}$ & Pain & Fatigue & tiffness \\
\hline \multicolumn{2}{|l|}{$\mathrm{N}=$} & 45 & 45 & 18. & 18 & 18) \\
\hline \multicolumn{7}{|c|}{ Social position and attitudes } \\
\hline \multicolumn{7}{|c|}{ Meaning of RA } \\
\hline \multirow[t]{2}{*}{ Bodlily } & 1 & $.27 *$ & .07 & .25 & $.42 \#$ & .32 \\
\hline & III & $.56^{*}$ & -.05 & $.39 \$$ & .36 & .28 \\
\hline \multirow[t]{2}{*}{ Relational } & $I$ & $.40^{*}$ & $\because 10$ & $.41 \#$ & $.71^{*}$ & -.09 \\
\hline & III & $.45^{*}$ & .07 & .35 & $47 \#$ & $.45 \#$ \\
\hline \multicolumn{7}{|l|}{ Coping Behavior: } \\
\hline \multirow[t]{2}{*}{ Action directed } & $I$ &. .05 & .02 & .19 & .02 & .03 \\
\hline & IIII &. .04 & .05 & .10 & .13 & -.21 \\
\hline \multirow[t]{2}{*}{ Seeking social support } & 1 & $-.26 \#$ & -.01 & $.41 \#$ & .32 & .20 \\
\hline & III & .09 & $-.32 \#$ & .29 & .27 & .19 \\
\hline \multirow[t]{2}{*}{ Awaiting/avoiding } & I & -.09 & .12 & $.37 \#$ & .28 & .24 \\
\hline & III & -.11 & .08 & .01 & .04 & .12 \\
\hline \multirow[t]{3}{*}{ Gender } & $\mathbb{I}$ & .18 & .22 & .06 & .01 & .01 \\
\hline & II & .14 & & .16 & .04 & $.41 \#$ \\
\hline & III & $30 \#$ & & $.62 *$ & $59^{*}$ &,- 02 \\
\hline \multicolumn{7}{|l|}{ Care facilities } \\
\hline \multirow[t]{3}{*}{ Dependent care facilities } & I & -.06 & -.19 & -.26 & -.28 & $-{ }_{-} 49$ \# \\
\hline & II & .011 & & -.10 & -.03 & $-.61 *$ \\
\hline & III & .01 & & -.25 & -.32 & -36 其 \\
\hline \multirow[t]{3}{*}{ Professional help } & I & $.45 *$ & .06 & .15 & .31 & .29 \\
\hline & II & .38 & .05 & .03 &.$\infty$ & 16 \\
\hline & III & $.34^{*}$ & -.18 & .24 & .29 & .19 \\
\hline \multicolumn{7}{|l|}{ Personal network: } \\
\hline Size & III & -.17 & .04 & .02 & -.15 & .12 \\
\hline Density & III & -.05 & .01 & $-.36 \#$ & -.31 & $-.48 *$ \\
\hline Relatives & III & -.01 & -.10 & -.18 & $-.46 \mathrm{H}$ & -.09 \\
\hline Non-relatives & III & -.20 & .27 & .32 & .30 & .14 \\
\hline Instrumental support & III & -.14 & -.06 & -.06 & -.09 & -.09 \\
\hline Emotional suppont & III & .02 &. .02 & .05 & .09 & -.21 \\
\hline
\end{tabular}

* $\mathrm{p}<.01 ; \# \mathrm{p}<.05$ 


\section{ANNEX X}

Pearson correlations between the control and outcome variables for the RA patients $(N=45)$ and $R A$ palient diary group $(N=22)$ in three interviews.

\begin{tabular}{|c|c|c|c|c|c|c|}
\hline & & $A D L$ & $\begin{array}{l}\text { Aids and } \\
\text { appliances }\end{array}$ & $\begin{array}{l}\text { Relational } \\
\text { functioning }\end{array}$ & Rest & $\begin{array}{l}\text { Lone- } \\
\text { liness }\end{array}$ \\
\hline \multicolumn{2}{|l|}{$(\mathbb{N}=$} & 45 & 45 & 18 & 18 & 18) \\
\hline \multicolumn{7}{|c|}{ Soctial position and aftitudes } \\
\hline \multicolumn{7}{|c|}{ Meaning of RA } \\
\hline \multirow[t]{2}{*}{ Bodily } & 1 & $.33 \#$ & .11 &,- 21 & .03 & .19 \\
\hline & III & $.52 *$ & .06 & $.28 \#$ & -.35 & .23 \\
\hline \multirow[t]{2}{*}{ Relational } & I & $.44 *$ & $-26 \#$ & .14 & $.18 *$ & $.46^{*}$ \\
\hline & III & $.47 *$ & .14 & $.43^{*}$ & -.32 & $.53 *$ \\
\hline \multicolumn{7}{|l|}{ Coping Behavior: } \\
\hline \multirow[t]{2}{*}{ Action directed } & I & -.03 & .05 &. $.33 \#$ & -.01 & -.08 \\
\hline & III & .02 & .09 & -.21 & $.39 \$$ & .02 \\
\hline \multirow[t]{2}{*}{ Seeking social support } & $\mathbb{1}$ & -.22 & .14 & -.14 & -.13 & -.09 \\
\hline & III & .07 & -.08 & .05 & .11 & .01 \\
\hline \multirow[t]{2}{*}{ Awailting/avoliding } & I & -.17 & -.14 & .22 & -.11 & .21 \\
\hline & III & -.20 & $-.26 \#$ & -.05 & .07 & $.28 \#$ \\
\hline \multirow[t]{3}{*}{ Dependent care facilities } & 1 & -.27 & .12 & -.05 & .21 & -.504 \\
\hline & II & & & & & \\
\hline & III & -.15 & -.05 & .25 & .09 & $-.46^{*}$ \\
\hline \multirow[t]{3}{*}{ Gender } & 1 & .20 & .04 & $-\infty$ & $-51 *$ & .24 \\
\hline & II & & & & & \\
\hline & III & $.25 *$ & .23 & -.02 & $-.41 \#$ & $.32 \#$ \\
\hline \multicolumn{7}{|l|}{ Care facilities } \\
\hline \multirow[t]{3}{*}{ Professional help } & $i$ & $.49^{*}$ & .08 & -.14 & .02 & .16 \\
\hline & II & & & & & \\
\hline & III & $.39 *$ & $.77 *$ & .01 & -.01 &. .02 \\
\hline \multicolumn{7}{|l|}{ Personal net work: } \\
\hline Size & III & $-.25 *$ & $.27 \#$ & -.14 & .14 & $-.34 *$ \\
\hline Density & III & -.18 & $-.50^{*}$ & -.06 & .02 & $-.45 *$ \\
\hline Relatives & III & -.23 & .19 & .09 & .03 & $-.41 *$ \\
\hline Non-relatives & III &. .08 & .13 & $-.25 \#$ & .17 & -.01 \\
\hline Instrumental support & III & .11 & -.01 & .06 & .06 & .19 \\
\hline Bimotional suppont & III & $-.31 \#$ & .12 & .11 & -.01 & -.05 \\
\hline
\end{tabular}

* $p<.01 ; \# p<.05$ 


\section{ANNEX XI}

$$
\begin{aligned}
& \text { का } \\
& \text { 웅영 }
\end{aligned}
$$

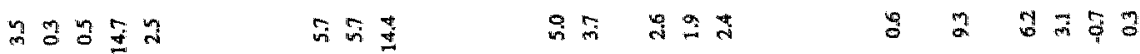

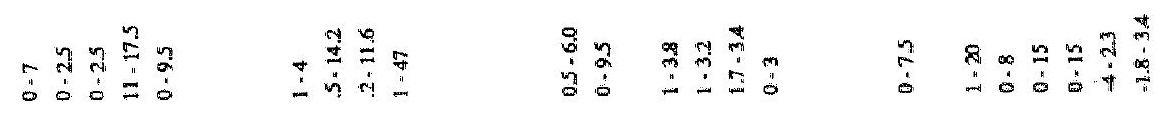

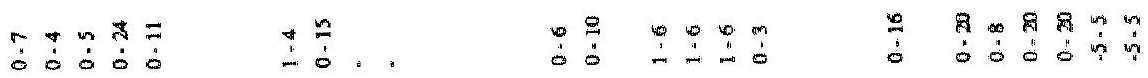

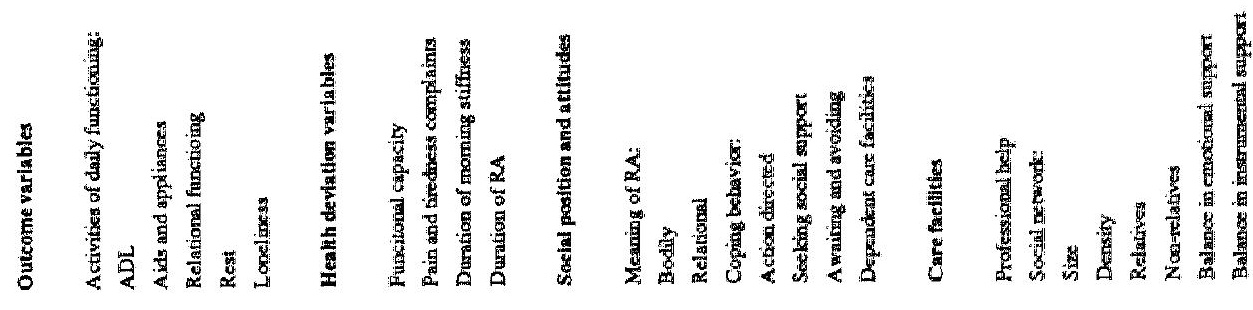





\section{CURRICULUM VITAE}

Roos-Marie Bal was born in Eindhoven, The Netherlands, 28 March, 1958. After finishing her HAVO in 1976, she started her Nursing Studies and graduated in 1980 at the Nijmegen School of Nursing. From 1980 to 1984 she studied Health Sciences, Nursing Science specialisation, at the University of Limburg, Maastricht, The Netherlands. After graduation, she followed a one-year programme on research at the same university. During this year she did a project with the Community Nursing Association of Breda (registration and documentation of the Nursing Process). From 1985 to 1990 she worked at the Department of Nursing Science, Faculty of Health Sciences, University of Limburg, Maastricht where she carried out the study presented here. She is now working at the Department of General Practice. 